FIELD APPLICATION OF AN INTERPRETATION METHOD OF

DOWNHOLE TEMPERATURE AND PRESSURE DATA FOR DETECTING

WATER ENTRY IN HORIZONTAL/HIGHLY INCLINED GAS WELLS

\author{
A Thesis \\ by \\ OCHI IKOKU ACHINIVU
}

\begin{abstract}
Submitted to the Office of Graduate Studies of
Texas A\&M University

in partial fulfillment of the requirements for the degree of

MASTER OF SCIENCE
\end{abstract}

December 2008

Major Subject: Petroleum Engineering 


\title{
FIELD APPLICATION OF AN INTERPRETATION METHOD OF \\ DOWNHOLE TEMPERATURE AND PRESSURE DATA FOR DETECTING \\ WATER ENTRY IN HORIZONTAL/HIGHLY INCLINED GAS WELLS
}

\author{
A Thesis \\ by \\ OCHI IKOKU ACHINIVU \\ Submitted to the Office of Graduate Studies of \\ Texas A\&M University \\ in partial fulfillment of the requirements for the degree of \\ MASTER OF SCIENCE
}

Approved by:

Chair of Committee, Ding Zhu

Committee Members, Daniel A. Hill

Yuefeng Sun

Head of Department, Stephen A. Holditch

December 2008

Major Subject: Petroleum Engineering 


\begin{abstract}
Field Application of an Interpretation Method of Downhole Temperature and Pressure Data for Detecting Water Entry in Horizontal/Highly Inclined Gas Wells.

(December 2008)

Ochi Ikoku Achinivu, B.Eng., University of Port-Harcourt

Chair of Advisory Committee: Dr. Ding Zhu
\end{abstract}

In the oil and gas industry today, continuous wellbore data can be obtained with high precision. This accurate and reliable downhole data acquisition is made possible by advancements in permanent monitoring systems such as downhole pressure and temperature gauges and fiber optic sensors. The monitoring instruments are increasingly incorporated as part of the intelligent completion in oil wells where they provide bottomhole temperature, pressure and sometimes volumetric flow rate along the wellbore - offering the promise of revolutionary changes in the way these wells are operated. However, to fully realize the value of these intelligent completions, there is a need for a systematic data analysis process to interpret accurately and efficiently the raw data being acquired. This process will improve our understanding of the reservoir and production conditions and enable us make decisions for well control and well performance optimization.

In this study, we evaluated the practical application of an interpretation model, developed in a previous research work, to field data. To achieve the objectives, we 
developed a simple and detailed analysis procedure and built Excel user interface for data entry, data update and data output, including diagnostic charts and graphs. By applying our interpretation procedure to the acquired field data we predicted temperature and pressure along the wellbore. Based on the predicted data, we used an inversion method to infer the flow profile - demonstrating how the monitored raw downhole temperature and pressure can be converted into useful knowledge of the phase flow profiles and fluid entry along the wellbore. Finally, we illustrated the sensitivity of reservoir parameters on accuracy of interpretation, and generated practical guidelines on how to initialize the inverse process. Field production logging data were used for validation and application purposes.

From the analysis, we obtained the production profile along the wellbore; the fluid entry location i.e. the productive and non-productive locations along the wellbore; and identified the fluid type i.e. gas or water being produced along the wellbore. These results show that temperature and pressure profiles could provide sufficient information for fluid identity and inflow distribution in gas wells. 


\section{DEDICATION}

This research is dedicated to God for His blessed assurance. 


\section{ACKNOWLEDGEMENTS}

My gratitude goes to my supervising professors, Dr. Ding Zhu, Dr. Daniel A. Hill, Dr. Yuefeng Sun and Dr. Eric Bickel, for their support, patience and valuable academic advice which kept me on course throughout my research. I sincerely appreciate your thought-provoking ideas and guidance. God bless you.

I am thankful to my wife, Nwanyioma, for her understanding, tolerance and love especially during those long hours and late nights.

I am grateful to Chevron Nigeria Limited for the scholarship award and financial sponsorship for my graduate study. Special appreciation goes to Stacey Olson and Henry Legarre for the extra lagniappe.

I acknowledge my parents, Mr. and Mrs. M. I. Achinivu, my parents' in-law, Mr. and Mrs. C. O. Chugbo, and my siblings, Alii, Uche and Obii, for their love and encouragement.

I give credit to Dr. Kenji Furui, Dr Keita Yoshioka and my colleagues Li Zhuoyi, and Weibo Sui for their immense contributions to the success of this research. 


\section{TABLE OF CONTENTS}

\section{Page}

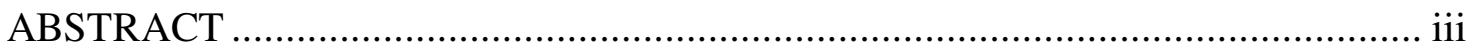

DEDICATION

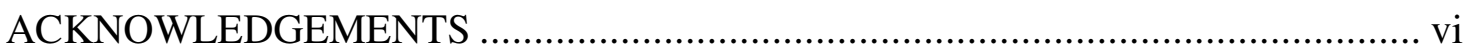

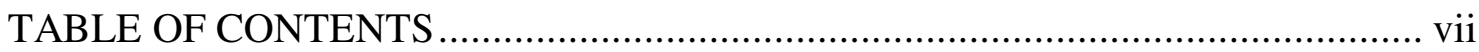

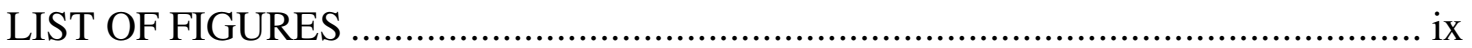

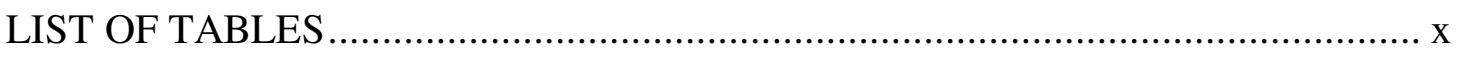

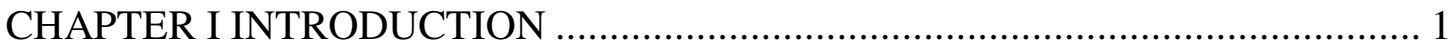

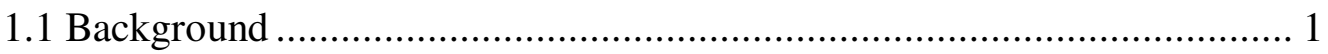

1.2 Literature Review .......................................................................... 2

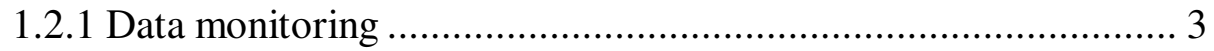

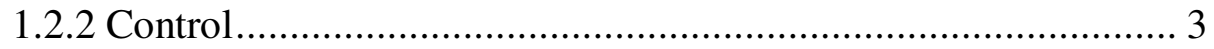

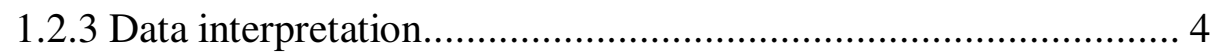

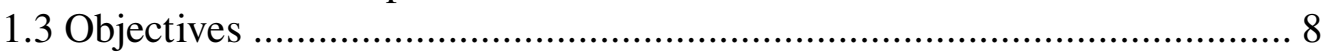

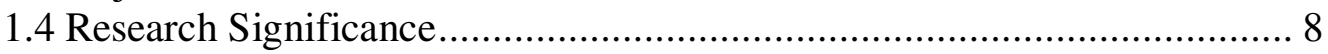

CHAPTER II INTERPRETATION METHOD .................................................... 10

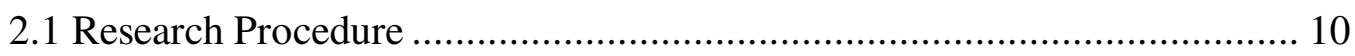

2.2 Model Overview ............................................................................. 10

2.3 Wellbore Model................................................................................. 11

2.3.1 Single-phase flow ................................................................ 13

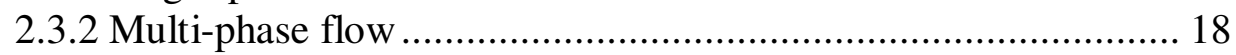

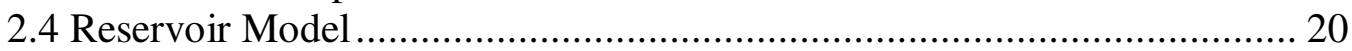

2.5 Inversion Model ................................................................................. 22

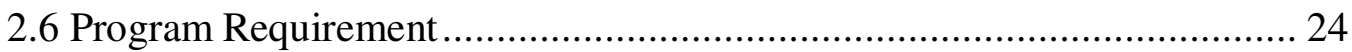

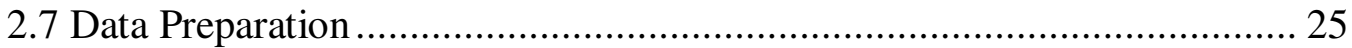

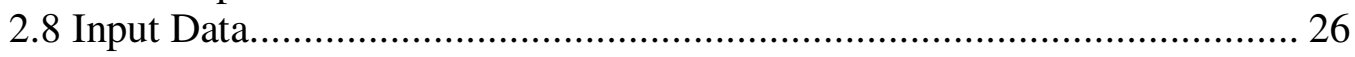

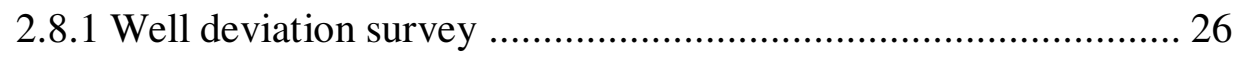

2.8.2 Completion and tubular data .................................................... 27

2.8.3 Downhole temperature and pressure .......................................... 28

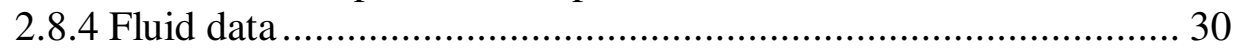

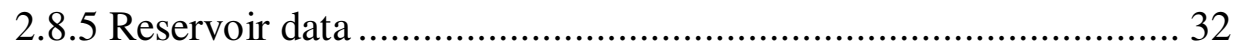

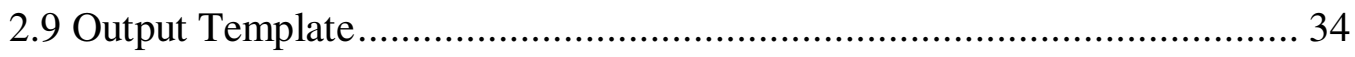




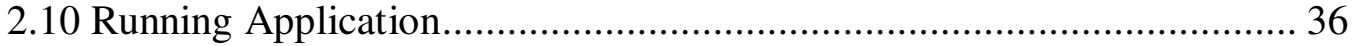

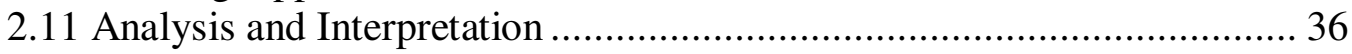

CHAPTER III FIELD APPLICATION ....................................................... 39

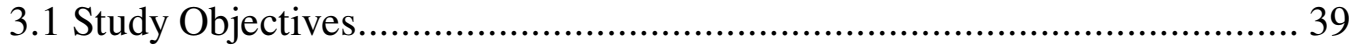

3.2 Gas Production without Water ....................................................... 42

3.2.1 Forward model .............................................................. 43

3.2.2 Inversion model ......................................................... 48

3.3 Gas Production with Water ............................................................ 53

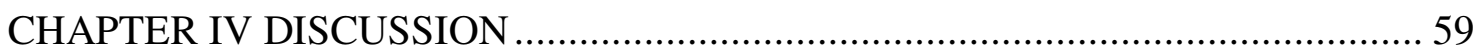

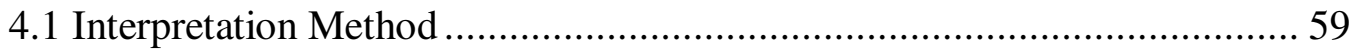

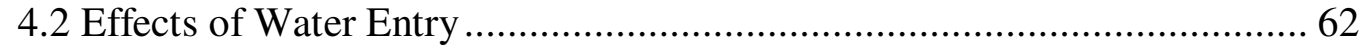

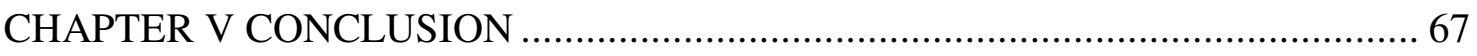

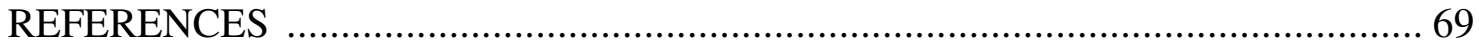

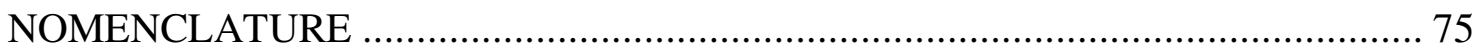

APPENDIX A: PARTIAL COMPLETION AND SLANT SKIN FOR SEGMENT .. 78

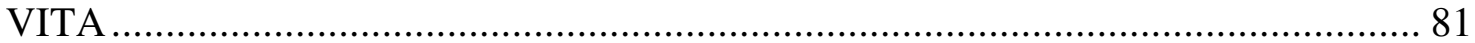




\section{LIST OF FIGURES}

Figure 1.1: The concept of intelligent well system....... 7

Figure 2.1: Differential volume element of a wellbore................................... 12

Figure 2.2: Forward model iteration procedure ......................................... 22

Figure 2.3: Inverse model calculation flow chart....................................... 24

Figure 2.4: Sample input sheet for well deviation data........................................ 27

Figure 2.5: Sample input sheet for completion and tubular data.......................... 28

Figure 2.6: Input template for temperature and pressure data............................. 29

Figure 2.7: Template for fluid data entry.............................................. 31

Figure 2.8: Cut-out section of the reservoir data input sheet. .............................. 33

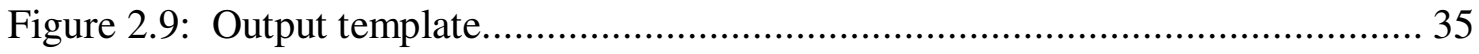

Figure 3.1: The schematic of the well structure ........................................... 40

Figure 3.2: Forward model result for gas production only ................................ 43

Figure 3.3: Forward model result of gas production at a higher production rate........ 46

Figure 3.4: Inversion results for single phase gas case .................................. 49

Figure 3.5: Inversion results for higher gas flow rate................................... 51

Figure 3.6: Forward model results for gas/water production case .......................... 54

Figure 3.7: Inversion for gas and water production...................................... 57

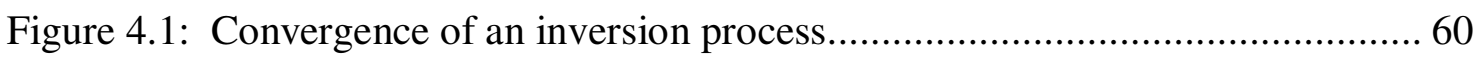

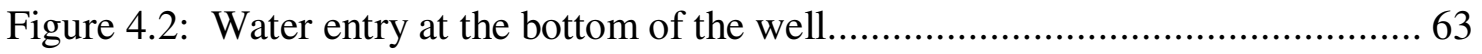

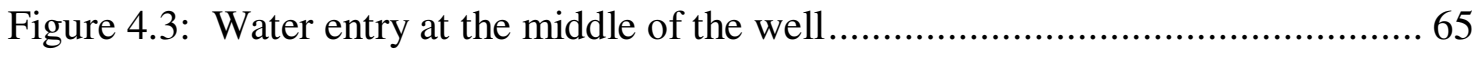




\section{LIST OF TABLES}

Page

Table 2.1 Input data sources ......................................................... 34

Table 3.1 Reservoir properties of the case example................................. 41 


\section{CHAPTER I}

\section{INTRODUCTION}

\subsection{Background}

Recent technological advancements in various fields are being harnessed in the oil and gas industry. These advancements gave birth to the intelligent/smart completions which have redefined the production engineering operations, especially in the field. The intelligent completion system is a production optimization system which consists of (1) data monitoring, (2) data interpretation and (3) production control.

Accurate and reliable downhole data acquisition has been made possible by advanced permanent monitoring systems such as downhole pressure and temperature gauges and fiber optic sensors. These downhole measurement instruments are increasingly incorporated as part of the intelligent completion in complex (highly slanted, horizontal, and multilateral) wells where they provide bottomhole temperature, pressure and sometimes volumetric flow rate along the wellbore - offering the promise of revolutionary changes in the way these wells are operated.

To fully realize the value of these intelligent completions, there is a need for a systematic data analysis process to efficiently interpret the raw data being acquired. This

This thesis follows the style of Society of Petroleum Engineers Journal. 
systematic data analysis process helps to improve our understanding of reservoir and production conditions using the acquired data and to interactively integrate the data interpretation aspect with the data monitoring and control components.

\subsection{Literature Review}

In the past, appreciation and application of intelligent technology was hindered by the cost and reliability of the intelligent instrumentation and the need for proficiency in the analysis and interpretation of monitored data (Zhu and Kenji 2006; Changhong et al. 2007). Today, with several trials, the initial incremental cost of choosing intelligent completion can easily be justified by the added-value in various production and reservoir management operations including: increase in ultimate recovery, increase in production, control of water breakthrough, gas coning, formation damage and sand production, optimization of gas lift and ESP systems, downhole leak detection, and superior Health, Safety and Environment (HSE) impact from unmanned production operation activities. The list goes on and on.

Long term reliability of the fiber optic sensors is promising. There are cases of improvement in reliability of permanent downhole gauges (Frota and Destro 2006; Van Gisbergen and Vandeweijer 1999). Kragas et al. (2002) documented that in a postinstallation perforating operations fiber optics gauges were selected for their reliability at high temperature and severe shock and vibration conditions associated with such operations. Just like in the data monitoring, the reliability of the interval control valve, ICV, has improved over time. In a study done by Leo de Best and Frans van den Berg (2006), an operator achieved a $96 \%$ probability of zonal control system survival after 5 
years and about $85 \%-90 \%$ probability of survival of flow control value over a period of 10 years.

\subsubsection{Data monitoring}

Reservoir temperature and pressure are measured and monitored with different downhole measurement tools including permanently installed quarts gauges, PLT gauges and fiber optic sensors. Fiber optic sensors find useful application in intelligent completions as the temperature measurement tool - distributed temperature sensor (DTS). Johnson et al. (2006a) noted in their paper that these sensors are gaining popularity in the oil and gas industry and have the capability of acquiring entire wellbore temperature profiles in user-specified measurement frequencies and in real time too. The duration of the measurement time is directly related to the data resolution - longer data acquisition time gives better data resolution. The fiber optic device can be deployed for permanent use by pumping through dedicated micro-tubing (Tolan et al. 2001; Lanier et al. 2003). Typical resolution is $0.1{ }^{\circ} \mathrm{C}$ although future tools like the Array Temperature Sensors (ATS) based on Bragg Gratings technology will achieve temperature resolution performance in the order of $0.01{ }^{\circ} \mathrm{C}$. Research into the application of Distributed Pressure Sensing (DPS) is also in progress, Drakeley et al. (2006).

\subsubsection{Control}

Interventionless zonal control in intelligent wells is achieved with remotely operated hydraulic line-operated Interval Control Valve (ICV). Flowmeter can be installed in the wellbore in conjunction with remotely operated variable control valves to maintain full control of zonal injection and withdrawal rates, Drakeley and Omdal (2008). In other 
applications, installing of remotely operated sliding sleeves and hydraulically controlled addressing unit achieve interventionless control, Chukwueke (2004).

\subsubsection{Data interpretation}

The data interpretation component of the intelligent well system deals with the analysis of monitored downhole data and inference of flow profile in the wellbore. Sensor technologies are quickly advancing in ability to continuously and permanently monitor downhole temperature, pressure and other downhole data along the well bore, qualitative interpretation models and methods are needed to translate the measured information to downhole flow profiles that can help engineers to control and optimize production performance.

The fact remains that the production optimization process is not truly intelligent if the data interpretation is inadequate and inefficient. Therefore to realize the full benefits of intelligent technology the monitoring, interpretation and control systems must be interactively integrated (Zhu and Kenji 2006; Leo de Best and Frans van den Berg 2006; Glandt 2003). The interpretation of acquired downhole data poses tremendous challenges because of the complexity of the thermodynamics and flow process. Subtle temperature changes could be caused by flow condition change, wellbore structure change, geothermal environment change, or simple just noise of measurement. To separate flow condition change from the other causes of temperature change, we require a comprehensive understanding of flow dynamics. 
Various authors (Lanier et al. 2003; Fryer and Shuzing 2005; Wijaya et al. 2005; Johnson and Sugianto 2002; Brown and Field 2005) have documented their work on the theoretical concepts of downhole data analysis and interpretation. Julian et al. (2007) used visualization software to interpret leak signatures using fiber optics DTS data. Their tool displays monitored downhole data without the inversion of the downhole data to flow profile in the wellbore. Studies done by other authors (Wang et al. 2008; Johnson et al. 2006b; Ouyang and Belanger 2004) have also shown promising results in downhole data interpretation. However, in the course of their study, most of these authors ascertained that the complexity of the interpretation process and current lack of userfriendly interpretation software are some of the application challenges in the oil and gas industry today.

Previous research (Yoshioka 2007; Yoshioka et al. 2005; Yoshioka et al. 2006) successfully developed an interpretation method to detect water and gas entry into horizontal, slanted and vertical wells. The interpretation method uses a forward model to predict well flowing pressure and temperature and applies inversion model to detect water and gas entry into wellbore using the observation data generated by the forward model.

Firstly, the forward model numerically solves a coupled segmented multiphase wellbore model and a steady state reservoir model to create a temperature and pressure profile to prove the feasibility of the concept. Then an inversion method is used to interpret distributed temperature and pressure data to obtain flow rate profiles along the wellbore. The inversion method, which is based on the Levenberg-Marquardt algorithm, 
is applied to minimize the differences between the measured profiles and the profiles calculated from the forward model of the well and reservoir flow system.

It is concluded that temperature profiles could provide sufficient information to identify fluid entries, especially in gas wells. But the mathematical complexity and advanced well structure lead to the challenges in model validation and application. In this study, we applied the wellbore-reservoir flow coupled thermal simulation model to high-rate gas wells with field data - slanted gas wells with water produced from bottom aquifer. The interpretation result was compared against production log data. The sensitivity of interpretation error to input reservoir properties were examined and the results showed that temperature and pressure abnormity caused by water production and flow rate changes can be detected theoretically and also practically.

Figure 1.1 shows the concept of intelligent system. This study focuses on field application of the data analysis and interpretation aspect of intelligent system, illustrated by the dotted circle. It demonstrates the field application of the developed model to analyze downhole data and characterize flow profile along the wellbore. It provides simple and detailed procedure on the practical application of the developed interpretation methods in the field by demonstrating how the monitored raw downhole measurement information can be converted into useful knowledge of the phase flow profiles to detect oil, gas and water entry along the wellbore. This study also discusses the data preparation process and initial guess for qualitative interpretation of downhole flow condition from the temperature and pressure data. The results and guidelines developed 
in this study will be useful setting realistic expectation for predictive capability of intelligent well system.

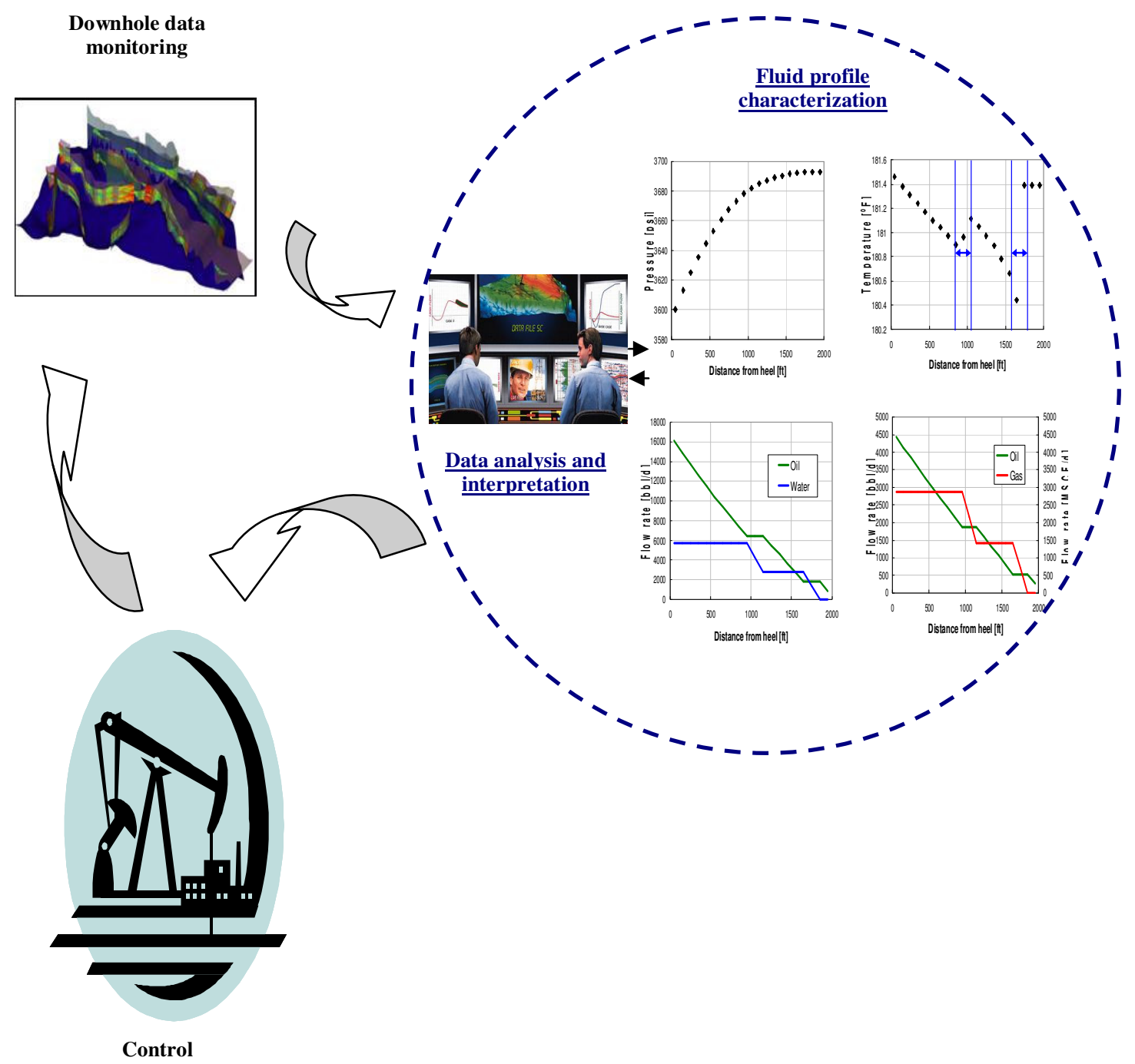

Fig. 1.1 The concept of intelligent well system. 


\subsection{Objectives}

This research work tests the viability of the coupled model as an interpretation method for field-measured wellbore temperature and pressure data. It studies the sensitivity of reservoir parameters on accuracy of interpretation, and generates practical guidelines on how to initialize the inverse process.

Specifically, the objectives of this research are:

1. Evaluate and demonstrate the applicability of the model to field problems in predicting temperature and pressure profiles, and fluid entry along the wellbore.

2. Infer phase flow profiles from monitored downhole data by applying the inverse model to actual field data.

3. Develop interpretative guidelines for qualitative interpretation of temperature and pressure profiles in intelligent wells to identify regions of oil, water and gas inflow.

\subsection{Research Significance}

Intelligent completions are designed to maximize the benefit of an integrated threecomponent production system. This production system consists of data monitoring, data interpretation and production performance control. Efficient and accurate interpretation of the monitored data is crucial to realizing the potential value of intelligent wells. In the oil and gas industry today, the advancement in downhole data monitoring in intelligent wells exceeds our progress to promptly interpret and apply data.

This research will greatly enhance the value of intelligent well installation by demonstrating how to practically apply the interpretation models to field problems and 
provide guidelines for qualitative interpretation of temperature and pressure profiles in intelligent wells - to detect productive zones, identify fluid type and obtain production profile along the wellbore. 


\section{CHAPTER II}

\section{INTERPRETATION METHOD}

\subsection{Research Procedure}

In this study, we applied the wellbore-reservoir flow coupled thermal model to field data. To achieve the objectives, we studied the original material on equation derivations and interpretation model development form previous work, sourced and obtained field data, quality-checked the field data and translated the data from received format to Excel input format. Then we created Excel template for input data entry, data update, and output data, diagnostic charts and graphs. Finally we carried out the interpretation procedure to predict temperature and pressure and to infer the flow profile from the predicted data. Sensitivity study of interpretation error to input reservoir parameters is also included in this work.

\subsection{Model Overview}

The interpretation model includes a forward model and an inverse model. The interpretation model for downhole temperature and pressure data is a coupled thermal wellbore/reservoir flow model. The model is built on fundamental flow and energy conservation equations for both the reservoir and wellbore. These equations are: Mass

balance, Darcy's law, Energy balance and Momentum balance. This section summarizes 
the basic governing equations employed in the interpretation model. Full details of the derivations are documented by Yoshioka (2007).

The governing equations for the wellbore and the reservoir are derived with due consideration to the mass and heat transfer between the wellbore and the reservoir. The wellbore and reservoir equations are coupled and solved simultaneously for flow rate, pressure, and temperature profiles along the wellbore. The derived equations work for horizontal, inclined and vertical wells.

The interpretation model assumes:

- Steady state flow condition in the reservoir

- One-dimensional (1-D) inflow from the reservoir

- Isolated reservoir segments

- Single-phase flow in a reservoir segment (segregated reservoir flow)

\subsection{Wellbore Model}

Considering the differential volume element shown in Fig. 2.1, the steady-state conservation equations for single phase and multiphase flow in the wellbore is outlined below.

For open hole or perforated liner completion, the pipe open ratio is defined as:

$$
\gamma=\frac{\text { Open area of pipe }}{\text { Surface area of pipe }}
$$

Hence, the surface area of a differential volume element can be expressed as $2 \pi R \gamma \Delta x$. where $\mathrm{R}$ is the pipe inner diameter. 


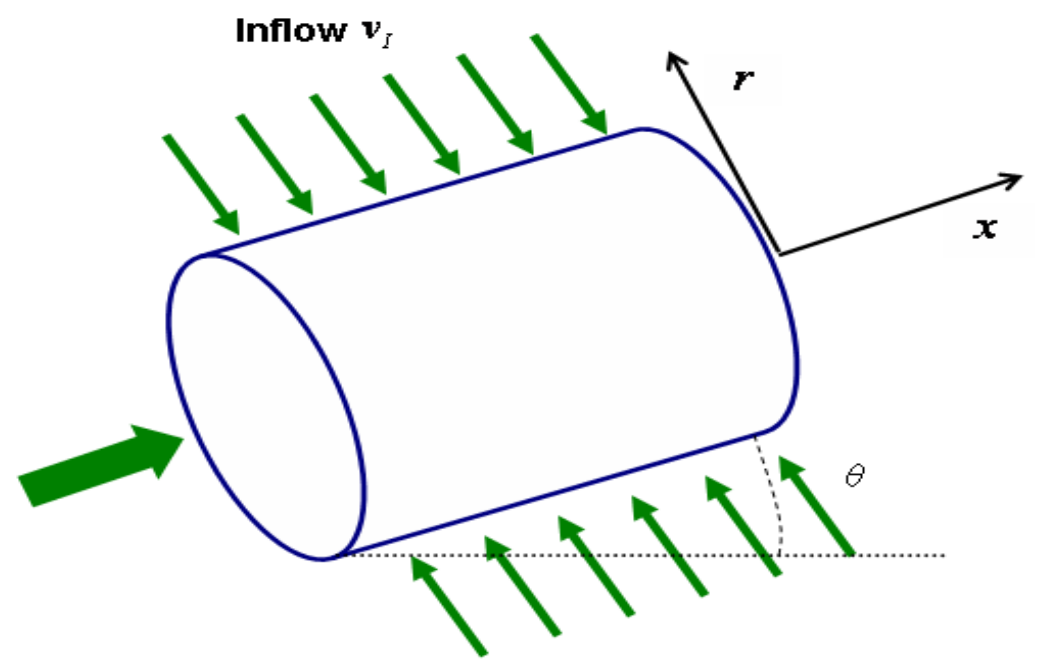

Fig. 2.1 Differential volume element of a wellbore.

The wellbore model accounts for fluid flow are in two directions: axial (x-direction) and radial (r-direction). We assume the velocity vector as:

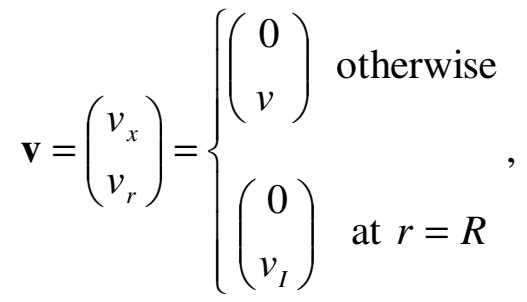

where $\mathbf{v}$ is the velocity vector and the subscript $I$ means inflow properties. Using the productivity index of the well, $J$, the inflow rate for a certain distance $(\Delta x)$ of the well can be written as: 


$$
\int_{\Delta x} 2 \pi R \gamma d x=J\left(p_{R}-p\right)
$$

where $p_{R}$ is the reservoir pressure.

\subsubsection{Single-phase flow}

We can account for the net input and output of intensive properties such as mass, momentum and total energy by using the shell balance.

\section{Mass balance}

For mass conservation, rate of increase of mass within the differential volume element is equal to the incoming mass flux and outgoing mass flux and is given by:

$$
\left\{\begin{array}{l}
\text { rate of } \\
\text { increase } \\
\text { of mass }
\end{array}\right\}=\left\{\begin{array}{c}
\text { rate of } \\
\text { mass } \\
\text { in }
\end{array}\right\}-\left\{\begin{array}{c}
\text { rate of } \\
\text { mass } \\
\text { out }
\end{array}\right\}
$$

Within the differential volume element, the rate of increase of mass is:

$$
\left\{\begin{array}{l}
\text { rate of } \\
\text { increase } \\
\text { of mass }
\end{array}\right\}=\pi R^{2} \Delta x \frac{\partial \rho}{\partial t}
$$

the rate of mass in is:

$$
\left\{\begin{array}{c}
\text { rate of } \\
\text { mass } \\
\text { in }
\end{array}\right\}=2 \pi R \gamma \Delta x\left(\rho v_{r}\right)_{R}+\pi R^{2}\left(\rho v_{x}\right)_{x}
$$

while the rate of mass out is: 
$\left\{\begin{array}{c}\text { rate of } \\ \text { mass } \\ \text { out }\end{array}\right\}=\pi R^{2}\left(\rho v_{x}\right)_{x+\Delta x}$

where $\rho$ is the fluid density.

Substituting Eqs. 2.5, 2.6 and 2.7 into Eq. 2.4 and simplifying for a steady-state system:

$$
\frac{d(\rho v)}{d x}=\frac{2 \gamma}{R} \rho_{I} v_{I}
$$

\section{Momentum balance}

The momentum balance over the differential volume is:

$$
\left\{\begin{array}{c}
\text { rate of } \\
\text { increase } \\
\text { of momentum }
\end{array}\right\}=\left\{\begin{array}{c}
\text { rate of } \\
\text { momentum } \\
\text { in }
\end{array}\right\}-\left\{\begin{array}{c}
\text { rate of } \\
\text { momentum } \\
\text { out }
\end{array}\right\}+\left\{\begin{array}{c}
\text { external } \\
\text { force on } \\
\text { the fluid }
\end{array}\right\} .
$$

The rate of increase of momentum in the x-direction is given as:

$$
\left\{\begin{array}{c}
\text { rate of } \\
\text { increase } \\
\text { of momentum }
\end{array}\right\}=\pi R^{2} \Delta x \frac{\partial\left(\rho v_{x}\right)}{\partial t}
$$

Then the rate of momentum in is:

$$
\left\{\begin{array}{c}
\text { rate of } \\
\text { momentum } \\
\text { in }
\end{array}\right\}=-2 \pi R \Delta x\left(\tau_{r x}\right)_{R}+\pi R^{2}\left(\rho v_{x} v_{x}+p-\frac{4}{3} \mu \frac{\partial v_{x}}{\partial x}\right)_{x}
$$

The rate of momentum out is: 


$$
\left\{\begin{array}{c}
\text { rate of } \\
\text { momentum } \\
\text { out }
\end{array}\right\}=\pi R^{2}\left(\rho v_{x} v_{x}+p-\frac{4}{3} \mu \frac{\partial v_{x}}{\partial x}\right)_{x+\Delta x}
$$

The external force on the fluid is:

$$
\left\{\begin{array}{l}
\text { external } \\
\text { force on } \\
\text { the fluid }
\end{array}\right\}=-\pi R^{2} \Delta x \rho g \sin \theta
$$

Combining and simplifying the momentum balance components and solving for steady state we obtain:

$$
\frac{d p}{d x}=-\frac{\rho v^{2} f}{R}-\frac{d\left(\rho v^{2}\right)}{d x}-\rho g \sin \theta
$$

where $f$ is the friction factor for porous pipe estimated as a function of the friction factor without radial flux and wall Reynolds number, Ouyang et al. (1998).

For laminar flow,

$$
f=f_{o}\left(1+0.04304\left(N_{\mathrm{Re}, w}\right)^{0.6142}\right) .
$$

For turbulence flow, friction factor for openhole completion is given as:

$$
f=f_{o}\left(1-29.03\left(\frac{N_{\mathrm{Re}, w}}{N_{\mathrm{Re}}}\right)^{0.8003}\right),
$$

and for perforated well, it is:

$$
f=f_{o}\left(1-0.0153\left(N_{\mathrm{Re}, w}\right)^{0.3978}\right) \text {. }
$$


where $N_{\mathrm{Re}}$ and $N_{\mathrm{Re}, w}$ are the Reynolds number and the wall Reynolds number that are given by

$f_{o}$ is the friction factor without radial influx and is estimated from the Moody's diagram or from Chen's correlation ${ }^{26}$ :

$$
f_{0}=\left[-4 \log \left\{\frac{\varepsilon}{3.7065}-\frac{5.0452}{N_{\mathrm{Re}}} \log \left[\frac{\varepsilon^{1.1098}}{2.8257}+\left(\frac{7.149}{N_{\mathrm{Re}}}\right)^{0.8981}\right]\right\}\right]^{-2}
$$

where $\varepsilon$ is the relative pipe roughness.

\section{Energy balance}

The energy balance equation is given by:

$$
\begin{gathered}
\left\{\begin{array}{c}
\text { rate of kinetic } \\
\text { and internal } \\
\text { energy increase }
\end{array}\right\}=\left\{\begin{array}{c}
\text { rate of } \\
\text { total energy } \\
\text { in }
\end{array}\right\}-\left\{\begin{array}{c}
\text { rate of } \\
\text { total energy } \\
\text { out }
\end{array}\right\} \\
+\left\{\begin{array}{c}
\text { rate of work } \\
\text { done on system } \\
\text { by external forces }
\end{array}\right\}+\left\{\begin{array}{c}
\text { rate of } \\
\text { energy } \\
\text { production }
\end{array}\right\}
\end{gathered}
$$

The rate of kinetic and internal energy increase is:

$$
\left\{\begin{array}{c}
\text { rate of kinetic } \\
\text { and internal } \\
\text { energy increase }
\end{array}\right\}=\pi R^{2} \Delta x \frac{\partial}{\partial t}\left(\frac{1}{2} \rho v^{2}+\rho U\right)
$$

The rate of total energy in is given as: 


$$
\left\{\begin{array}{c}
\text { rate of } \\
\text { total energy } \\
\text { in }
\end{array}\right\}=2 \pi R \Delta x\left(e_{r}\right)_{R}+\pi R^{2}\left(e_{x}\right)_{x}
$$

The rate of total energy out is:

$$
\left\{\begin{array}{c}
\text { rate of } \\
\text { total energy } \\
\text { out }
\end{array}\right\}=\pi R^{2}\left(e_{x}\right)_{x+\Delta x}
$$

The rate of work is done by gravity force is:

$$
\left\{\begin{array}{c}
\text { rate of work } \\
\text { done on system } \\
\text { by external forces }
\end{array}\right\}=-\pi R^{2} \Delta x \rho v g \sin \theta \text {. }
$$

The energy production in the system is zero, Hill (1990).

Combining and simplifying the energy balance components and neglecting insignificant terms we obtain

$$
\frac{d T}{d x}=K_{J T} \frac{d p}{d x}+\frac{2}{R \rho v}\left(\gamma \rho_{I} v_{I}+\frac{1-\gamma}{C_{P}} \alpha\right)\left(T_{I}-T\right)-\frac{g \sin \theta}{C_{P}}
$$

where $K_{\mathrm{JT}}$ is Joule - Thomson coefficient given by:

$$
K_{J T}=\frac{\beta T-1}{\rho C_{P}}
$$

and $C_{p}$ is the heat capacity, $\beta$ is the coefficient of isobaric thermal expansion and $\alpha$ is the overall heat transfer coefficient 


\subsubsection{Multi-phase flow}

To obtain the multiphase flow equations for mass and energy balance, the conserved properties are weighted by their volume fraction (holdup) in the system.

\section{Mass balance}

The mass balance for phase $i$ (= oil, water, or gas) is given by:

$$
\frac{d\left(\rho_{i} v_{i} y_{i}\right)}{d x}=\frac{2 \gamma y_{i, I}}{R} \rho_{i} v_{i, I}
$$

where $y_{i}$ is a volume fraction of phase $i$.

\section{Energy balance}

If we assume that the pressures and temperatures in each phase and neglect kinetic energy and viscous shear terms, we obtain:

$$
\frac{d T}{d x}=\frac{\left(\rho \nu C_{p} K_{J T}\right)_{T}}{\left(\rho \nu C_{p}\right)_{T}} \frac{d p}{d x}+\frac{2}{R}\left[\frac{\gamma\left(\rho \nu C_{p}\right)_{T, I}+(1-\gamma) \alpha_{T}}{\left(\rho \nu C_{p}\right)_{T}}\right]\left(T_{I}-T\right)-\frac{(\rho v)_{T}}{\left(\rho \nu C_{p}\right)_{T}} g \sin \theta
$$

where $\alpha_{T}$ is an overall heat transfer coefficient for multi-phase flow .

\section{Momentum balance}

Our interpretation model applies the homogeneous model for oil-water flow and a homogeneous with drift-flux model for gas-liquid flow by Ouyang and Aziz (2000). 
For oil-water two-phase flow, the momentum balance equation is given with mixture properties as:

$$
\frac{d p}{d x}=-\frac{\rho_{m} v_{m}{ }^{2} f_{m}}{R}-\frac{d\left(\rho_{m} v_{m}{ }^{2}\right)}{d x}-\rho_{m} g \sin \theta,
$$

Where $\rho_{m}$ is the mixture density

The two-phase velocity is:

$$
v_{T P}=\frac{\rho_{o}}{\rho_{m}} v_{s o}+\frac{\rho_{w}}{\rho_{m}} v_{s w}
$$

The oil-water mixture viscosity is given by:

$$
\mu_{m}=\mu_{c}\left(1-y_{d}\right)^{-2.5}
$$

where the subscript $c$ means continuous phase and $d$ means dispersed phase.

For liquid-gas two-phase flow, the momentum balance is given by:

$$
\frac{d p}{d x}=\frac{1}{1-\left(\rho_{l} v_{s l}+\rho_{g} v_{s g}\right) \frac{v_{s g}}{p}}\left[-\frac{f \rho_{m} v_{T P}^{2}}{R}-\rho_{m} g \sin \theta+\left(\frac{d p}{d x}\right)_{a W}\right],
$$

where $v_{s l}$ and $v_{s g}$ are superficial velocities of liquid and gas respectively. $\left(\frac{d p}{d x}\right)_{a W}$ is an accelerational pressure drop caused by wall friction.

The mixture properties are given by:

$$
\rho_{m}=\rho_{l} y_{l}+\rho_{g} y_{g}
$$




$$
\mu_{m}=\mu_{l} y_{l}+\mu_{g} y_{g},
$$

The two-phase velocity is:

$$
v_{T P}=\frac{\rho_{l}}{\rho_{m}} v_{s l}+\frac{\rho_{g}}{\rho_{m}} v_{s g} .
$$

The in-situ velocity of gas is estimated from drift-flux model as:

$$
v_{g}=C_{0}\left(v_{s l}+v_{s g}\right)+v_{d},
$$

where $v_{d}$ is the drift velocity and $C_{0}$ is the profile parameter.

\subsection{Reservoir Model}

To obtain the equations for the reservoir temperature profile we combine Darcy's equation and energy balance equation.

\section{Mass balance}

The mass balance is given by:

$$
\phi \frac{\partial \rho}{\partial t}=-\nabla \cdot(\rho \mathbf{u}) .
$$

where $\mathbf{u}$ is the Darcy velocity,

$$
\mathbf{u}=-\frac{\mathbf{k}}{\mu} \cdot(\nabla p+\rho \mathbf{g}) .
$$




\section{Energy balance}

The energy balance equation is given by:

$$
\frac{\partial}{\partial t}(\rho U)=-\nabla \cdot(\rho U \mathbf{v})-p \nabla \cdot \mathbf{v}-\nabla \cdot \mathbf{q}+(-\boldsymbol{\tau}: \nabla \mathbf{v})
$$

In terms of enthalpy, internal energy is given by:

$$
U=H-\frac{p}{\rho}
$$

where $U, \mathbf{q}, \boldsymbol{\tau}$ and $H$ are the internal energy, heat flux, the shear stress tensor and the enthalpy respectively. Combining Eq. 2.38 and Eq. 2.39 and replacing the interstitial velocity, v, with the Darcy velocity, $\mathbf{u}$, we obtain

$$
\begin{aligned}
0 & =\rho C_{p} \mathbf{u} \cdot \nabla T-\beta T \mathbf{u} \cdot \nabla p-\nabla \cdot K_{T} \nabla T+\mathbf{u} \cdot \nabla p \\
& =\rho C_{p} \mathbf{u} \cdot \nabla T-\beta T \mathbf{u} \cdot \nabla p-K_{T} \nabla^{2} T+\mathbf{u} \cdot \nabla p
\end{aligned}
$$

The four terms on the RHS of Eq. 2.40 represent the thermal energy transported by convection, thermal energy change caused by fluid expansion, thermal energy transported by heat conduction and the viscous dissipative heating respectively.

\section{Coupled Model}

The working equations of the wellbore and the reservoir are highly dependent each other and there is high non-linearity between reservoir and wellbore temperature. Therefore, in the development of the prediction model (forward model) the equations for the reservoir flow are coupled with the wellbore equations and solved iteratively at the same time. Firstly, the equations are discretized with a finite difference scheme and then 
by successive substitution, the matrices for each equation are solved as many times as necessary until the solution converges. Fig. 2.2 shows the schematic of the flow diagram for the solution procedure.

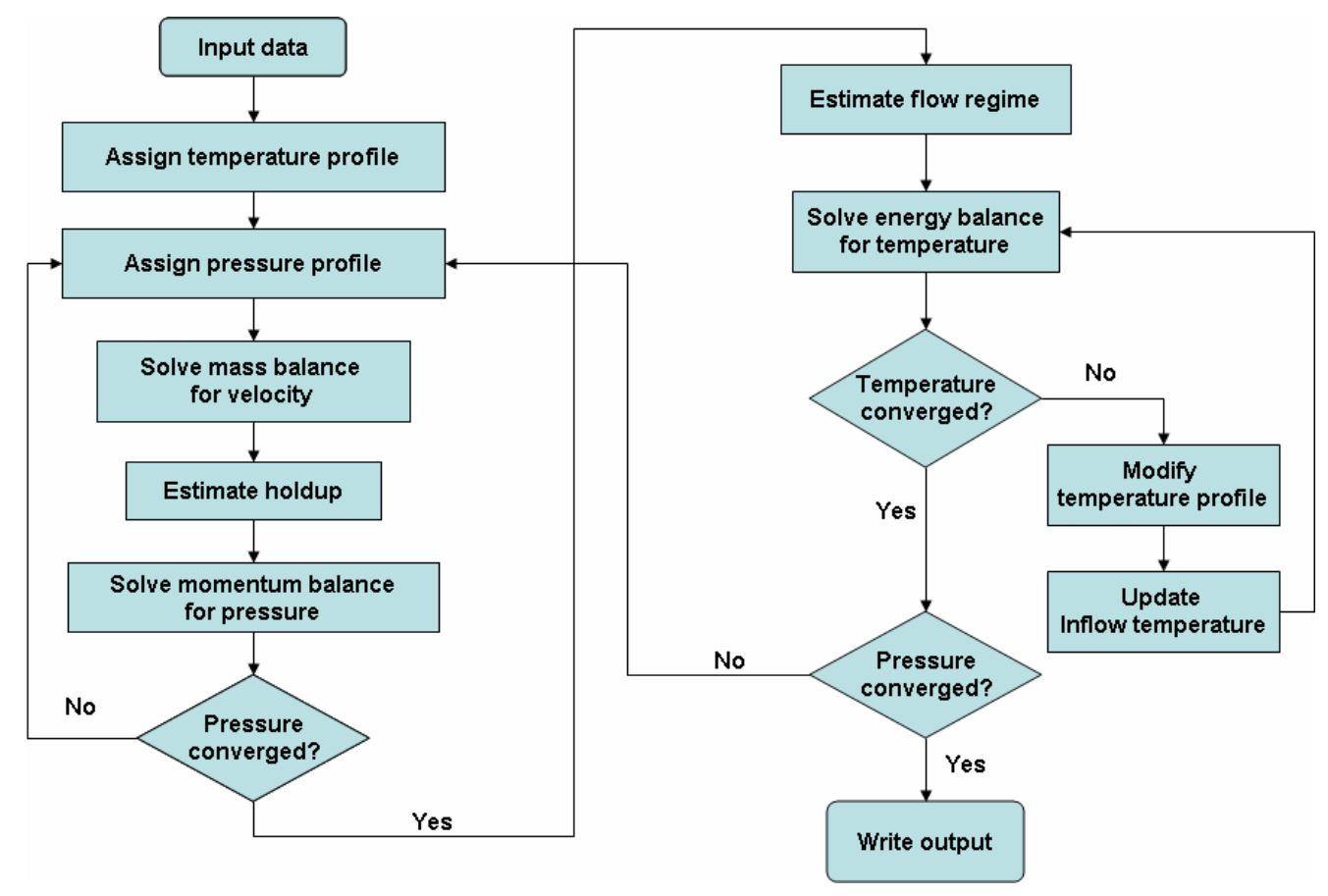

Fig. 2.2 Forward model iteration procedure.

\subsection{Inversion Model}

The reservoir and wellbore coupled model is used as a forward model to generate pressure and temperature profiles and total flow rate. A forward model with $N$ segments will generate $N$ pressures and $N$ temperatures and total flow rate for each phase. The 
inversion model inverts the generated observation data ( $N$ pressure and $N$ temperature points and total flow rate) to obtain the productivity distribution along the well.

The productivity index $J$ is defined as:

$$
J=\frac{q}{\Delta p}
$$

The discrepancy between observation data and calculated data is the objective function to be minimized. The objective function is given by:

$$
\begin{aligned}
E(\mathbf{w}) & =\mathbf{e}_{p}{ }^{\mathrm{T}} \mathbf{e}_{p}+\mathbf{e}_{T}{ }^{\mathrm{T}} \mathbf{e}_{T}+\mathbf{e}_{q}{ }^{\mathrm{T}} \mathbf{e}_{q} \\
& =\sum_{j=1}^{N}\left[\left(\mathbf{D}_{p}\right)_{j j}\left(p_{c j}-p_{m j}\right)^{2}+\left(\mathbf{D}_{T}\right)_{j j}\left(T_{c j}-T_{m j}\right)^{2}\right]+\sum_{i=1}^{3}\left(\mathbf{D}_{q}\right)_{i i}\left(q_{c i}-q_{m i}\right)^{2}
\end{aligned}
$$

where $\mathbf{e}_{p}, \mathbf{e}_{\boldsymbol{T}}, \mathbf{e}_{\boldsymbol{q}}$ are the error components for pressure, temperature and flow rate respectively and $\mathbf{D}_{p}, \mathbf{D}_{T}$, and $\mathbf{D}_{Q}$ are weights for each error element and are diagonal matrices

The Levenberg-Marquardt Algorithm, Marquardt (1963), is the minimization method used in the inverse model. It combines the method of least-squares estimation and a steepest descent method with a blending factor $\lambda$. The update vector is given as:

$$
\mathbf{w}=\mathbf{w}_{0}-(\mathbf{H}+\lambda \mathbf{I})^{-1} \mathbf{d}
$$

where, $\mathbf{w}_{0}, \mathbf{I}, \mathbf{H}$ and $\mathbf{d}$ are initial guess of the parameters, the identity matrix, the Hessian matrix and the gradient vector respectively. The Hessian matrix and the gradient vector are given by:

$$
\mathbf{H}=\mathbf{J}_{p}{ }^{\mathrm{T}} \mathbf{J}_{p}+\mathbf{J}_{T}{ }^{\mathrm{T}} \mathbf{J}_{T}+\mathbf{J}_{q}{ }^{\mathrm{T}} \mathbf{J}_{q} .
$$


and

$$
\mathbf{d}=\mathbf{J}_{p}{ }^{\mathrm{T}} \mathbf{e}_{p}+\mathbf{J}_{T}{ }^{\mathrm{T}} \mathbf{e}_{T}+\mathbf{J}_{q}{ }^{\mathrm{T}} \mathbf{e}_{q},
$$

where $\mathbf{J}_{p}, \mathbf{J}_{T}$, and $\mathbf{J}_{Q}$ are Jacobian matrices. The Jacobian matrices are solved numerically. Fig. 2.3 illustrates the procedure of the inversion.

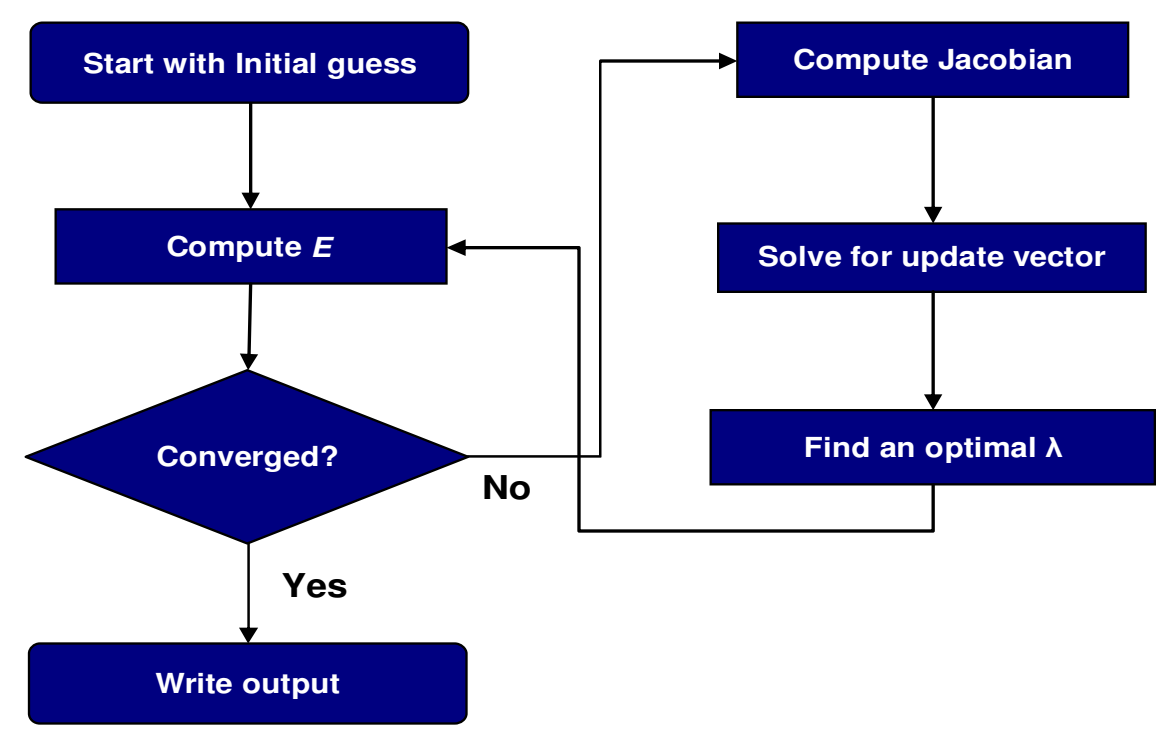

Fig. 2.3 Inverse model calculation flow chart.

\subsection{Program Requirement}

The forward and inverse models are programmed into execution files that can be run on a standard computer system. The computer softwares needed for program usage are $\mathrm{C}++$, Microsoft Excel and Text. Although the $\mathrm{C}++$ program reads its input data from Text files, the Excel software provides interface for input data entry, data update and 
output. The program also requires the downhole data acquired along the wellbore completion zones such as temperature and pressure data obtained from permanent gauges, fiber optic sensors, etc., others are the reservoir rock and fluid properties, well deviation survey, completions and pipe data.

\subsection{Data Preparation}

Data gathering, preparation and entry can be accomplished by following steps:

- Split the completion zone into segments

- Populate the input template sheets with field measured temperature, pressure, permeability (measured or estimated) and skin

- Enter the other input data in the Excel template

- Export input data from Excel to text file

- Run the program

To handle the statistical fluctuation encountered in fiber optics measurement, raw DTS data should be averaged and normalized before it is analyzed. This smoothening process improves temperature data resolution to less $0.1{ }^{\circ} \mathrm{C}$. We can also improve the DTS data resolution by making the data acquisition time longer if we do not need to capture short term production changes or we can complete the well with single-ended fiber systems (has better resolution than double ended fiber system). For wells with partial completion and slanted well bore skin we derived appropriate equation, in Appendix A, to distribute these skin effects at the segment level. 


\subsection{Input Data}

There is a minimal data requirement to use the model as outlined above but any additional measured information can be used to corroborate the interpretation. The quality of the data directly affects the interpretation results. Temperature and pressure data are essential for the interpretation model. These data can be provided by downhole sensors (intelligent completion), downhole gauges or production logging. Simple Excel templates are available for input. These are user friendly color coded worksheets that the Engineer is already conversant with. Data is entered in the green cells only, while the rest of the cells are automatically populated by a combination of spreadsheet calculations and Excel look-up functions. Each of the input data categories has its own entry sheet.

\subsubsection{Well deviation survey}

The depth and deviation data are some of the critical data needed to ensure interpretation accuracy. Well depth data should be as precise as possible and all reference depths should be noted. Caliper logs or tubing tally, if available, should be used to verify exact depths. The well deviation survey input category requires the measured depth and true vertical depth of the well, Fig. 2.4 shows a sample of the input sheet. 


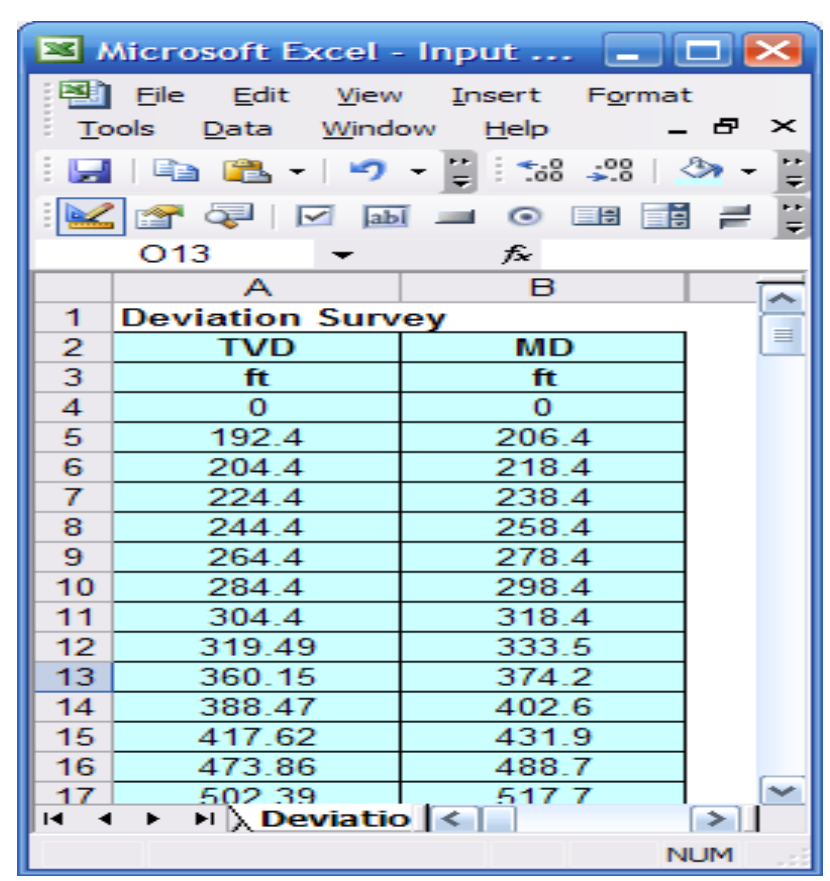

Fig. 2.4 Sample input sheet for well deviation data.

\subsubsection{Completion and tubular data}

Well structure data include wellbore diameter, completion information and well trajectory survey (measured depth and vertical depth that also provide the deviation angle of the wellbore). To calculate pressure drop, roughness of the pipe needs to be estimated. The completion information (completion type and geometry dimension) will be used to calculate completion skin factor. The depth and deviation data are also critical data needed to ensure interpretation accuracy. Caliper logs or tubing tally, if available, should be used to verify exact depths and well structure. The interpretation model handles various completion types (open hole, slotted liner and cased and perforated completions). Therefore knowledge of the thermal conductivity of the pipe material, cement as well as the fraction of pipe area open to flow are required. Again, the 
interpretation model consists of a segmented well bore model that allows independent variation of the well bore deviation angle for each segment if required. The model thus can be applied to undulating horizontal or deviated wells. Fig. 2.5 is the sample input interface.

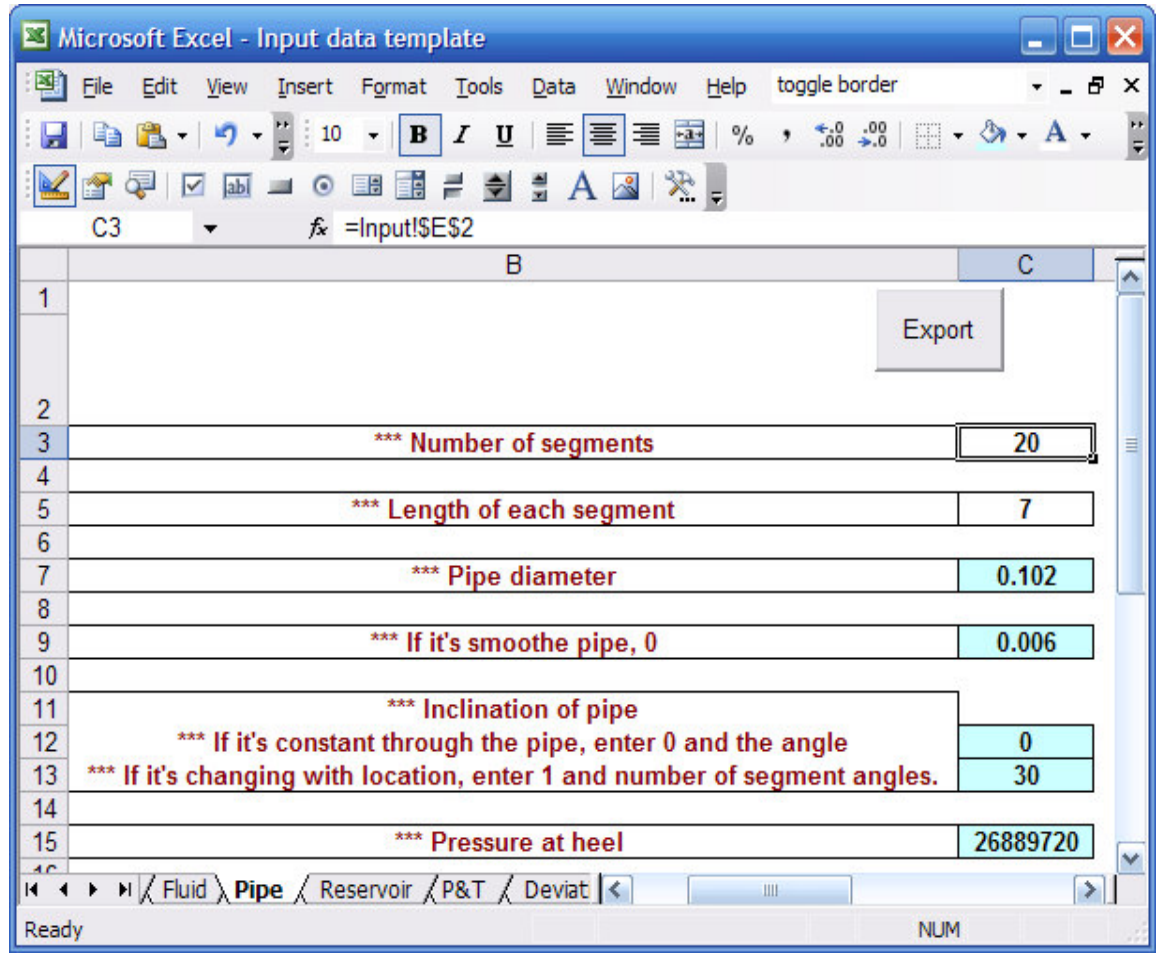

Fig. 2.5 Sample input sheet for completion and tubular data.

\subsubsection{Downhole temperature and pressure}

Downhole temperature and pressure can be measured by downhole sensor or production logging tools. They are the most important input in the interpretation procedure. Fig. 2.6 is a cut-out section of the entry sheet. For downhole sensor measurements, temperature 
data provides more accurate results if it is measured outside the tubing in the protective annulus. In this configuration we can detect subtle temperature changes (especially in low non-aquifer water production situations) before they are masked by fluid mixing in the well bore. Inside tubing against completions, fluid fixing adds more difficult to interpretation. The depth resolution is not as important as the absolute accuracy (resolution and noise level). The interpretation will lose its meaning when the noise level of the downhole measurement is as high as the resolution since the theoretical calculation depends on very small change in temperature $\left(\sim 0.1^{\circ} \mathrm{C}\right)$, Sui $(2008)$. In this paper, the temperature and pressure data used in the field examples are provided by production logging.

\begin{tabular}{|c|c|c|c|c|}
\hline \multicolumn{5}{|c|}{$\mathbb{3}$ Microsoft Excel - Input data te... $=\square x$} \\
\hline \multicolumn{5}{|c|}{ 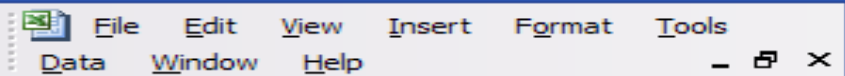 } \\
\hline \multicolumn{5}{|c|}{ 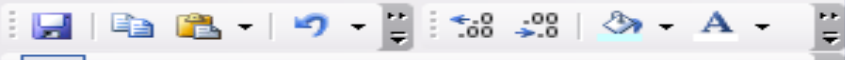 } \\
\hline \multirow[t]{3}{*}{ 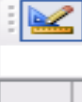 } & \multicolumn{4}{|c|}{ 国 至| } \\
\hline & \multicolumn{4}{|c|}{ F10 $\quad-\quad f x$} \\
\hline & A & $\mathrm{B}$ & $\mathrm{C}$ & \\
\hline 1 & Depth & Pressure & Temperature & \\
\hline 2 & $\mathrm{ft}$ & psia & $\operatorname{deg} \mathrm{C}$ & \\
\hline 3 & 5605.5 & 2844.515 & 111.729 & \\
\hline 4 & 5605.6 & 2844.584 & 111.729 & \\
\hline 5 & 5605.7 & 2844.629 & 111.729 & \\
\hline 6 & 560 & 2844.605 & 111.737 & \\
\hline 7 & 560 & 2844.612 & 111.741 & \\
\hline 8 & 5606 & 2844.648 & 111.741 & \\
\hline 9 & 5606.1 & 2844.768 & 111.741 & \\
\hline 10 & 5606.2 & 2844.854 & 111.741 & \\
\hline 11 & 5606.3 & 2844.890 & 111.741 & \\
\hline 12 & 5606.4 & 2845.014 & 111.741 & \\
\hline 13 & 5606.5 & 2845.099 & 111.743 & \\
\hline 14 & 5606.6 & 2845.092 & 111.747 & \\
\hline 15 & 5606.7 & 2845.175 & 111.744 & \\
\hline 16 & 5606.8 & 2845.258 & 111.740 & \\
\hline 17 & 56069 & 2845280 & 111739 & 2 \\
\hline \multirow[t]{2}{*}{144} & 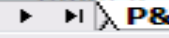 & Devia $\mid<$ & & \\
\hline & & & NUM & \\
\hline
\end{tabular}

Fig. 2.6 Input template for temperature and pressure data. 


\subsubsection{Fluid data}

Various reservoir fluid properties (viscosity, density or API gravity) and fluid thermodynamics properties (heat capacity, heat conductivity and thermal expansion coefficient) are required by the prediction model. Other data are water salinity, gas-oil ratio and surface tension. Fig. 2.7 illustrates the fluid data entry template.

Since some of the fluid data depend on reservoir temperature and pressure, the user has the option of specifying the properties that should be kept constant and the properties that should be recalculated with variation in reservoir temperature and pressure. The interpretation program contains correlation that carries out automatic recalculation of temperature and pressure dependent variables. The interpretation model can be applied to single phase oil, single phase gas, and immiscible water/oil or immiscible water/gas systems. 


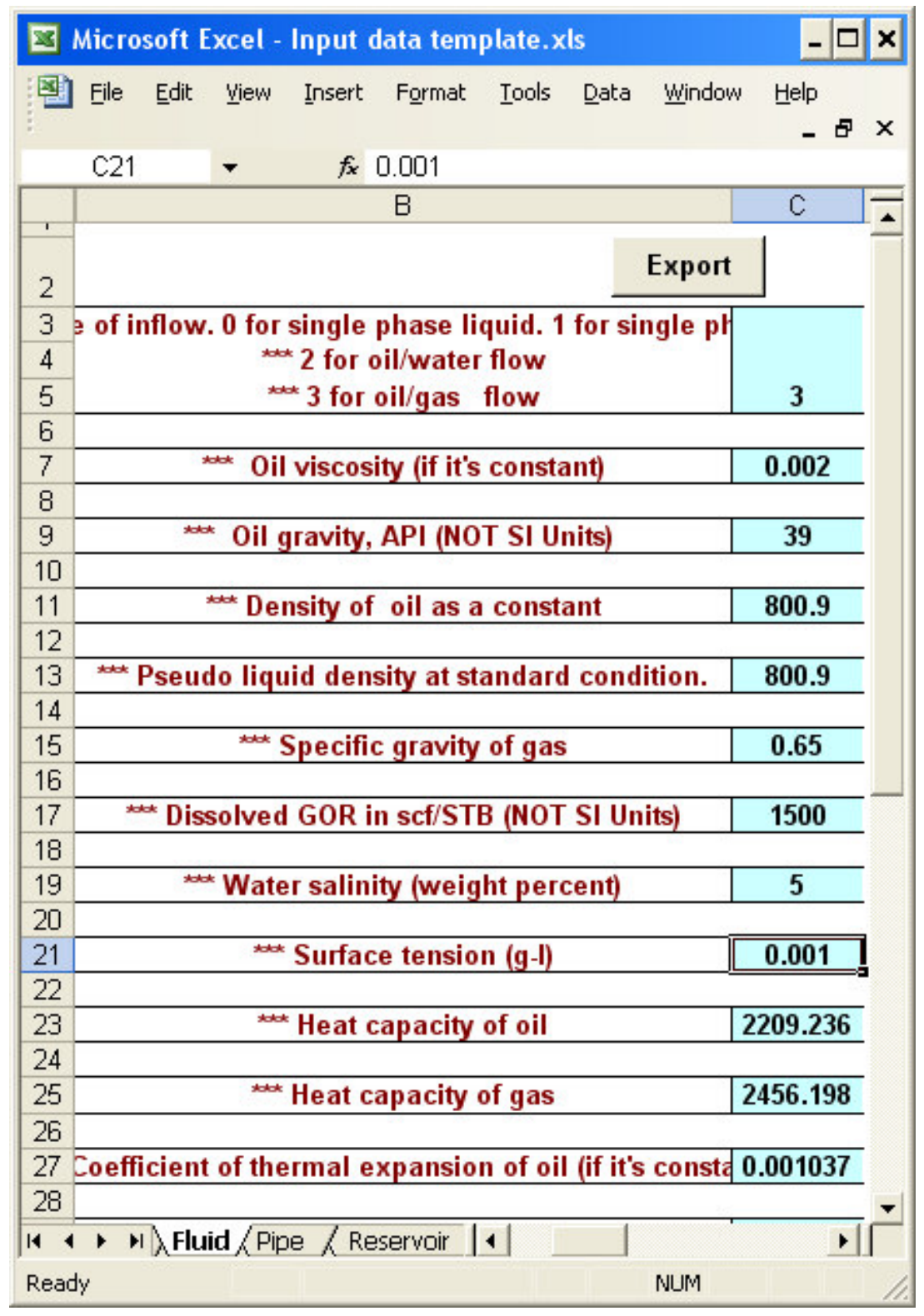

Fig. 2.7 Template for fluid data entry. 


\subsubsection{Reservoir data}

The reservoir data include the formation permeability, formation temperature, geothermal gradient, thermal conductivity of formation rock, formation pressure, reservoir drainage dimension (drainage radius and thickness). Formation damage information such as damage skin factor and its distribution are needed. Fluid contacts (gas-oil oil-water and gas-water) information will be useful in explaining extraneous influence on the wellbore temperature profile.

The geothermal gradient can be estimated from temperature logs, if available, or obtained by running temperature logs in non-flowing offset wells or by shutting in the well and acquiring stabilized downhole temperature after a long shut-in period. If the reservoir heterogeneity information is available, the reservoir can be segmented, and the reservoir can be characterized discretely. A sample screen for reservoir data entry is shown in Fig. 2.8. 


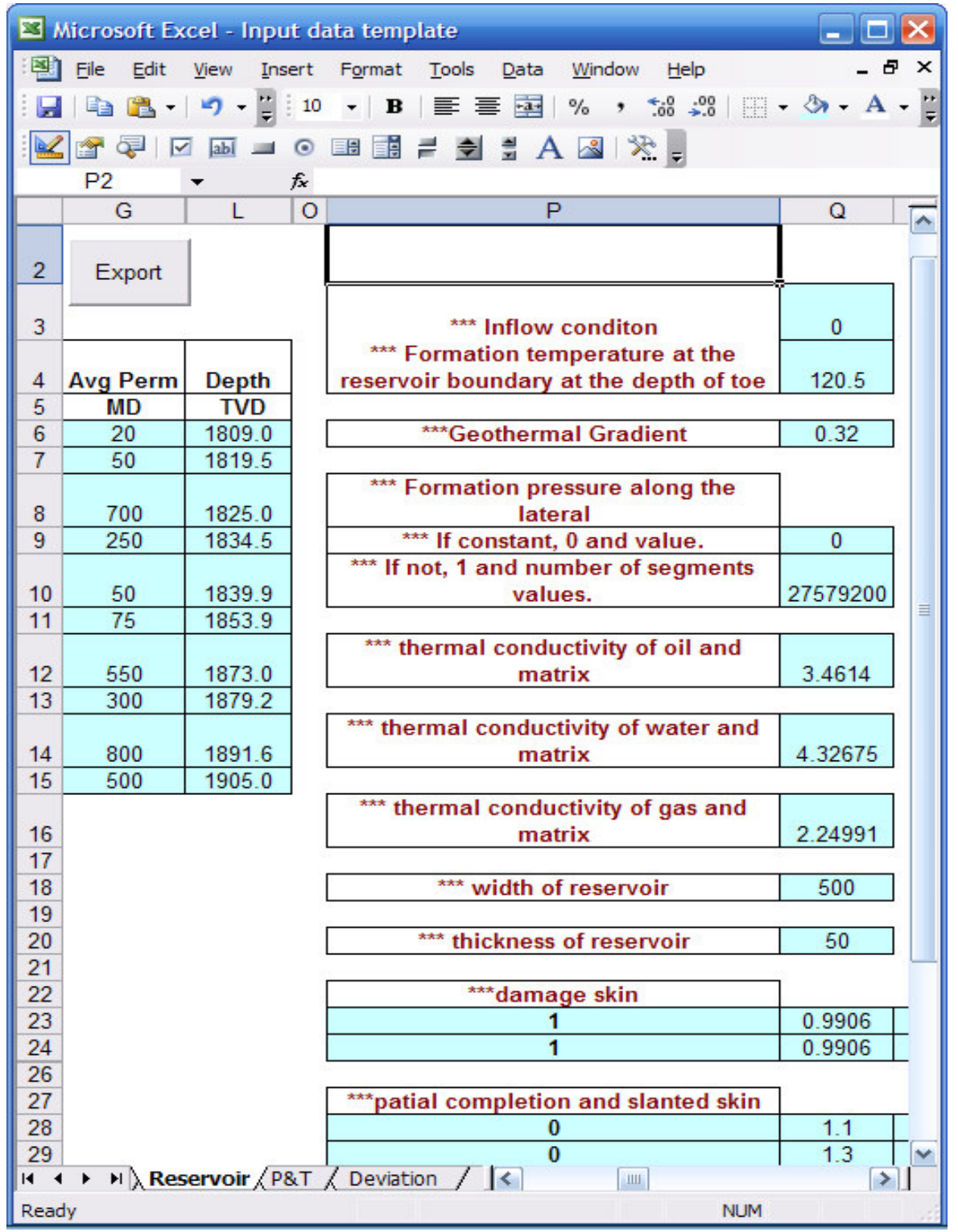

Fig. 2.8 Cut-out section of the reservoir data input sheet.

In the field, the input data can be gathered from sources that are easily accessible to the user. Table 2.1 shows the entry category data and the possible/typical company location where the various parameters can be sourced. 
Table 2.1 Input data sources.

\begin{tabular}{|l|l|}
\hline Input Category & \multicolumn{1}{|c|}{ Source } \\
\hline Well deviation survey & - well file, workover file, drilling file \\
\hline $\begin{array}{l}\text { Downhole Temperature \& } \\
\text { Pressure }\end{array}$ & $\begin{array}{l}\text { - down hole gauges and sensors, well file, well } \\
\text { tests }\end{array}$ \\
\hline Fluid data & $\begin{array}{l}\text { - well log, production tests, PVT studies, } \\
\text { correlations }\end{array}$ \\
\hline Reservoir data & $\begin{array}{l}\text { - well log, production tests, well tests (flowing } \\
\text { and build up) }\end{array}$ \\
\hline $\begin{array}{l}\text { Completion and tubular } \\
\text { data }\end{array}$ & - well file, well schematic, end of well report \\
\hline
\end{tabular}

\subsection{Output Template}

The basic output template is an excel spreadsheet, Fig. 2.9, that displays the figures of the calculated results. It outputs the production fluid flow rates (oil, water, gas), as well as the predicted fluid inflow profiles along the well completion zones.

The temperature profile outputs include the wellbore predicted temperature and the inflow temperature (just before the fluid enters the wellbore). The remaining output parameters are the predicted wellbore pressure, the flow phase profile and phase fraction. These predicted/calculated pressure and temperature profiles are plotted with the field measured data as a function of well depth for comparison purposes. Besides the original template charts, other user-specific plots can be created as desired. 

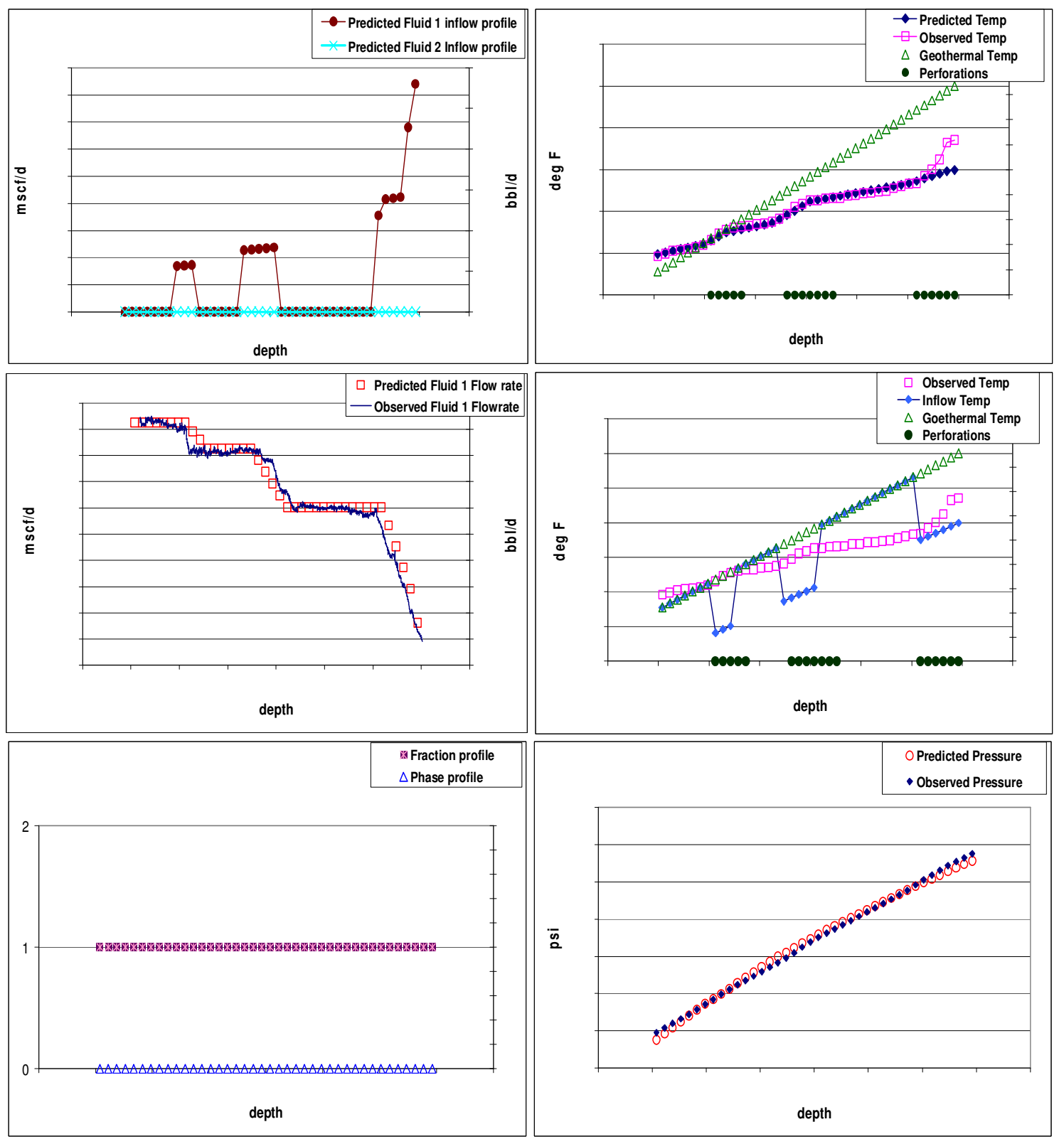

Fig. 2.9 Output template. 


\subsection{Running Application}

The program has two modules, the prediction and the inverse modules. In the prediction mode, the forward model generates initial observation data. This initial data obtained by running the forward model consist of estimated temperature profile, pressure profile and total flowrate for each fluid phase.

In inversion mode, the interpretation model infers the flow profile from the measured temperature and pressure data by correcting the calculated temperature and pressure against the measured temperature and pressure, and updating the flow profile until the difference between the two (defined as an error function) meets the criteria of conversion.

\subsection{Analysis and Interpretation}

Meaningful interpretation analysis on any acquired downhole temperature data requires that we understand the interaction and influence of geothermal gradient and thermal processes on fluids flowing inside the reservoir and in the wellbore. Temperature changes in a well bore occur comparatively to the geothermal temperature profile. This geothermal temperature gradient serves as the initial temperature profile for flowprofiling interpretation.

Generally temperature changes are caused by flow friction in the reservoir; Joule Thompson effect - cooling in gas in most cases, heating in oil/water; elevation changes in the wellbore and geothermal gradient in the subsurface. Inflow fluid is expected to enter the well from the reservoir at the geothermal temperature at the entry depth. This fluid undergoes Joule Thomson cooling or heating in the near wellbore due to pressure 
drop and then mixes with other inflow fluids as it flows up the wellbore. It is found that the resulting well stream temperature is directly related to the percentage of each inflow zone contribution and also the fluid type at the inflow location. Hence for correct interpretation, care should be taken to ensure the accuracy of the fluid properties because the temperature changes are sensitive to contrast in reservoir fluid properties of each phase. Pressure profile are relatively less sensitive to flow dynamics than temperature profiles, nevertheless, pressure profiles corroborates the temperature tend analysis for different flow conditions, (Dawkrajai 2006; Van der Steen 2006).

When oil and water are produced from the same depth, oil warms up (viscous dissipative heating) faster than water because of different thermal properties and therefore enters the wellbore with higher temperature. In this scenario, the water enters with a lower temperature and 'cools' the temperature profile. However, when a well produces water by coning from warmer aquifer below production zone a warming effect and associated high entry temperature is encountered. Exothermic reaction of the cement sidetrack plug is known to cause an increase in the wellbore temperature profile.

Besides the fluid type, pressure drawdown is another factor that control Joule Thomson behavior of inflow fluids. Small frictional heating can be expected for a high rate (high permeability) reservoirs since the pressure drawdown is often small while high frictional heating occurs in reservoir with large drawdown even if the flow rate is low. High pressure drawdown yields high Joule Thomson heating (Brown 2006; Pinzon et al. 2007) . At very high pressures, gas exhibits warm Joule Thomson effects. This may be 
attributed to the change of gas properties into liquid properties as the gas is compressed under high pressure.

To discern flow contribution, detect gas, oil or water inflow zones and to locate contributing sections along the wellbore, we need to look for deviation of the thermal profile of the well when compared with the geothermal temperature baseline. These anomalous deviations depict trends that can be analyzed and interpreted to yield useful well information that subsequently form the basis for production optimization and well control. The geothermal baseline can be obtained from field temperature database or by shutting in the well and acquiring stabilized downhole temperature data.

Slope changes which usually occur at inflow sections identify the producing zone from the non-producing zones and sometimes can be used to mark the inflow boundary of one fluid from another fluid along the wellbore. 


\section{CHAPTER III}

\section{FIELD APPLICATION}

\subsection{Study Objectives}

We have applied the model for flow condition interpretation to some field cases to validate the model and to investigate the feasibility of using downhole pressure and temperature data to locate water entries in gas wells. The specific study objectives were to:

1. Obtain the production profile along the wellbore. This includes the amount of fluid flowing into the wellbore at the various completion zones and the cumulative flow rate in the wellbore.

2. Obtain the fluid entry location: It is desired to know the completions that were actually producing the fluid and those that were not i.e. the productive and nonproductive locations along the wellbore.

3. Identify fluid type: To further characterize flow profile, it is desired to know the different fluid types - gas or water being produced along the wellbore. This aims to advise optimization and control activities for better reservoir management.

The analysis was carried out on a gas producing well. The wellbore is inclined with about 30-degrees deviation from the vertical. The schematic of well structure is shown in

Fig. 3.1, and the reservoir information is listed in Table 3.1. The reservoir properties that are dependent on temperature and/or pressure are automatically recalculated by our 
model as the reservoir condition changes. The well penetrates several reservoir units/layers however only three of the units/layers are completed. The multilayer completion has four perforated zones. The first and second perforated zones are completed in two different reservoir units while the third and fourth perforated zones are completed in the same reservoir unit and are treated as one perforation zone in this study. The various layers are characterized by similar porosities and net-to-gross ratios but have wide permeability range. The gas-water contact is at $4245 \mathrm{~m}$.

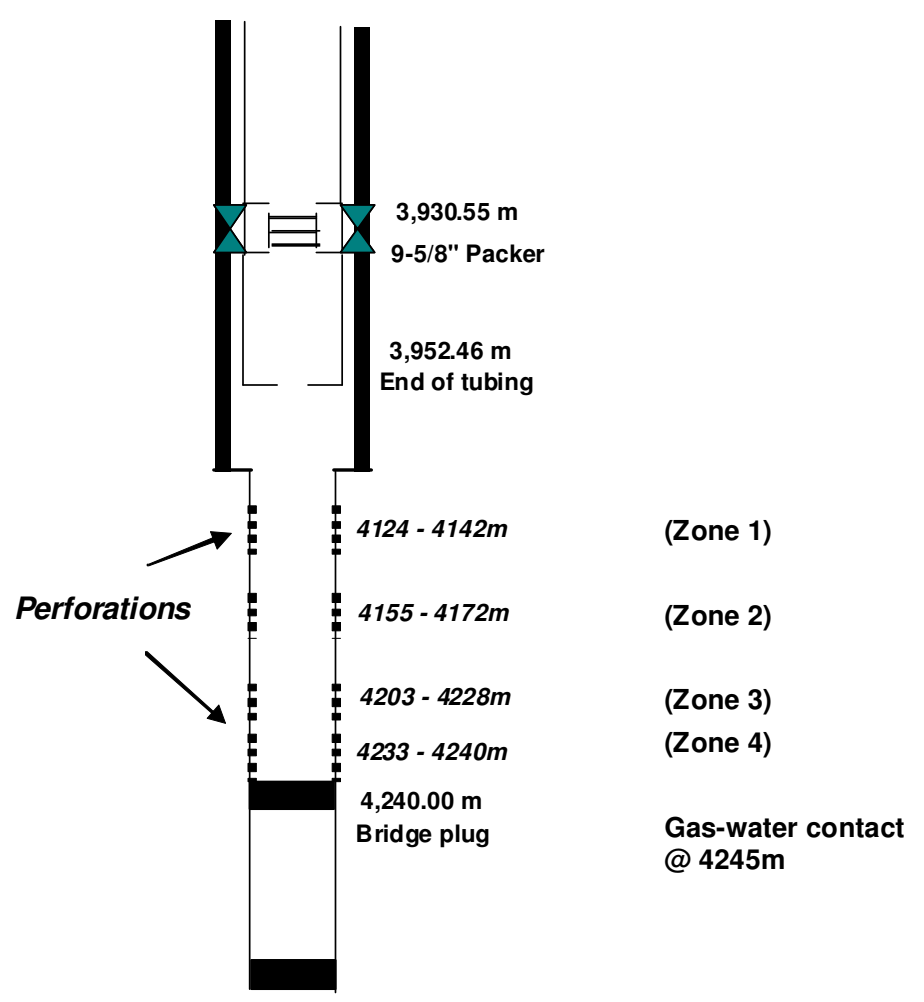

Fig. 3.1 The schematic of the well structure. 
Table 3.1 Reservoir properties of the case example.

\begin{tabular}{|l|c|c|}
\hline Specific gravity of gas & $\mathbf{0 . 8 8}$ & - \\
\hline Water salinity (weight percent) & $\mathbf{5}$ & $\mathbf{\%}$ \\
\hline Heat capacity of gas & $\mathbf{2 4 5 6}$ & J/kg-K \\
\hline $\begin{array}{l}\text { Coefficient of thermal expansion of } \\
\text { water }\end{array}$ & $\mathbf{0 . 0 0 0 5}$ & /K \\
\hline Heat conductivity of gas & $\mathbf{0 . 0 2}$ & W/m.K \\
\hline Pipe diameter & $\mathbf{0 . 1 5}$ & $\mathbf{m}$ \\
\hline Pipe roughness & $\mathbf{0 . 0 0 0 6}$ & - \\
\hline Inclination of pipe from vertical & $\mathbf{3 0}$ & $\mathbf{d e g}$ \\
\hline Casing OD & $\mathbf{0 . 1 6 8}$ & $\mathbf{m}$ \\
\hline $\begin{array}{l}\text { Thermal conductivity of casing } \\
\text { material }\end{array}$ & $\mathbf{1 7}$ & W/m.K \\
\hline Cement OD & $\mathbf{0 . 2 1 6}$ & $\mathbf{m}$ \\
\hline Thermal conductivity of cement & $\mathbf{1 . 7}$ & W/m.K \\
\hline Reservoir temperature & $\mathbf{1 3 5}$ & ${ }^{\mathbf{C}}$ \\
\hline Geothermal Gradient & $\mathbf{0 . 0 3 1}$ & $\mathbf{}$ C / m \\
\hline Reservoir pressure & $\mathbf{4 4 8 6}$ & $\mathbf{p s i a}$ \\
\hline $\begin{array}{l}\text { Thermal conductivity of water and } \\
\text { matrix }\end{array}$ & $\mathbf{4 . 3 3}$ & W/m.K \\
\hline $\begin{array}{l}\text { Thermal conductivity of gas and } \\
\text { matrix }\end{array}$ & $\mathbf{2 . 2 5}$ & W/m.K \\
\hline Dimension of reservoir & $\mathbf{6 0 0}$ & $\mathbf{m}$ \\
\hline Thickness of reservoir & $\mathbf{1 2 0}$ & $\mathbf{m}$ \\
\hline Damage skin & $\mathbf{0}$ & - \\
\hline Slanted borehole skin & & - \\
\hline \multicolumn{1}{|c|}{ zone 3 and 4} & $\mathbf{- 1 . 0 1}$ & \\
\hline & $\mathbf{1 . 4} \mathbf{- 6 8 2}$ & $\mathbf{m D}$ \\
\hline Reservoir permeability & & \\
\hline
\end{tabular}

Good production history was available and production logging was run at several flow rates when the well was mainly producing gas, and also when the well started to produce significant water a few years later. The temperature, pressure, and density data from production logging and the total flow rate at the surface provide enough 
information to use the interpretation model to estimate downhole flow condition, especially to locate the water zones along the wellbore. We have first used the production profile from the production logging to generate the temperature and pressure profile by the forward model to verify the sensitivity of the interpretation model. We then used the temperature and pressure data measured from logging tools to regenerate the flow profile by the inverse model. Sensitivity study has been carried out to see the effect of the amount and location of water to the interpretation results.

\subsection{Gas Production without Water}

The first example is when the well produces mainly gas with insignificant amount of water. It demonstrates in this example how to estimate downhole flow profile from temperature and pressure data for single phase gas wells. A multi-rate, multi-speed production logging has provided the temperature, pressure and other data along the well completion zone. With surface flow rate, the production logging analysis has created a flow profile along the completion zone.

Production logging data for this case stopped at the depth of $4222 \mathrm{~m}$ even though the perforations extended to $4240 \mathrm{~m}$. In the calculation, zones 3 and 4 were grouped as one zone for completion skin calculation.

This example considers two flow rates, with one flow rate being $50 \%$ more than the other. This approach will verify consistency of model results when we compare the results from the two rates and will also differentiate the effect of magnitude of the flowrate on the interpretation procedure, if significant. 


\subsubsection{Forward model}

Starting from the flow profile by production logging on the lower flowrate (Fig. 3.2a) we used the forward model to generate the downhole flow conditions. Fig. 3.2b shows the flow rate distribution for the case, and Figs. 3.2c and 3.2d display the temperature and pressure curve calculated by the forward model. As can be seen from the figures, the calculated temperature and pressure have reasonable match with the data measured by production logging. This proves that thermodynamics phenomena we rely on to reproduce the flow condition is responsive enough for the theoretical model. The calculated temperature profile shows visible response to the inflows at the perforation zones while the slope change along the temperature curve identifies the gas inflow adjunction with the perforation locations.

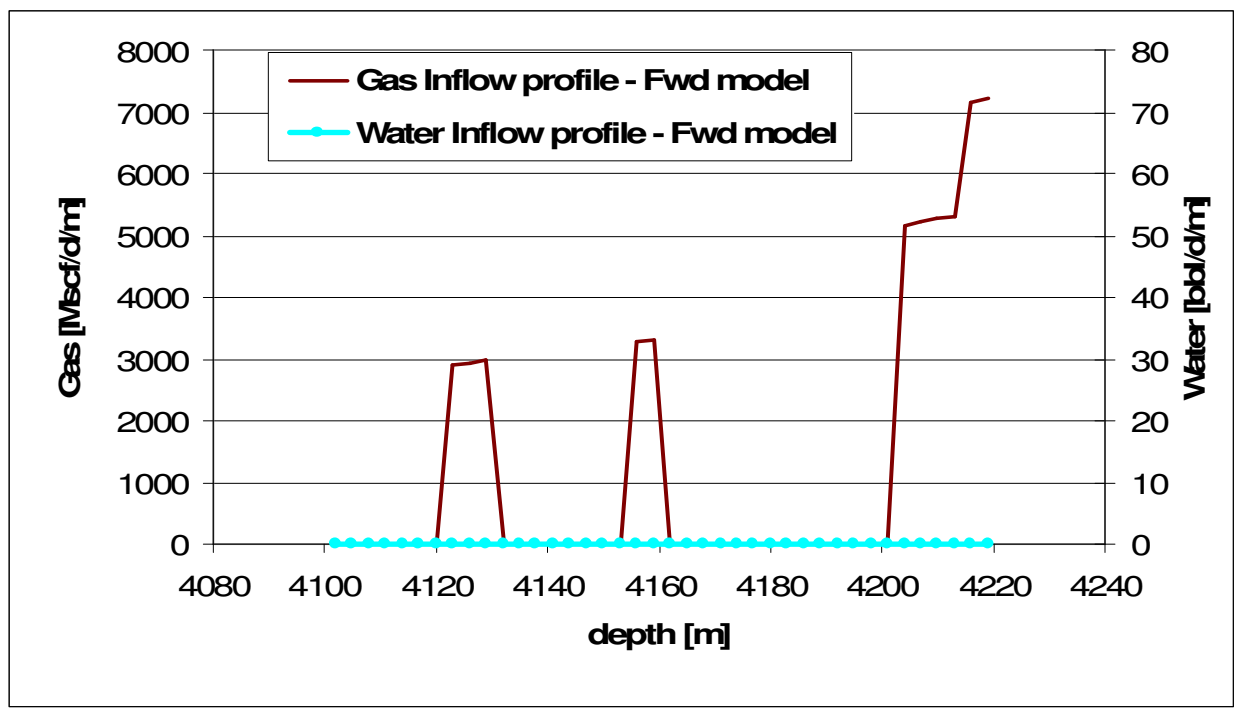

a. Inflow profile used in the forward model.

Fig. 3.2 Forward model result for gas production only. 


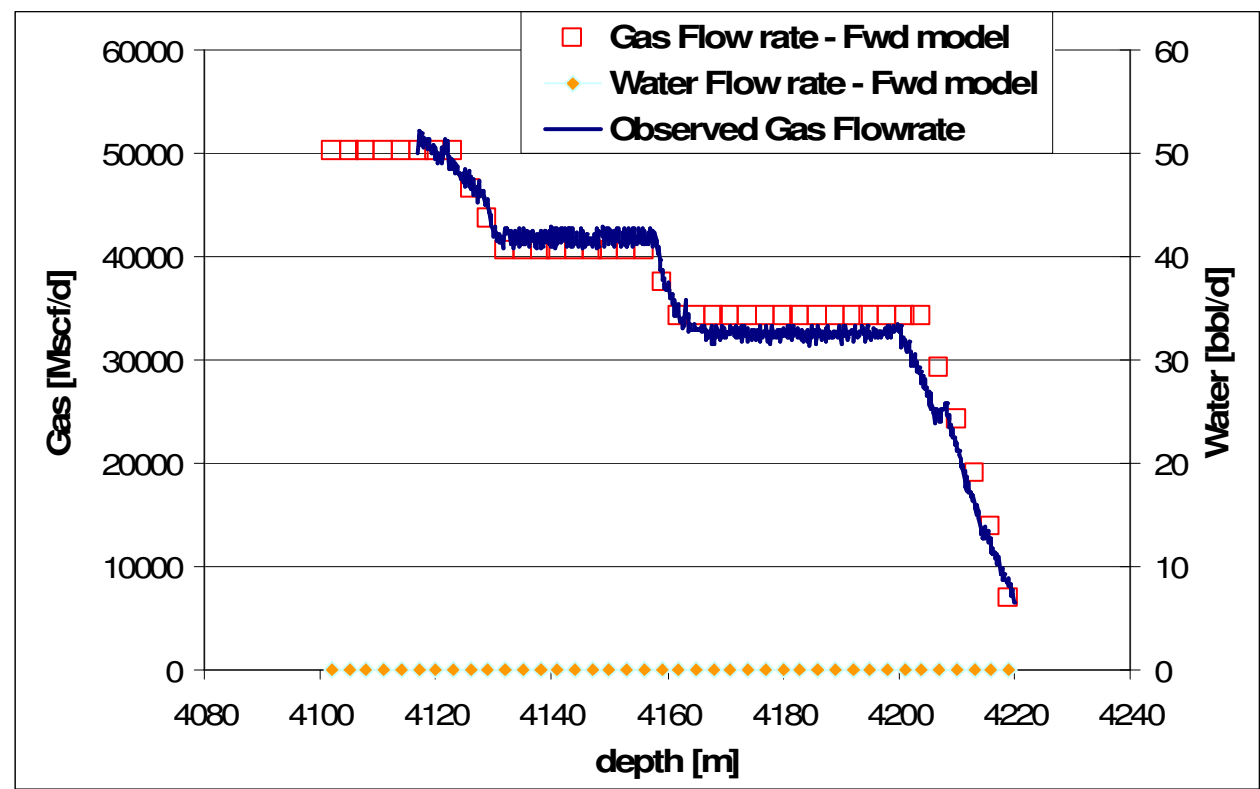

b. Flow distribution from the forward model.

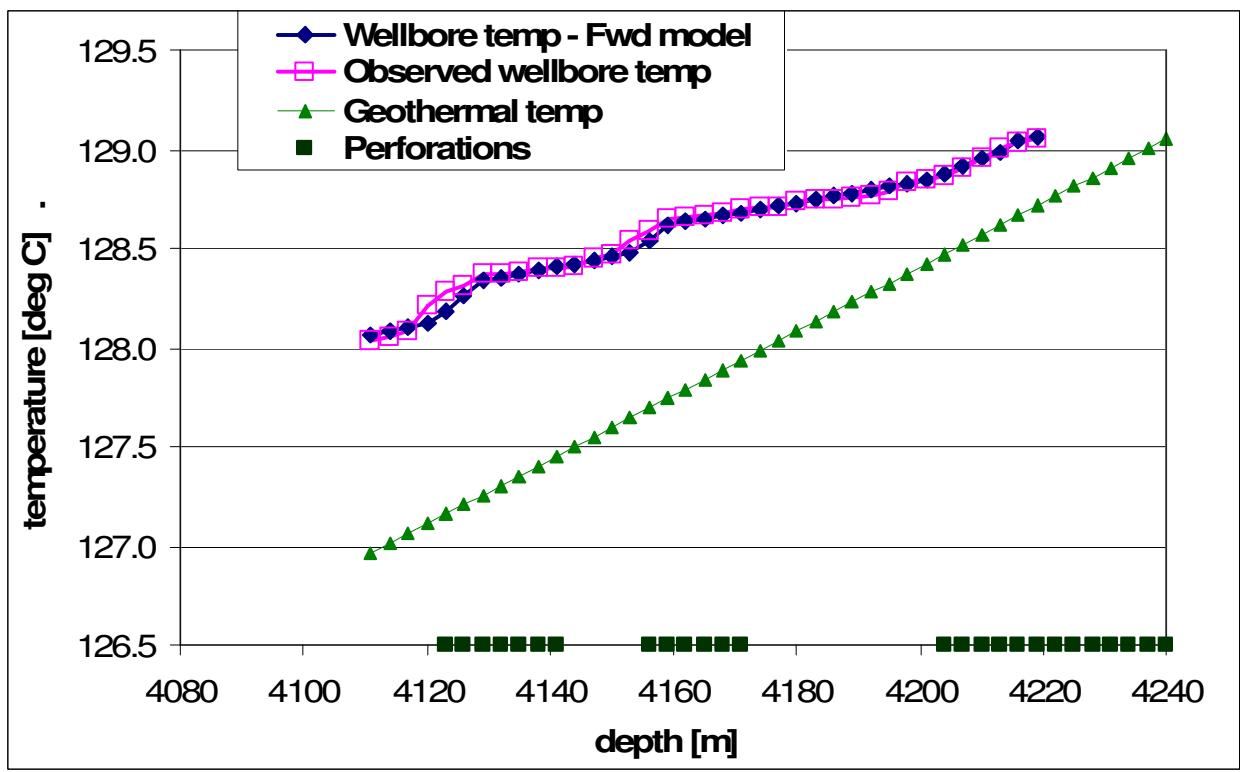

c. Temperature results from the forward model.

Fig. 3.2 Continued. 


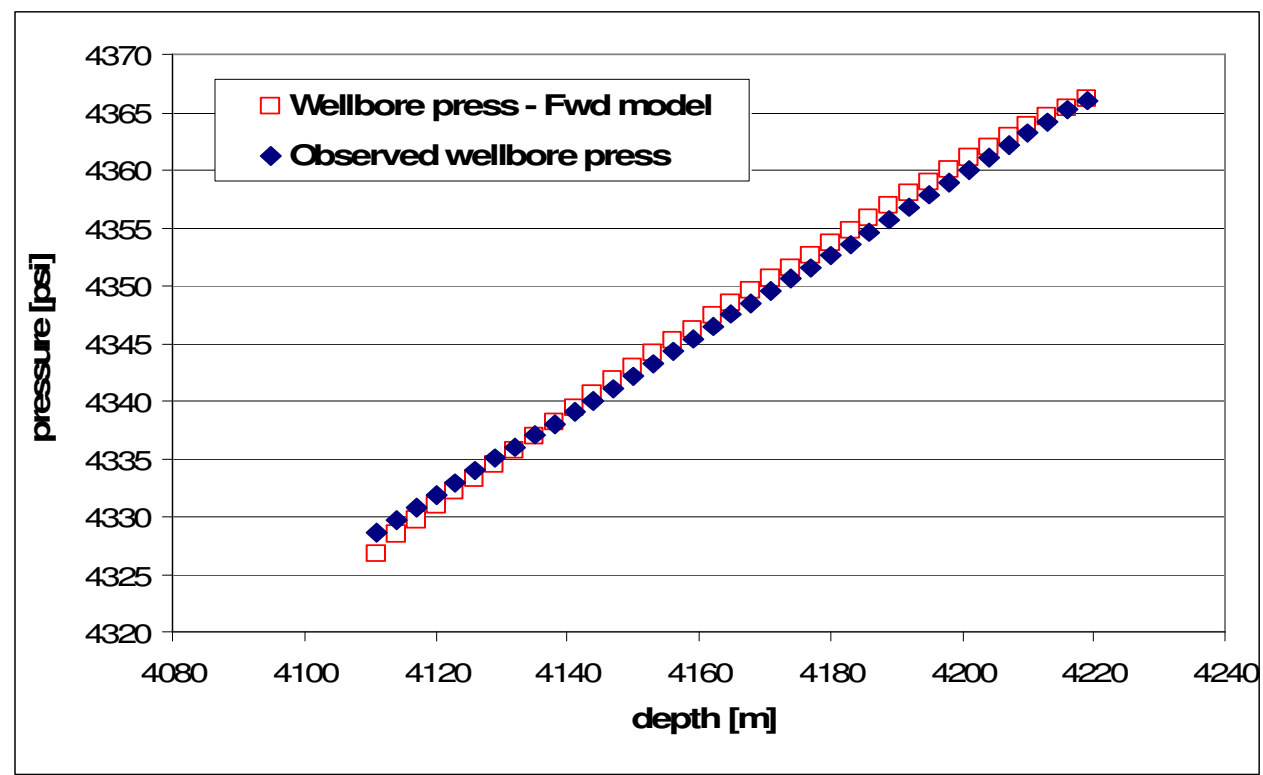

\section{d. Pressure results from the forward model.}

Fig. 3.2 Continued.

For the higher production rate (50\% more), Fig. 3.3 shows the forward model results. As in the lower rate prediction case, the calculated temperature and pressure have reasonable match with the data measured by production logging. From both Figs. 3.2c and 3.3c, the temperature response to the inflows at the perforations are visible, and this is critical to invert the flow rate from the temperature data. The slope change along the temperature curve corresponds with perforation locations and can be used to identify the gas inflow.

For gas production, pressure curves in both low and high flow rate cases are relatively smooth even across the perforations (Figs. 3.2d and 3.3d), and pressure data does not provide enough information for flow profile inversion. 


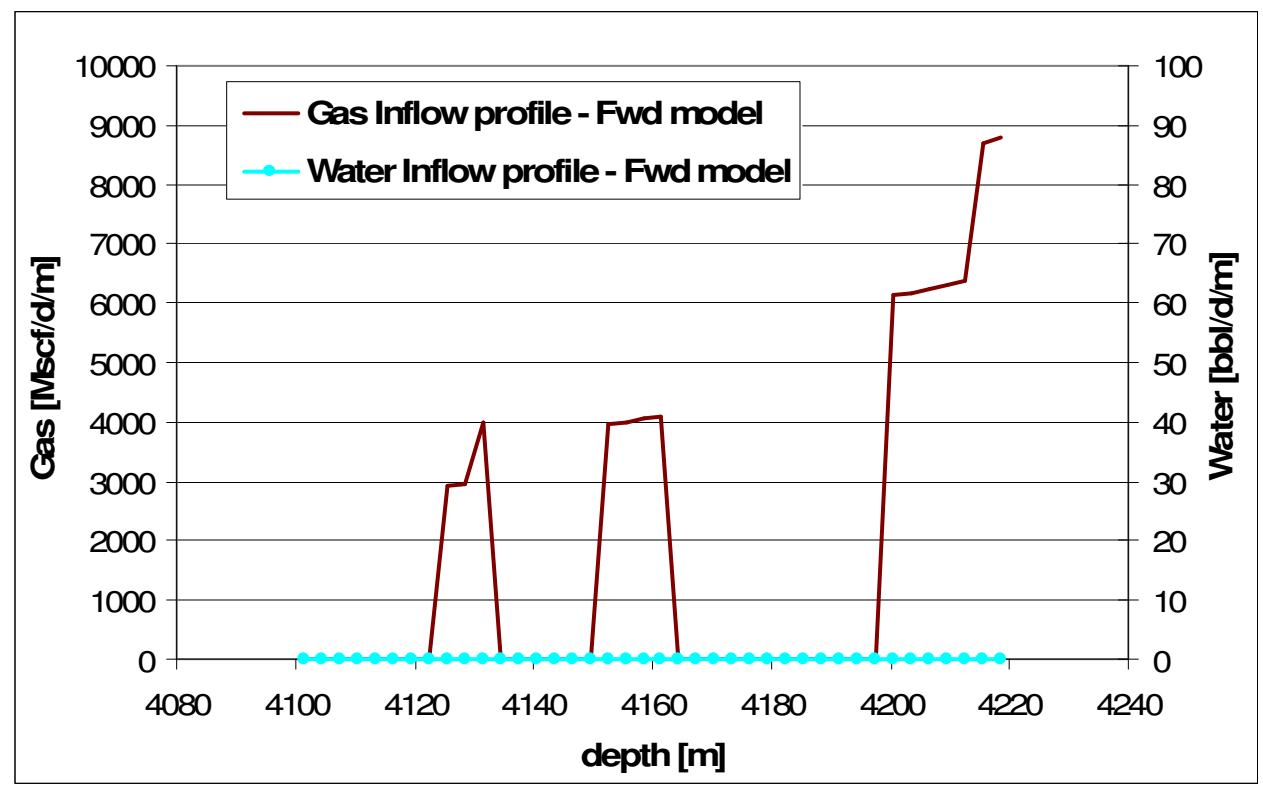

a. Inflow profile used in the forward model.

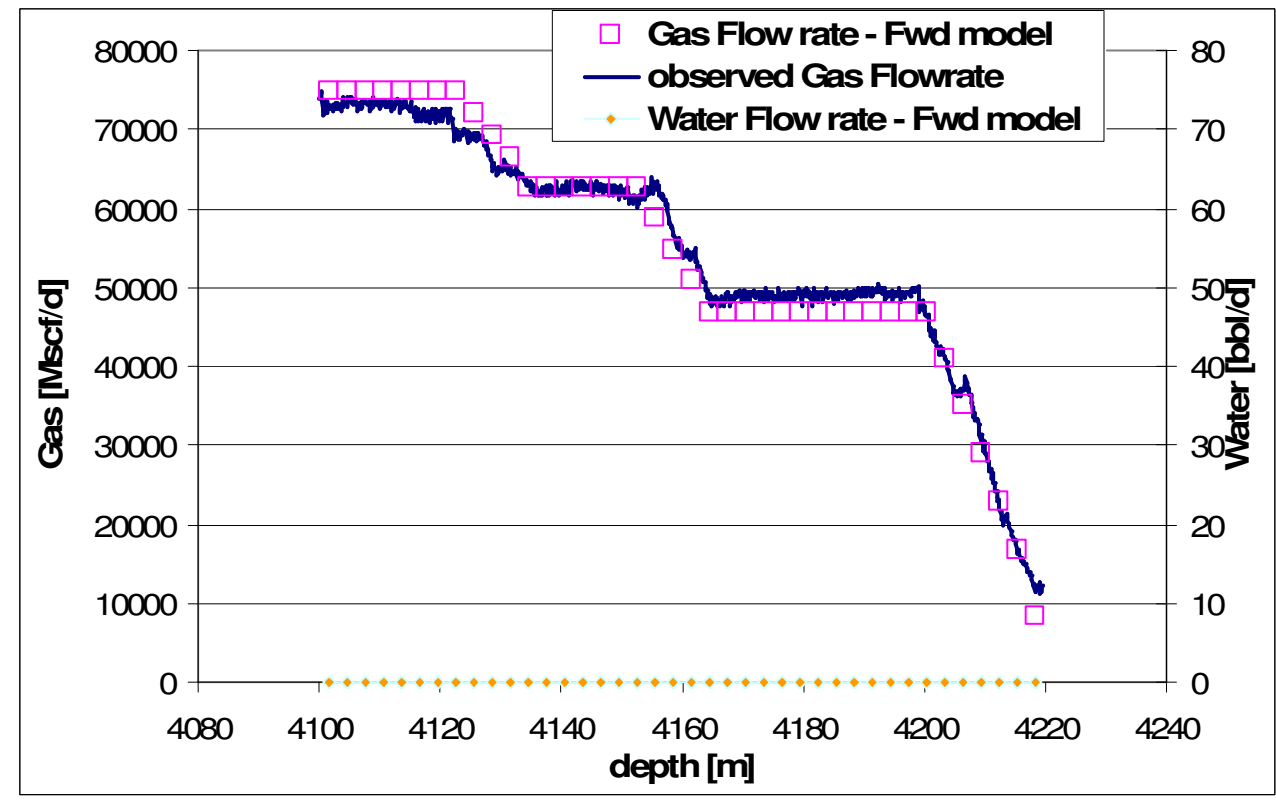

b. Flow distribution from the forward model.

Fig. 3.3 Forward model result of gas production at a higher production rate. 


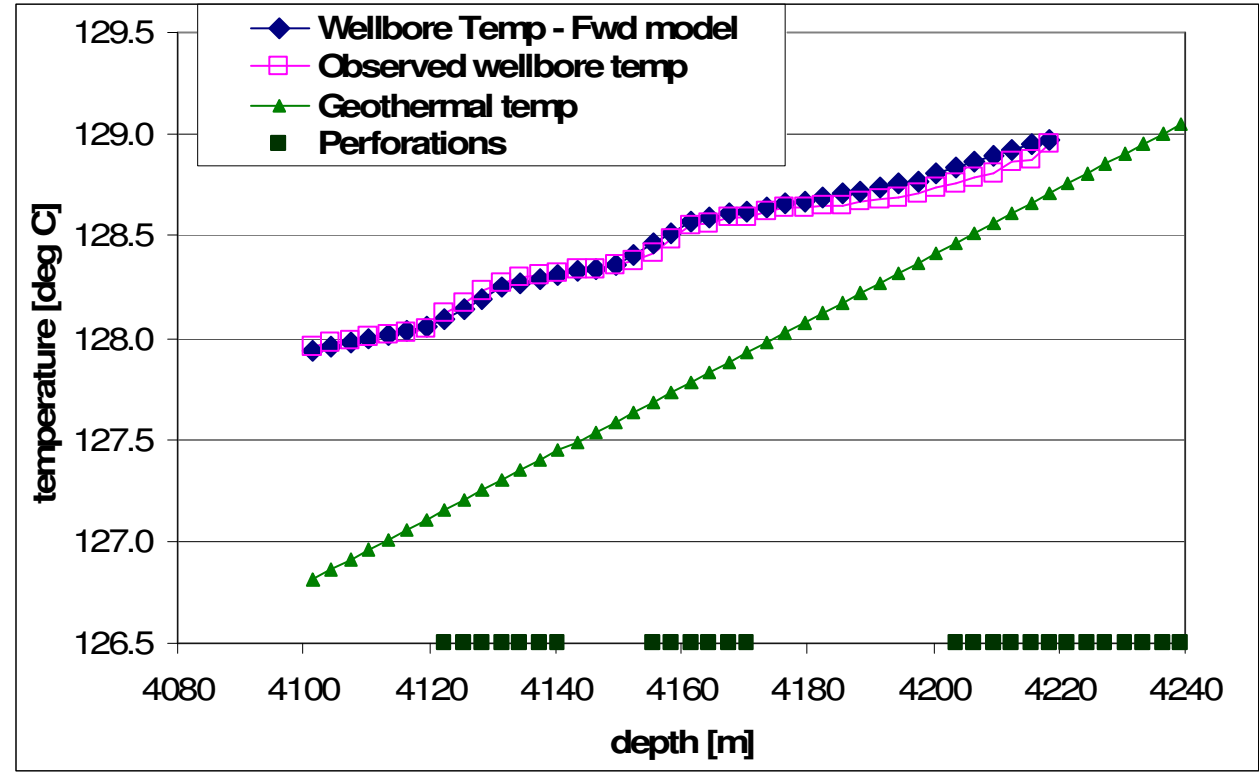

c. Temperature results from the forward model.

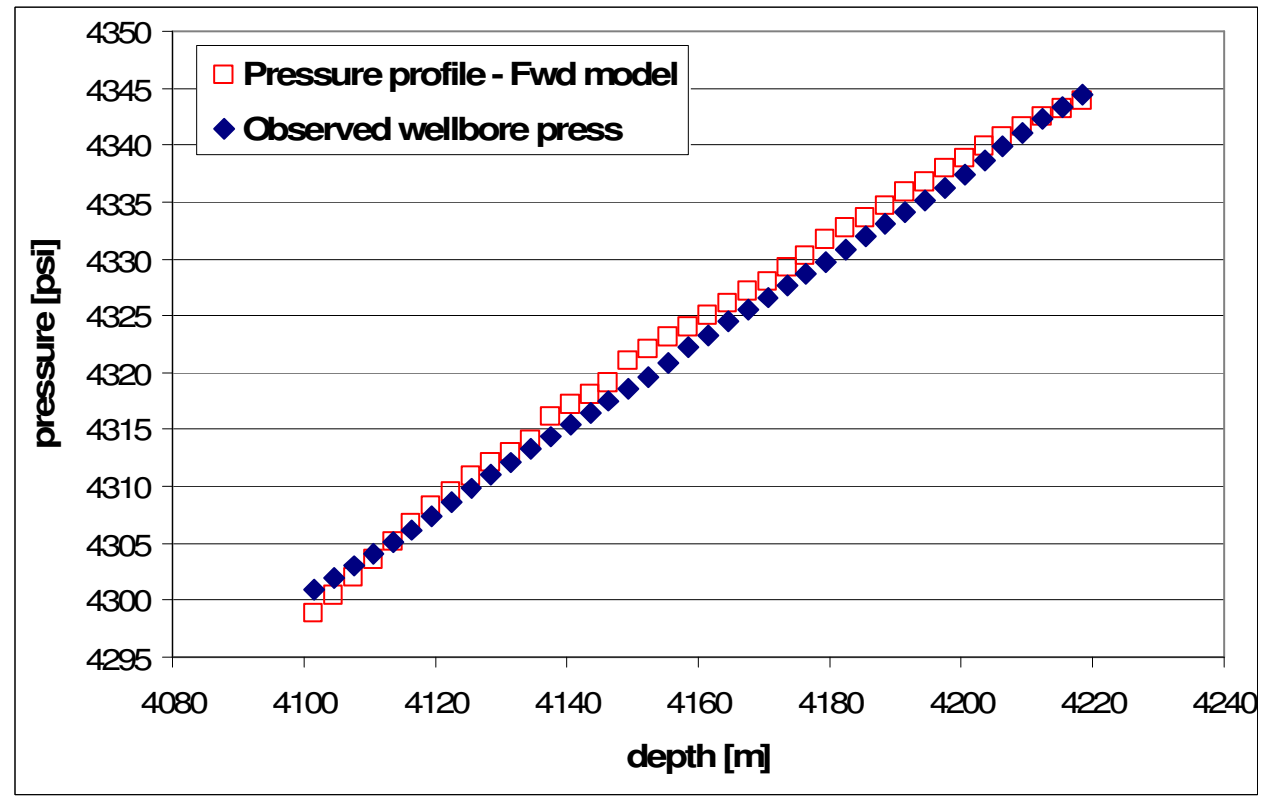

d. Pressure results from the forward model.

Fig. 3.3 Continued. 
At the lower flow rate (Fig. 3.2), most production is from the bottom perforation. While this is still true at the higher flow rate (Fig. 3.3), the middle perforation zone contributed more flow than the top perforation zone. This feature can be observed on temperature profile (Fig. 3.2c versus Fig. 3.3c).

\subsubsection{Inversion model}

To use the inverse model to infer the flow profile from the measured temperature and pressure data, we first assumed a permeability profile to generate the corresponding flow profile. This initial flow profile can give us an estimated temperature and pressure profile by running the same forward model. The calculated temperature and pressure were then corrected against the measured temperature and pressure by updating the flow profile until the difference between the two (defined as an error function) meets the criteria of conversion. To confirm the inverted flow profile, we compared it with the one from production logging. We applied the inversion to both low and high flow rates.

Figure 3.4 shows the inversion result from the interpretation model with Fig. 3.4a as inverted temperature, Fig. 3.4b as inverted pressure, and Fig. 3.4c and $\mathbf{d}$ as the final flow rate profile and permeability after convergence. It is clear that the inversion in this case is successful, and we can interpret flow rate distribution of a single phase gas well from measured temperature and pressure. 


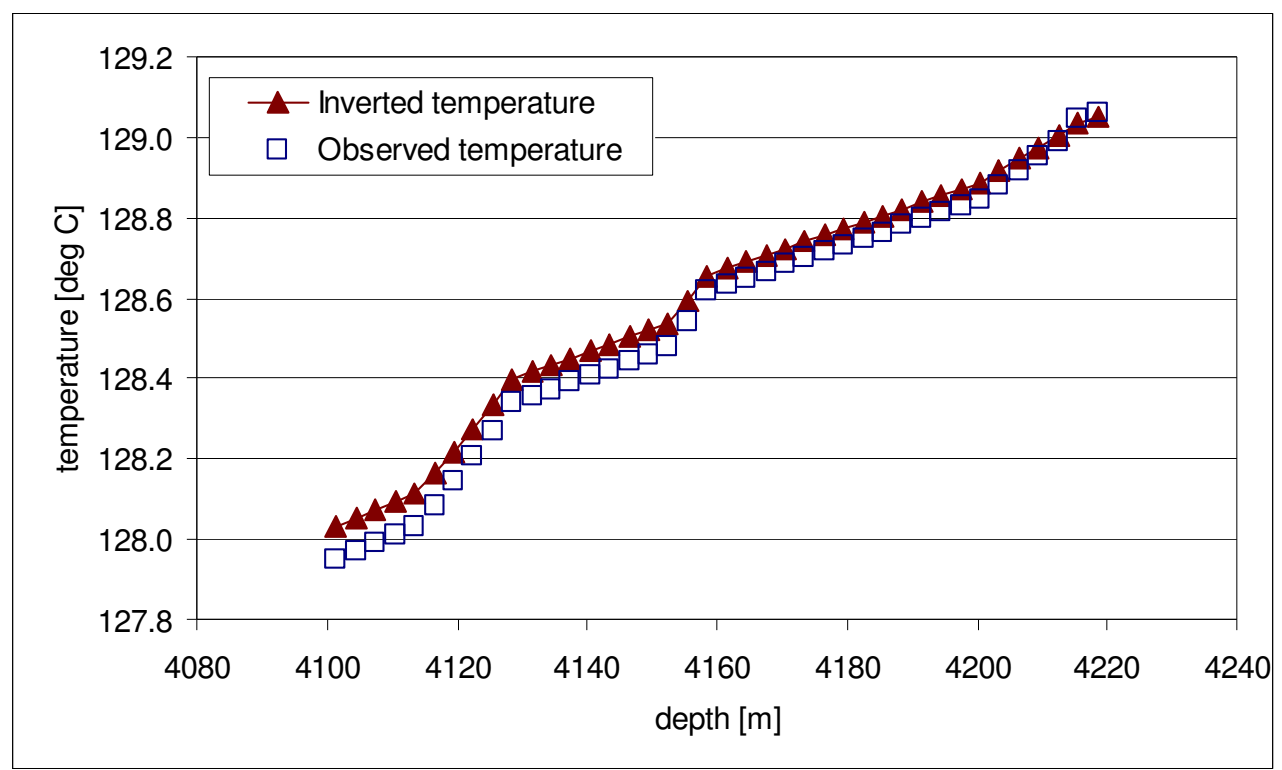

a. Temperature used to generate flow profile.

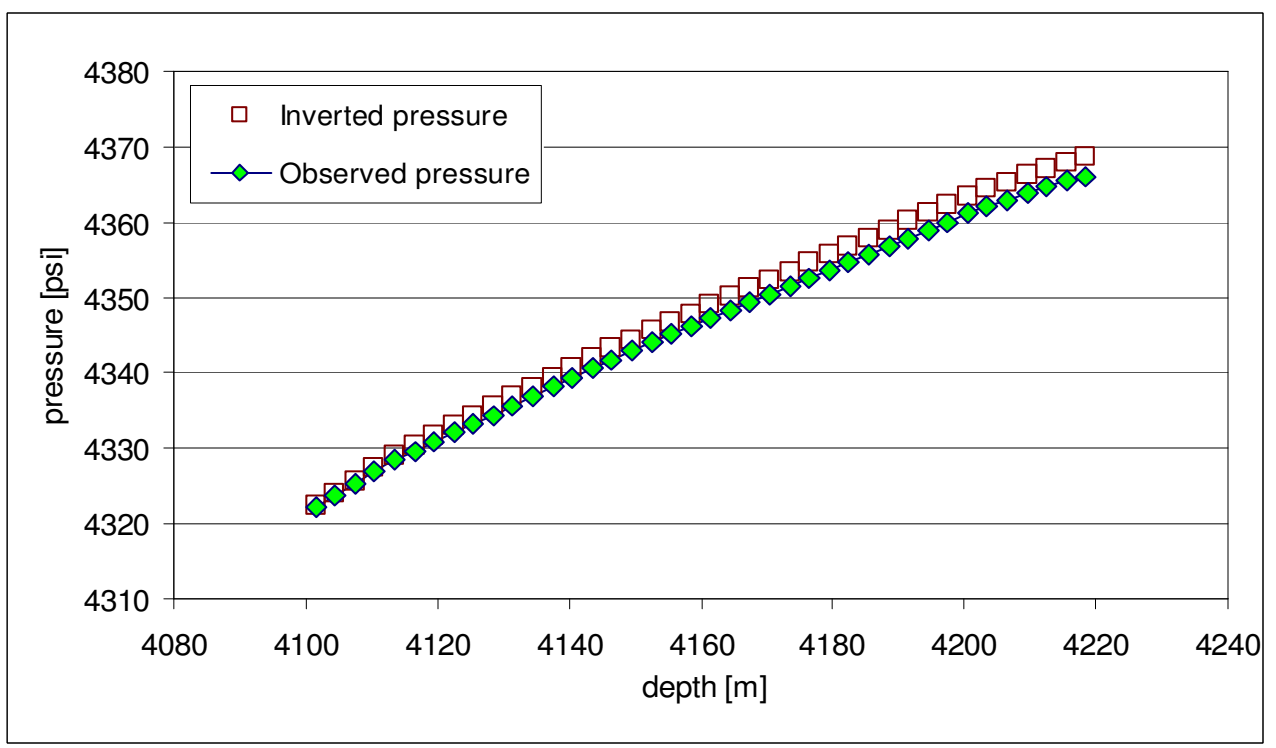

b. Pressure used to generate flow profile.

Fig. 3.4 Inversion result for single phase gas case. 


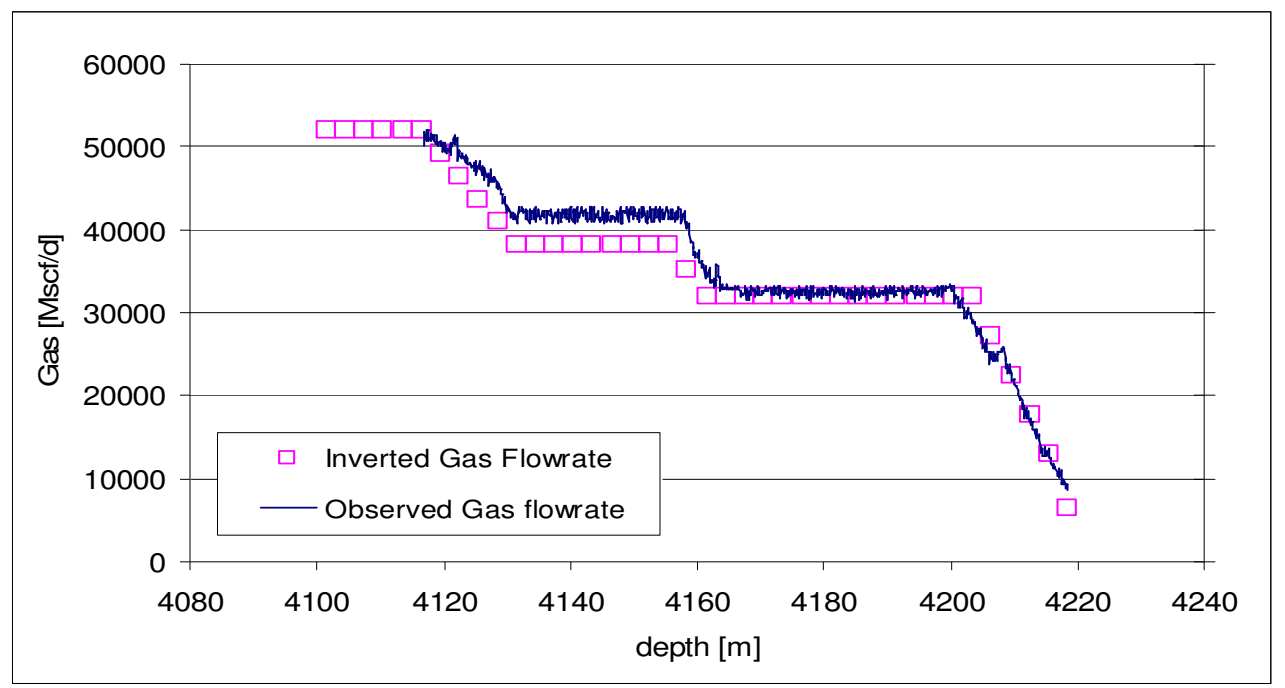

\section{c. Inverted flow rate profile from measured data.}

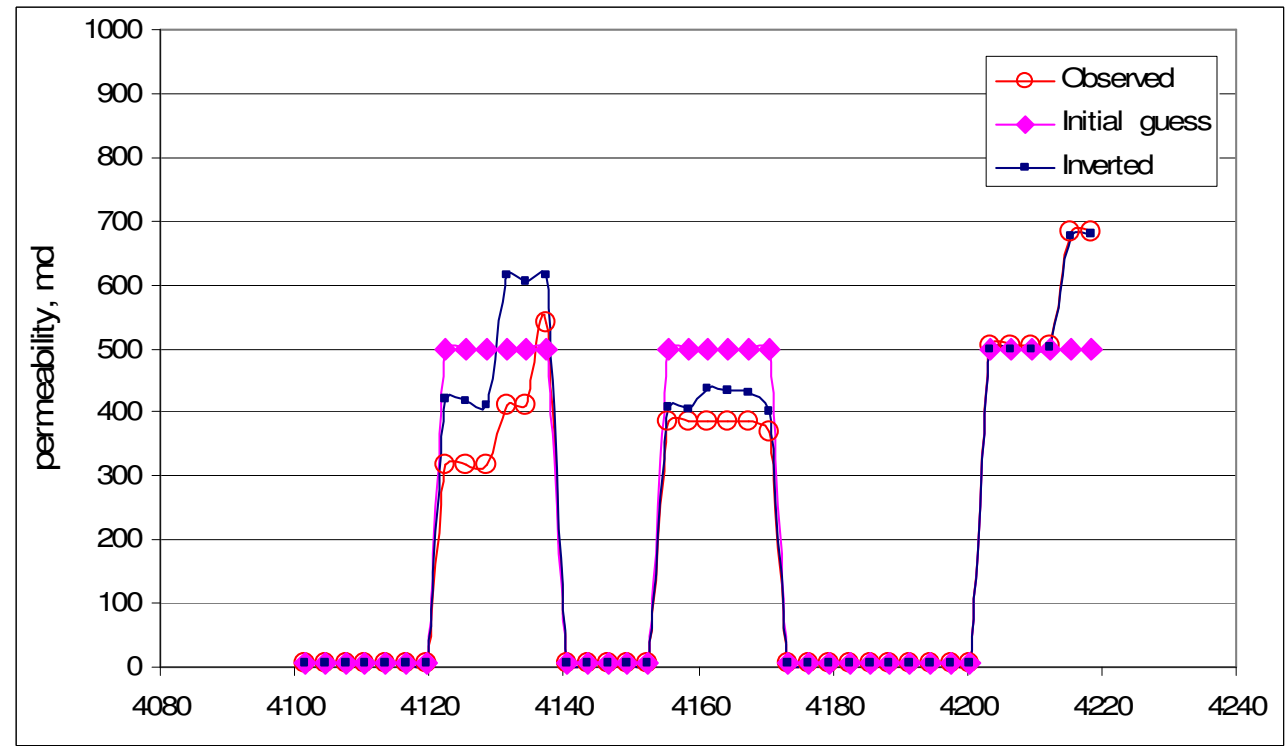

d. Inverted permeability profile.

Fig. 3.4 Continued.

Fig. 3.5 is the inversion result for the higher flow rate case. It shows on Fig. 3.5 that when the final overall conversion was achieved, temperature at the lower part of the 
wellbore gave a rough match. The inverted wellbore temperature profile in Fig. $\mathbf{3 . 5 c}$ is slightly higher than the observed wellbore temperature profile around the bottom perforation region. As we will see in the next section, the steep slope of the observed temperature profile at the bottom perforation zone is peculiar with aquifer water encroachment. Gas entry produces a gentle slope.

The well completion configuration in Fig. 3.1 shows that the gas-water contact is about 4mTVD from the bottom perforations. While flowing at the higher rate, it is possible the well established bottom water encroachment which influenced the temperature profile. The inversion result may have been affected by this bottom water effect that was not considered in the higher rate case. Nevertheless, we do not have the downhole data at the bottom depth (below $4222 \mathrm{~m}$ ) to ascertain water entry.

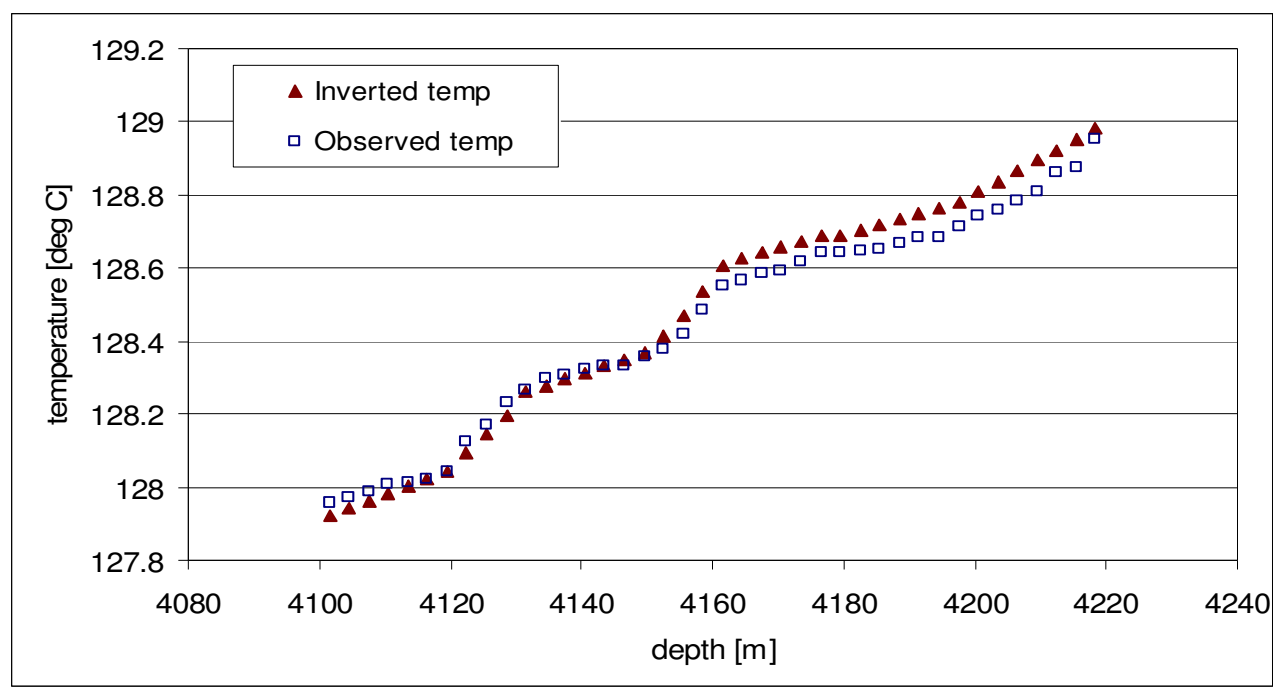

a. Temperature from the inverse model.

Fig. 3.5 Inversion results for higher gas flow rate. 


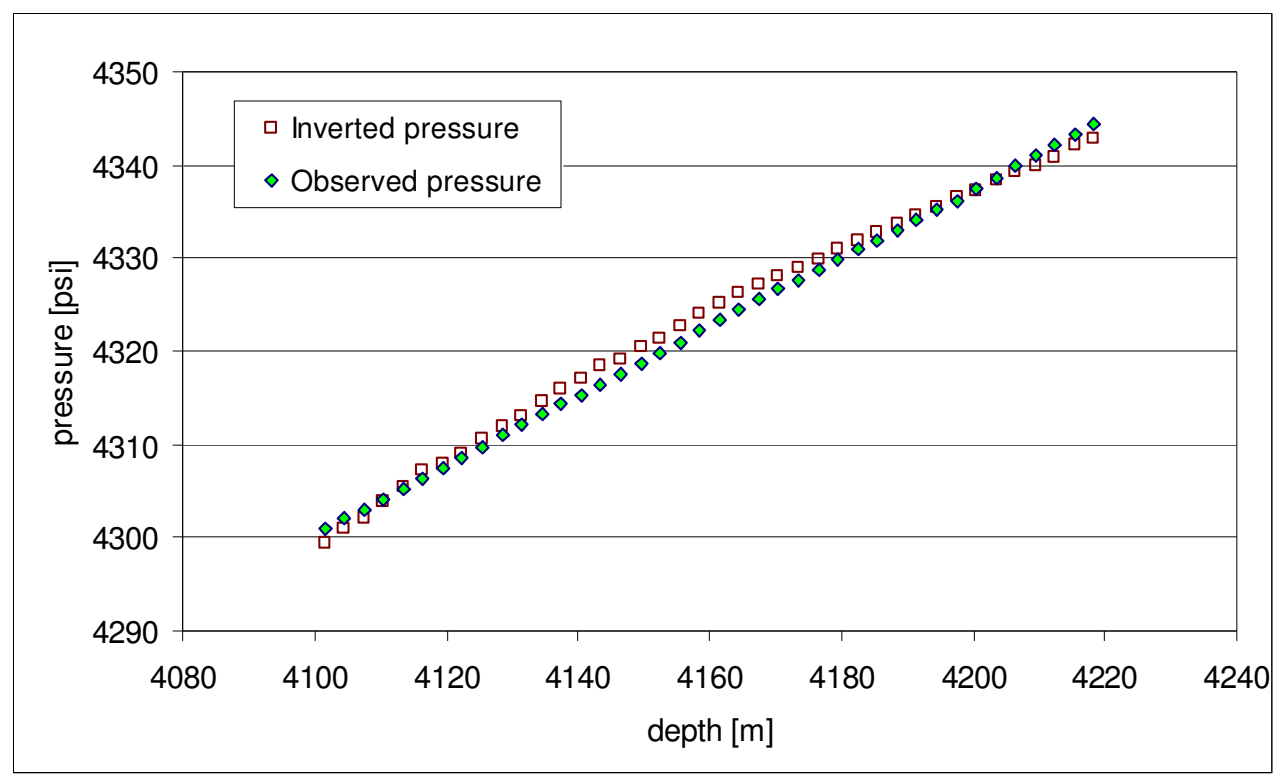

b. Pressure from the inverse model.

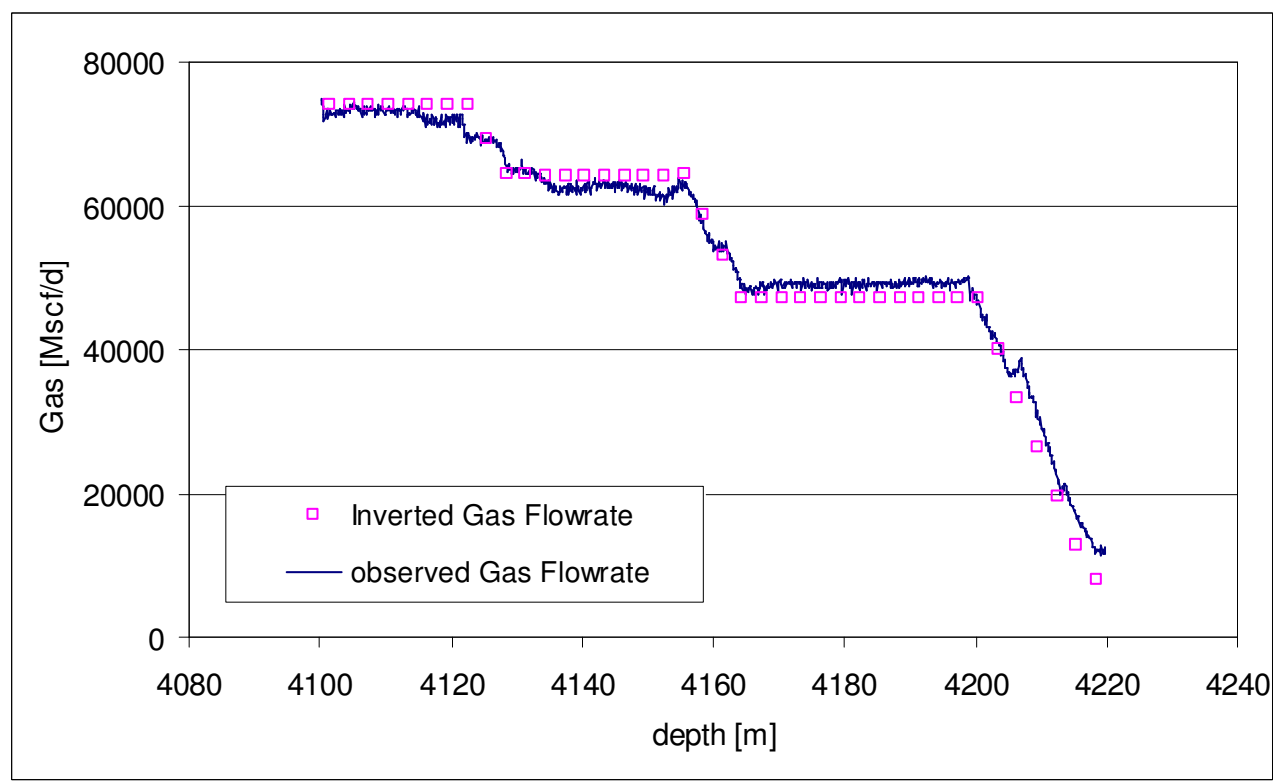

c. Flow rate from the inverse model.

Fig. 3.5 Continued. 


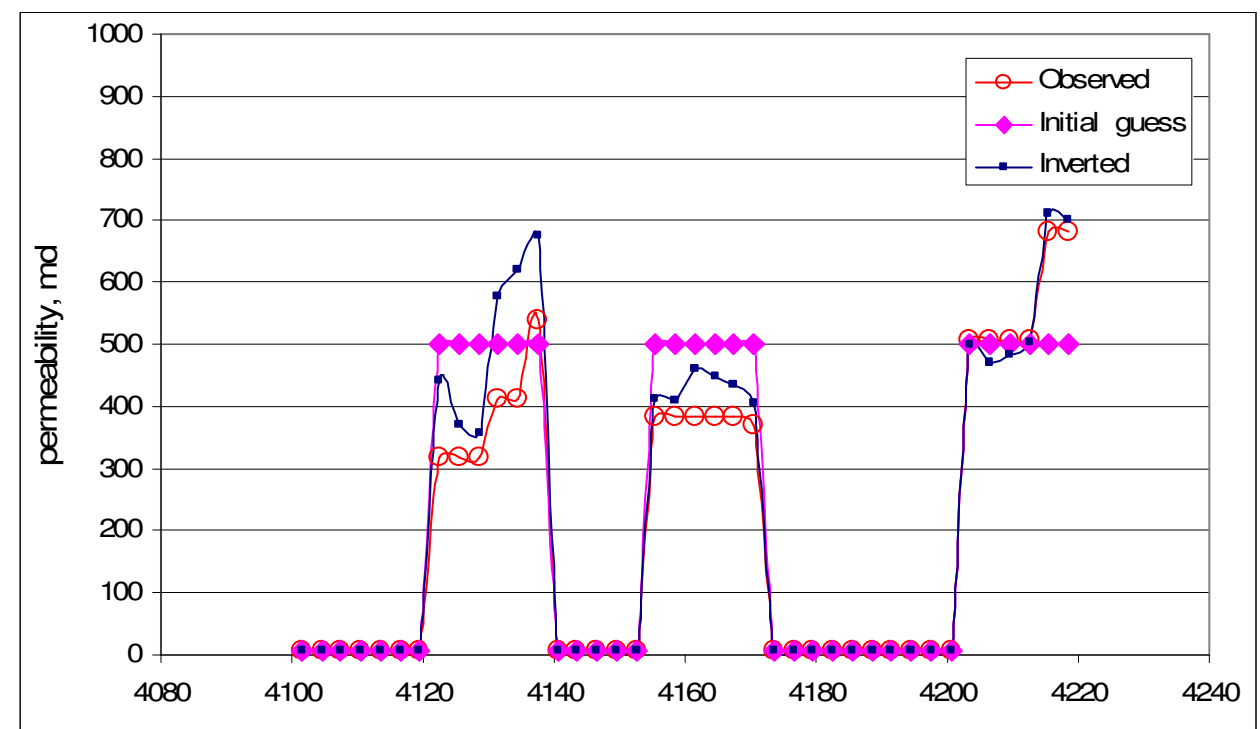

\section{d. Inverted permeability profile.}

Fig. 3.5 Continued.

\subsection{Gas Production with Water}

A few years after the initial production, the well started producing water $(0.04 \mathrm{bbl} / \mathrm{Mscf})$. A new production log was run to acquire bottomhole data at current conditions. The objective was to locate water entry along the wellbore. In this study, we applied the interpretation model to the downhole data measured by production logging to detect water entry in to the well. The procedure starts with using the flow profile by production logging to generate the flow rate, temperature and pressure distribution along the completion zone by the forward model. Slug flow was assumed in the wellbore when the flow was two phases. The result in this case (Fig. 3.6) shows the promising application with a good match between the calculated profiles and the measured profiles. Interestingly, on the temperature plot (Fig. 3.6c) the entering fluid temperature is 
obviously higher than the local geothermal temperature, suggesting bottom water from the aquifer below the payzone. We also evidenced the slope change on the pressure plot with higher pressure gradient towards the bottom of the wellbore (Fig. 3.6d), supporting the idea of bottom water entry.

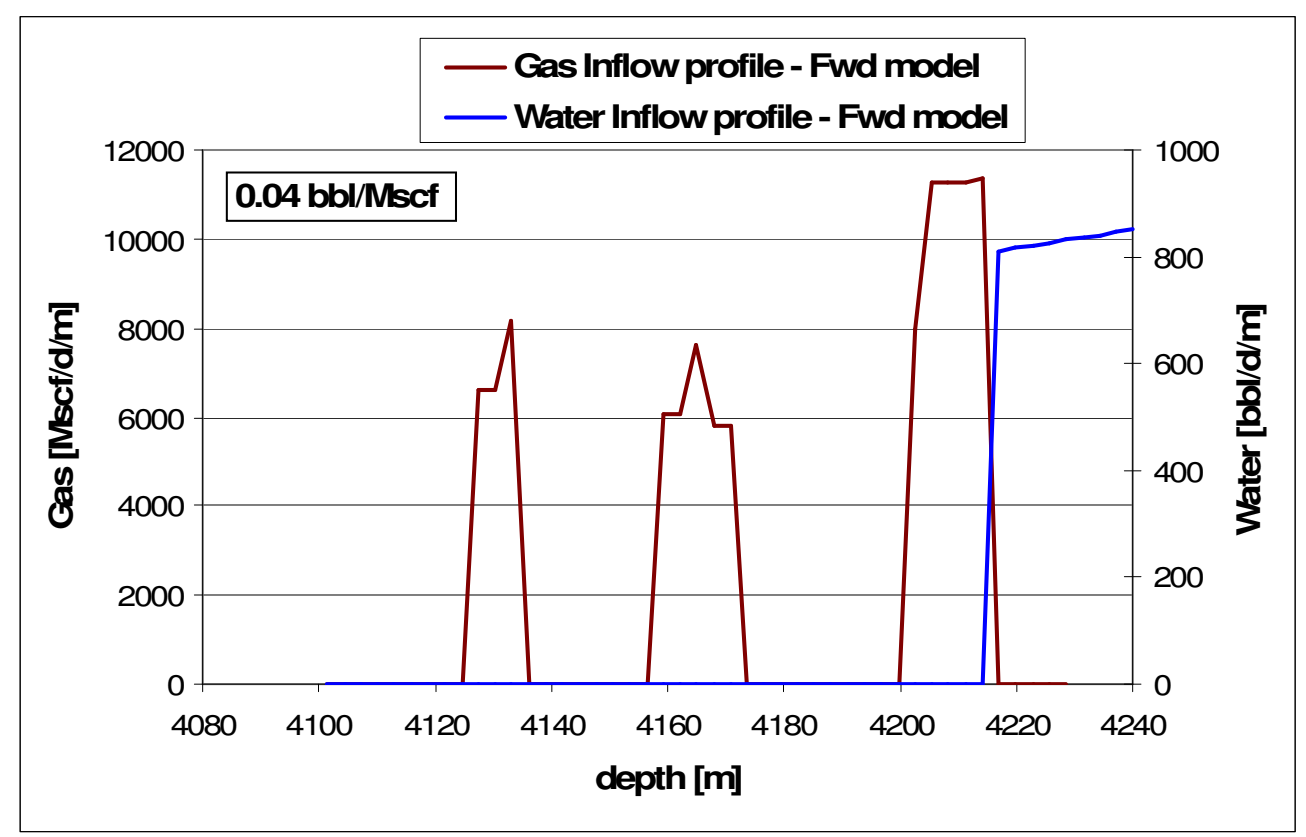

a. Flow rate used in the forward model.

Fig. 3.6 Forward model results for gas/water production case. 


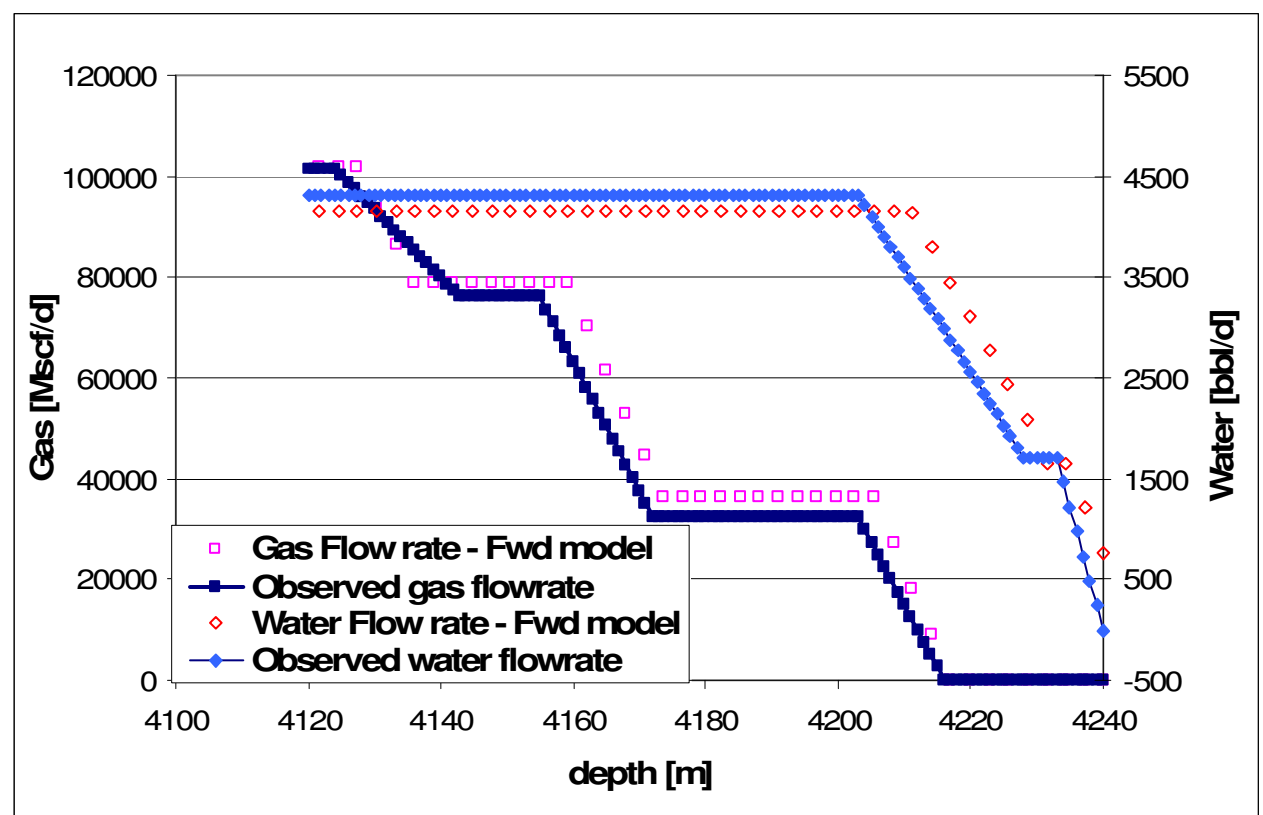

b. Flow profile.

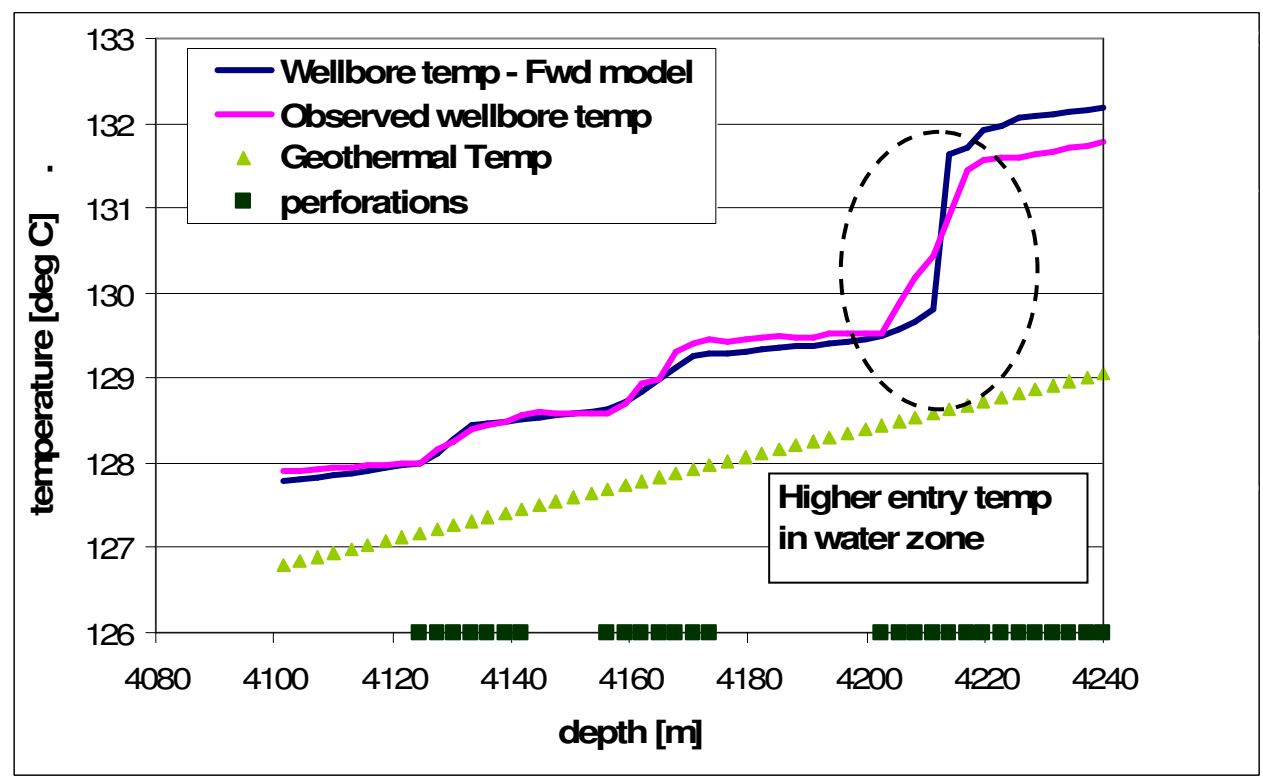

\section{c. Temperature predicted.}

Fig. 3.6 Continued. 


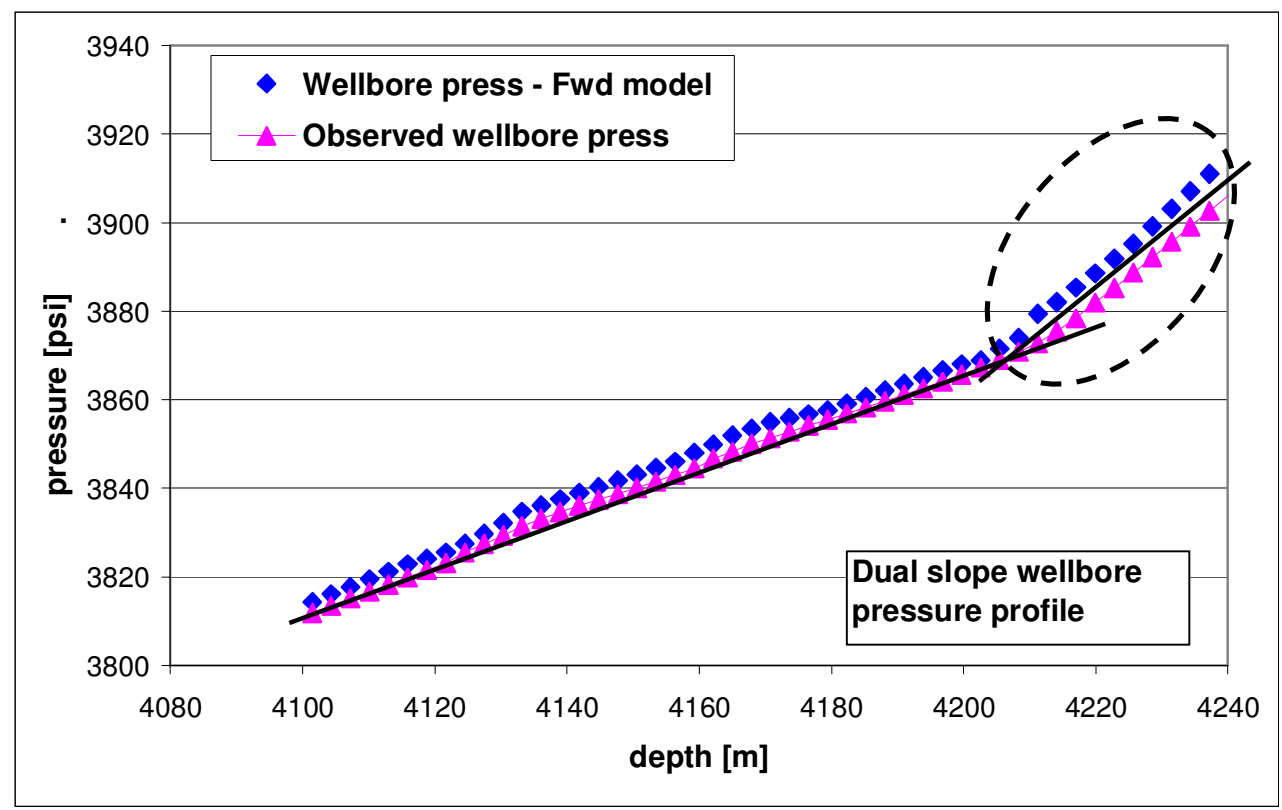

d. Pressure predicted.

Fig. 3.6 Continued.

To carry on the analysis, the inverse model was used to generate the flow profile from the measured temperature and pressure, and the result is shown in Fig. 3.7. When the convergence criterion of the inversion model was satisfied, the flow distribution of water and gas captured the distribution features of the profile from the production logging interpretation (Fig. 3.7c), and the match is reasonable. It needs to be emphasized here that the characteristic of the temperature and pressure data (higher entering temperature and changing slope of pressure curve) provided critical information to start the inversion. In this study, water production from the bottom of the well was considered to ensure fast convergence and the success of the interpretation. 


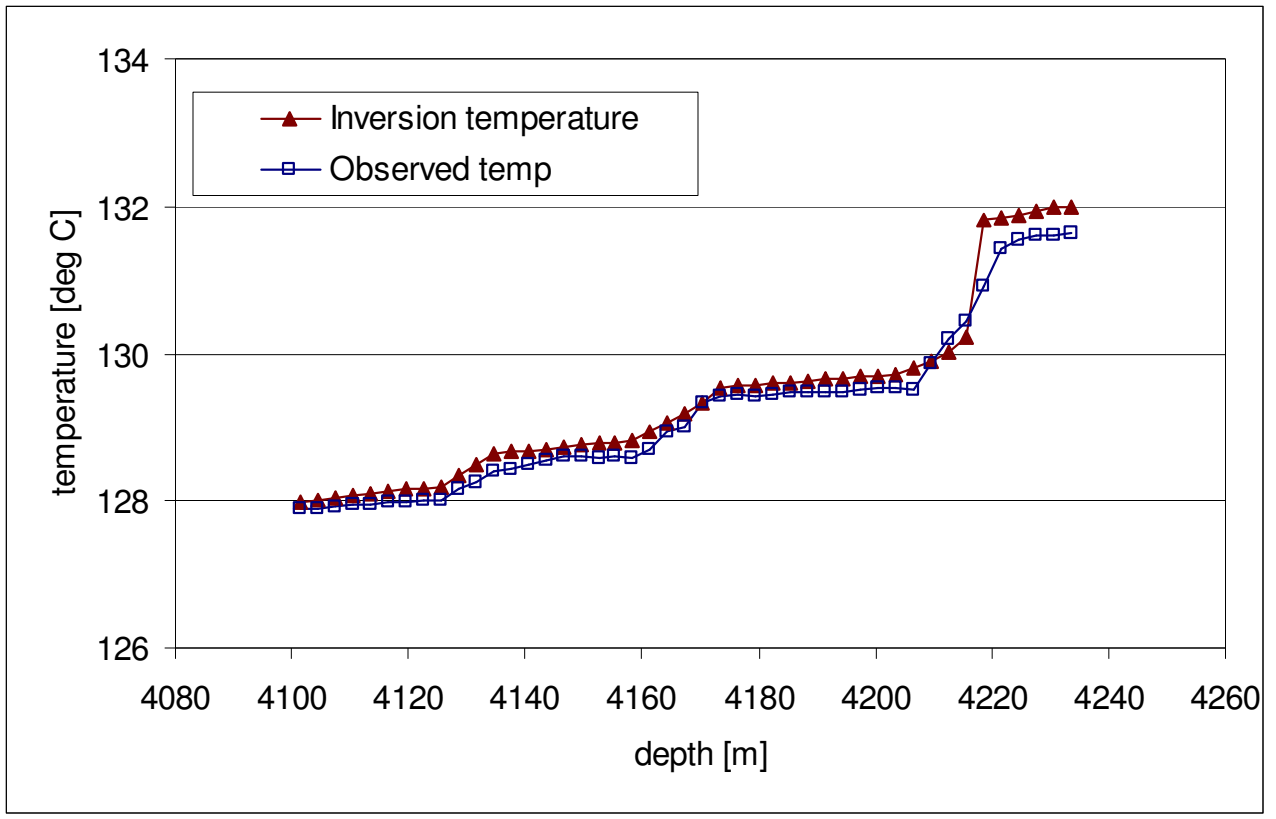

a. Inverted temperature.

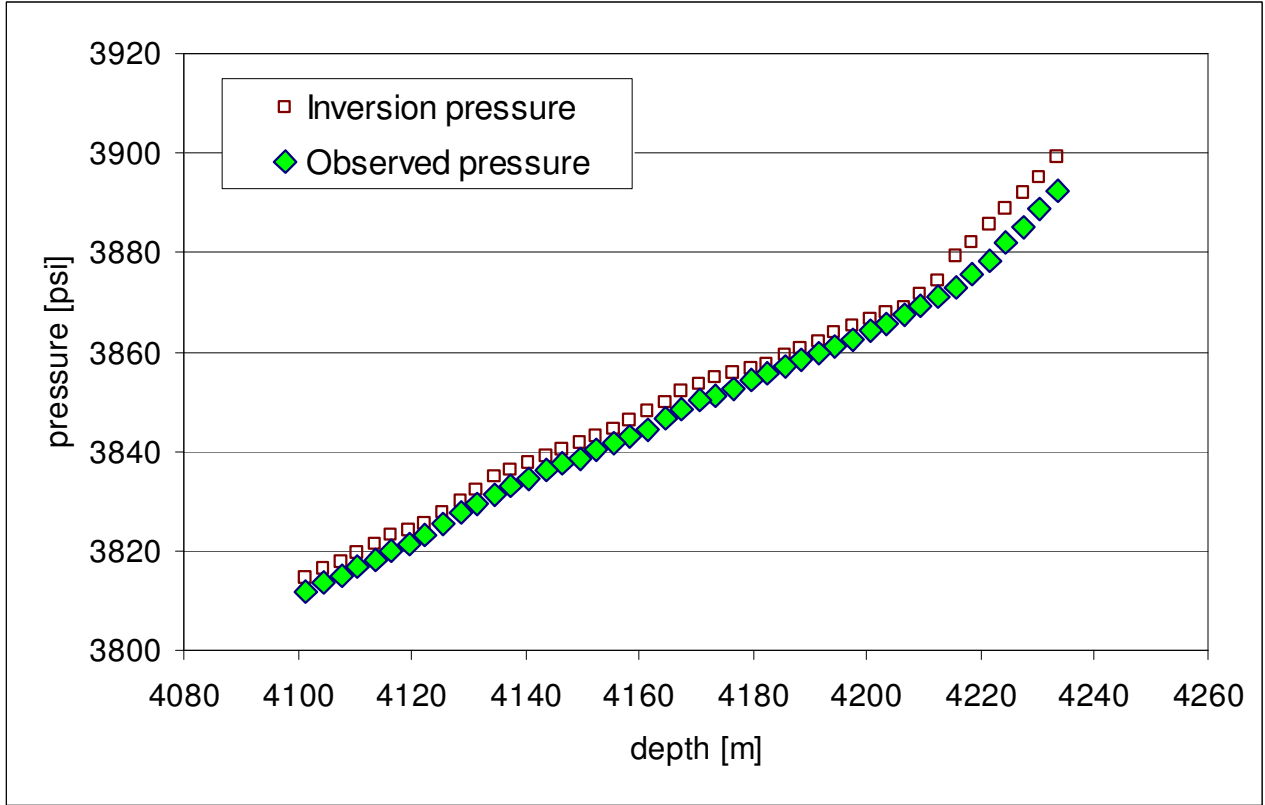

\section{b. Inverted pressure.}

Fig. 3.7 Inversion for gas and water production. 


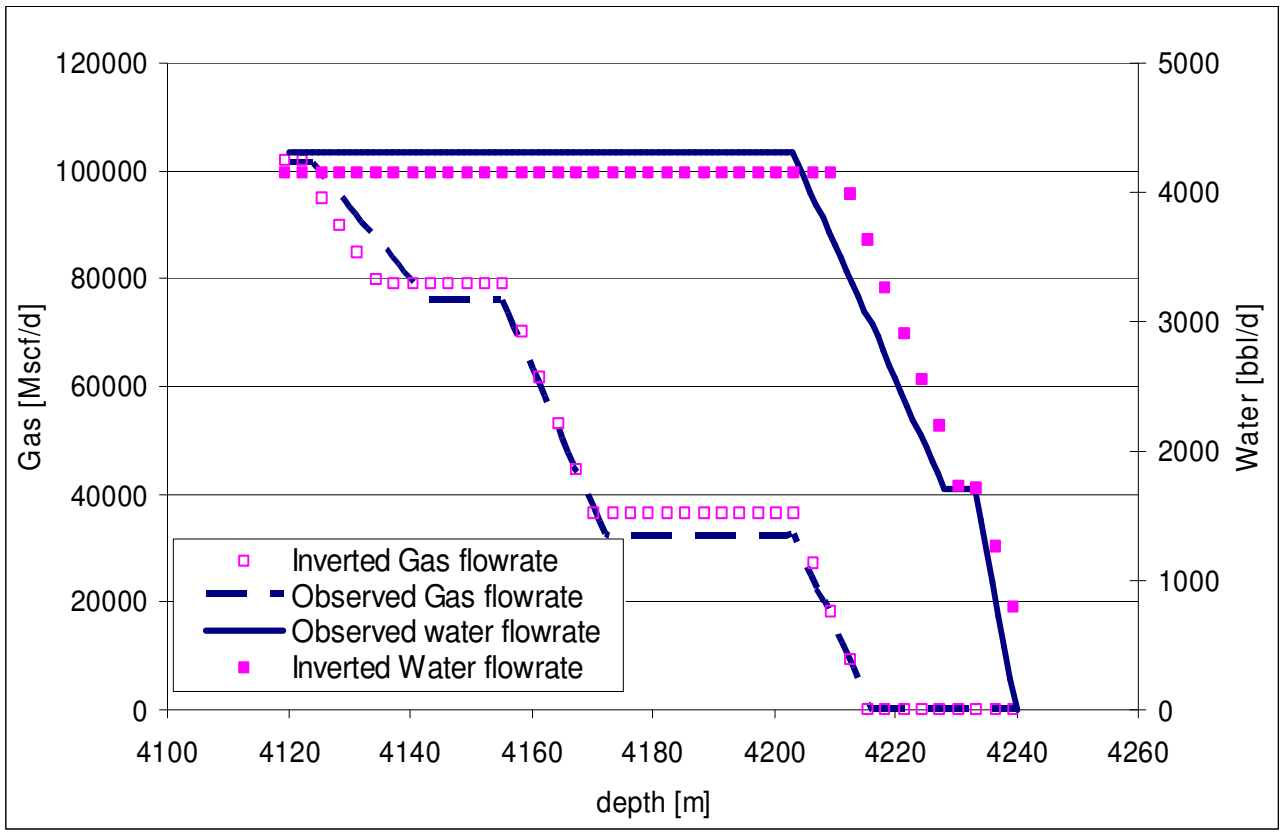

\section{c. Inverted flow profile for gas/water production.}

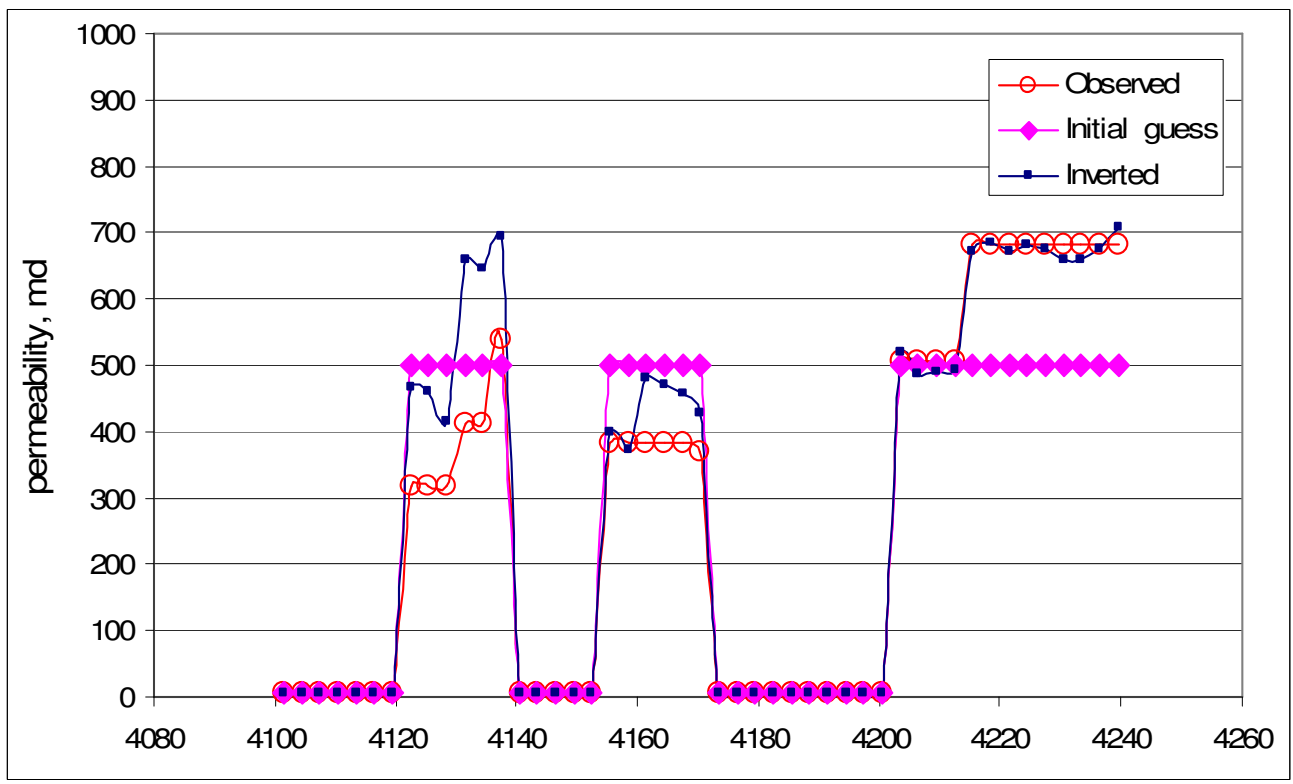

\section{d. Inverted permeability profile.}

Fig. 3.7 Continued. 


\section{CHAPTER IV}

\section{DISCUSSION}

\subsection{Interpretation Method}

The inversion model treats formation permeability as an unknown variable, and changes the permeability for a pre-assigned fluid type (water or gas) of each segregated reservoir to match the measured temperature and pressure data. Obviously, the critical step of an inversion is the initial guess. Generally, for single phase flow we use uniform initial guess for all segments and run the forward model to estimate the temperature and pressure distribution. The calculated temperature and pressure are compared with the measured ones to confirm that a reasonable magnitude of the permeability is assumed. Then we run the inversion model. When the objective function meets the convergence criteria, we consider the inversion being completed. If the convergence cannot be achieved in a reasonable number of iterations ( 40 was used in this study), we may need a better initial guess of permeability distribution for the inversion program. Fig. 4.1 illustrates a convergence process of temperature, pressure, permeability and flow rate for a successful inversion. Initial guess of inversion parameter is made and the inversion process is allowed to run through a specified number of iterations. At the end of the iteration the initial guess can be adjusted if the converged result is unacceptable. We may also consider adjusting the iteration size. From Fig. 4.1a, b, $\mathbf{c}$ and $\mathbf{d}$ we see the convergence of temperature, pressure, flowrate and permeability profiles after 40 
iterations. Comparing the $40^{\text {th }}$ iteration profiles with the observed profiles shows we have a reasonable convergence.

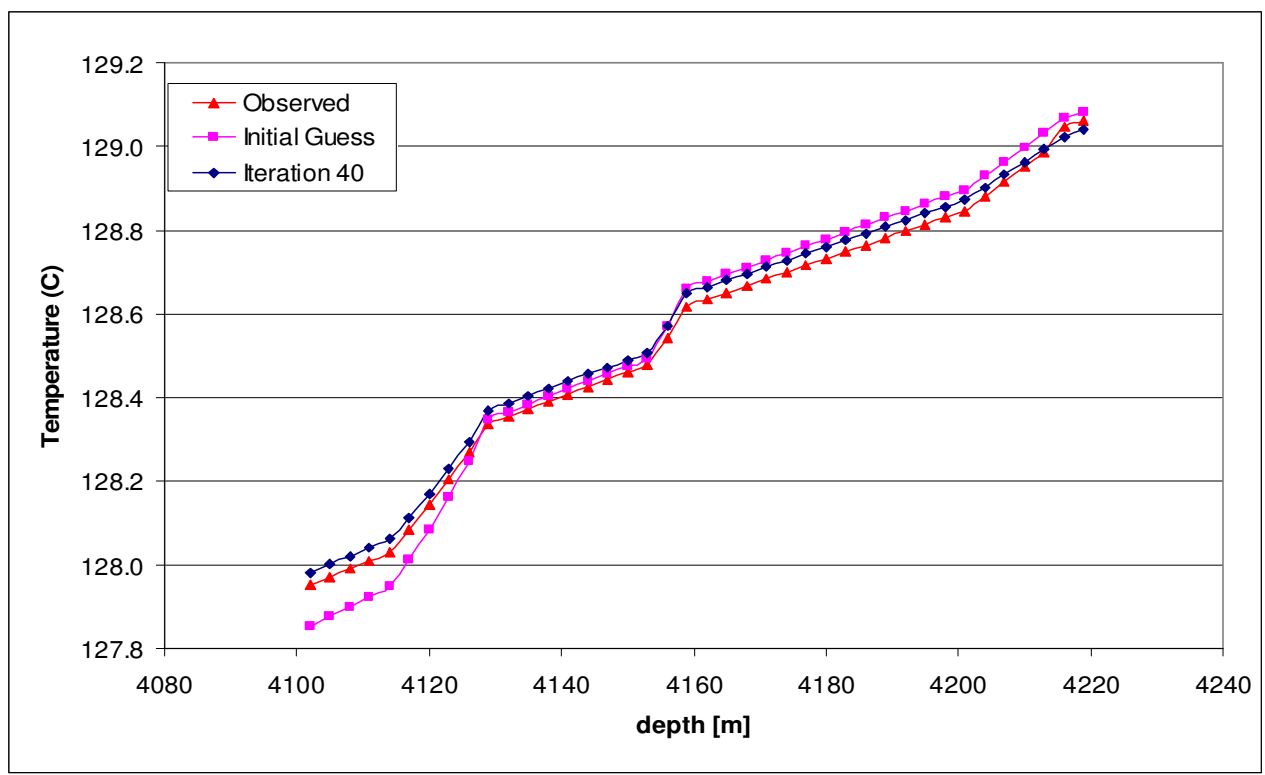

a. Temperature.

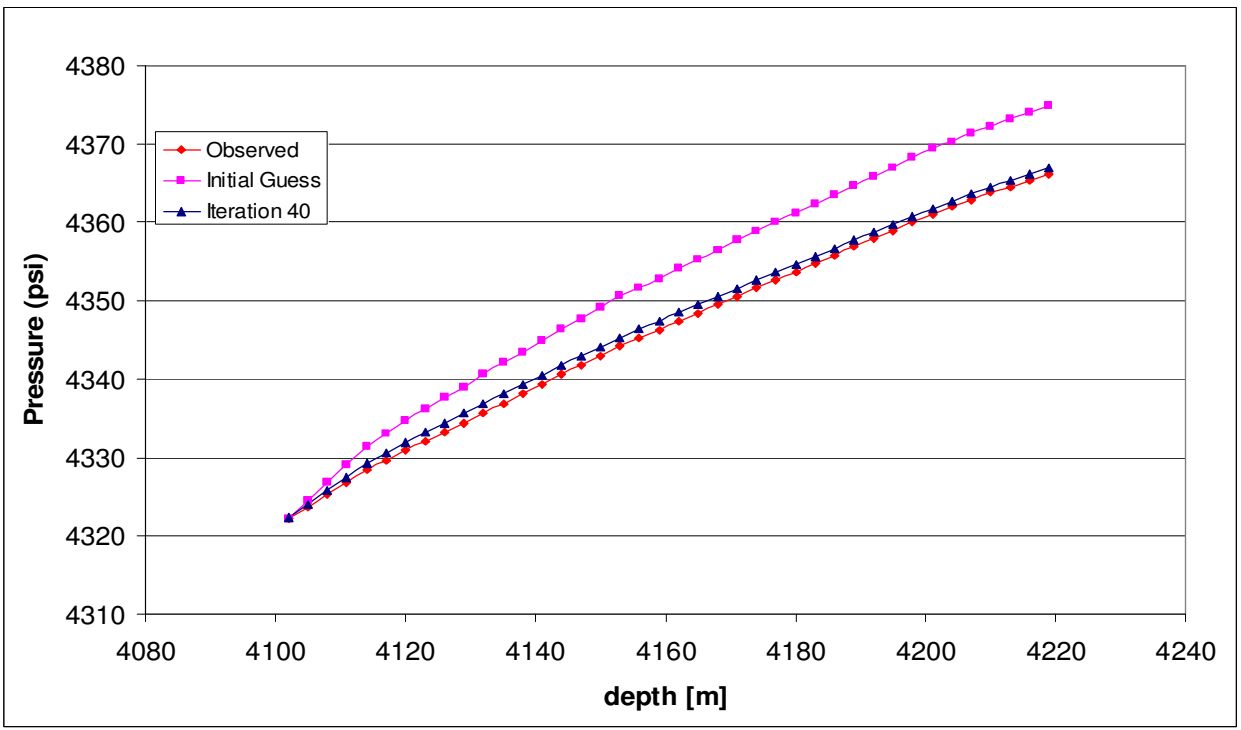

b. Pressure.

Fig. 4.1 Conversion of an inversion process. 


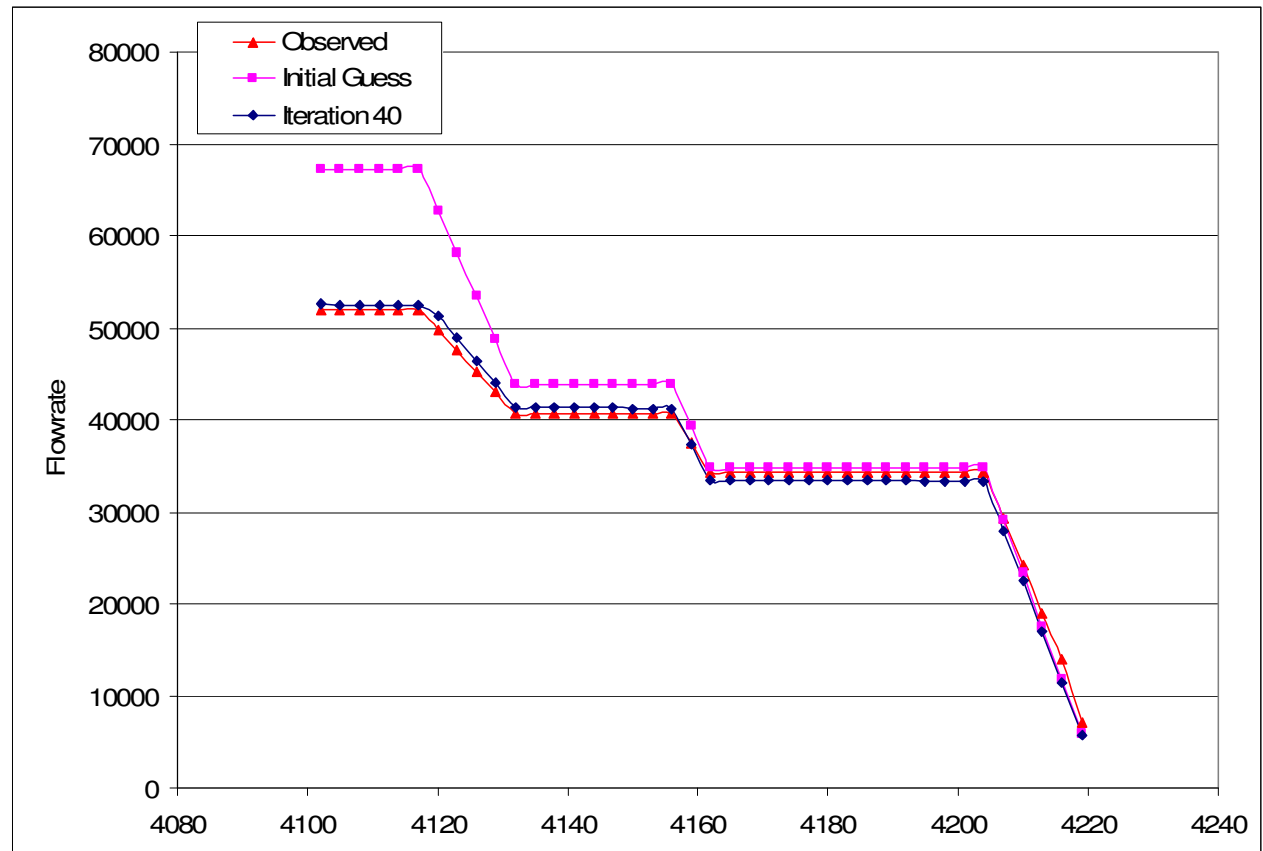

\section{c. Flowrate.}

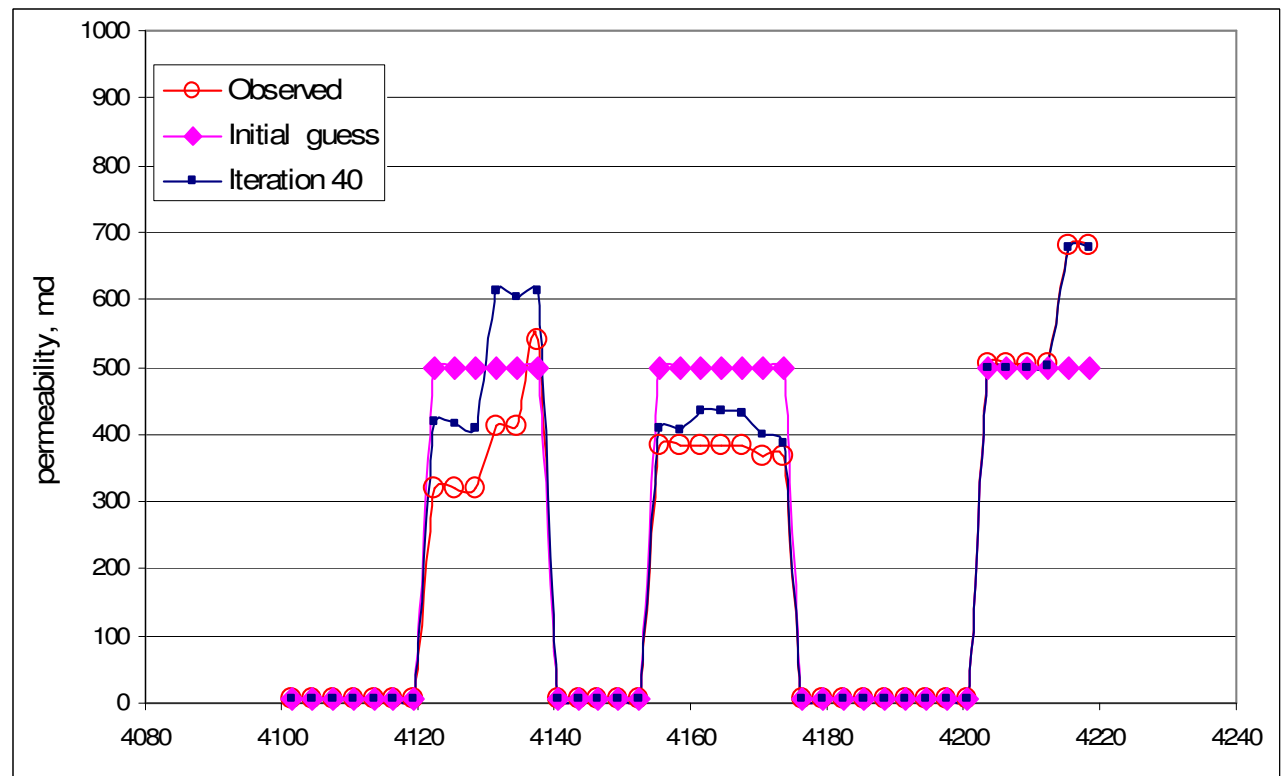

\section{d. Permeability.}

Fig. 4.1 Continued. 


\subsection{Effects of Water Entry}

To obtain a successful inversion within reasonable iteration, we strongly recommend analyzing the pressure and temperature data and identifying the features that are principally related to flow distribution before running the model. This can be even more difficult for gas and water two phase flow. Combining the features of pressure and temperature curves can help us identify water locations preliminarily. To illustrate this, we have conducted a study with the forward model for two hypothetical cases. The cases used the same input data, except one has water produced from the bottom perforations (Fig. 4.2), and the other has water from the middle perforations (Fig. 4.3). The hypothetical cases illustrate the effect of location and quantity of water entry. The flow distribution is displayed in Fig. 4.2a for bottom water, and in Fig. 4.3a for middle water. For the bottom water entry case (Fig. 4.2b), the gas plus water production temperature profile was superimposed on the gas-only temperature profile to amplify water entry effect and the resultant trend change. In reality, the temperatures profile after the water entry region will not be the same with temperature profile for gas-only production. The middle water entry temperature plots, (Fig. 4.3b), were not superimposed. The water/gas ratio is $0.03 \mathrm{bbl} / \mathrm{Mscf}$ for bottom water case and $0.01 \mathrm{bbl} / \mathrm{Mscf}$ for middle water case. 


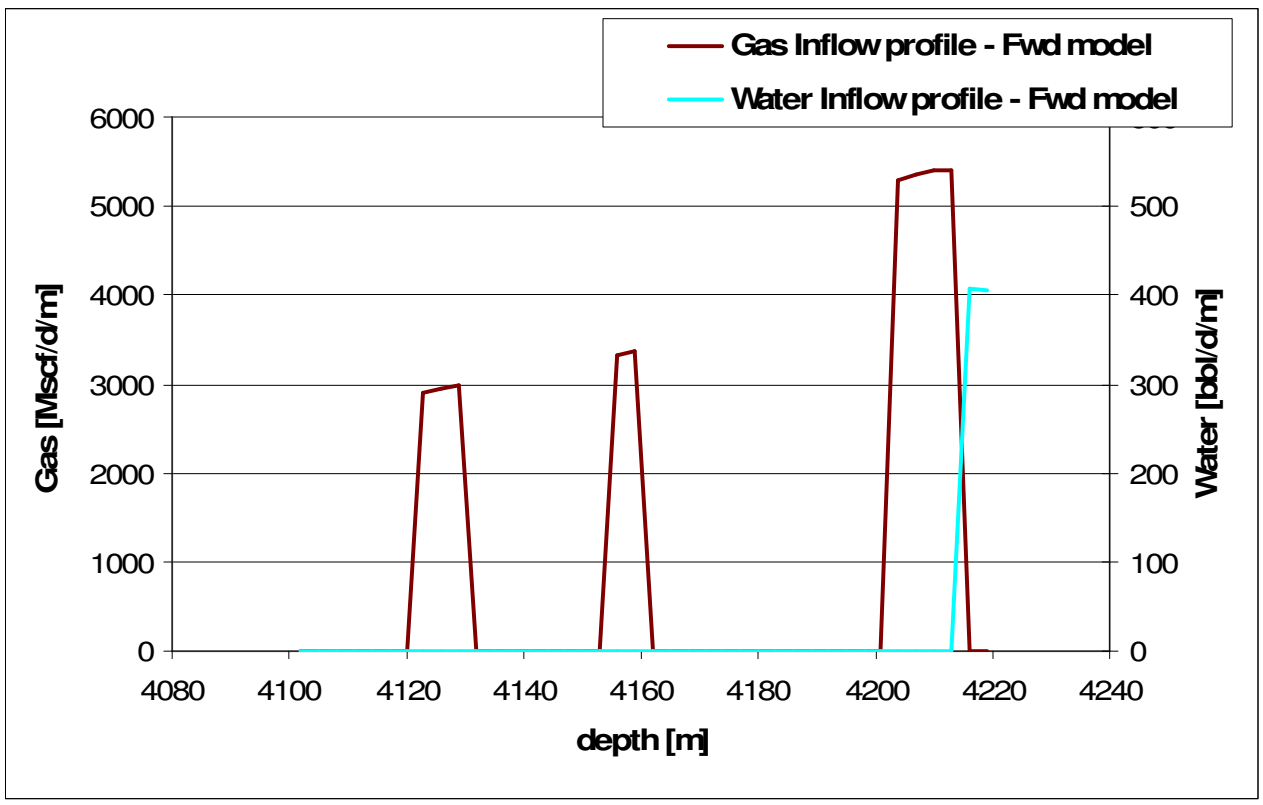

a. Inflow rate.

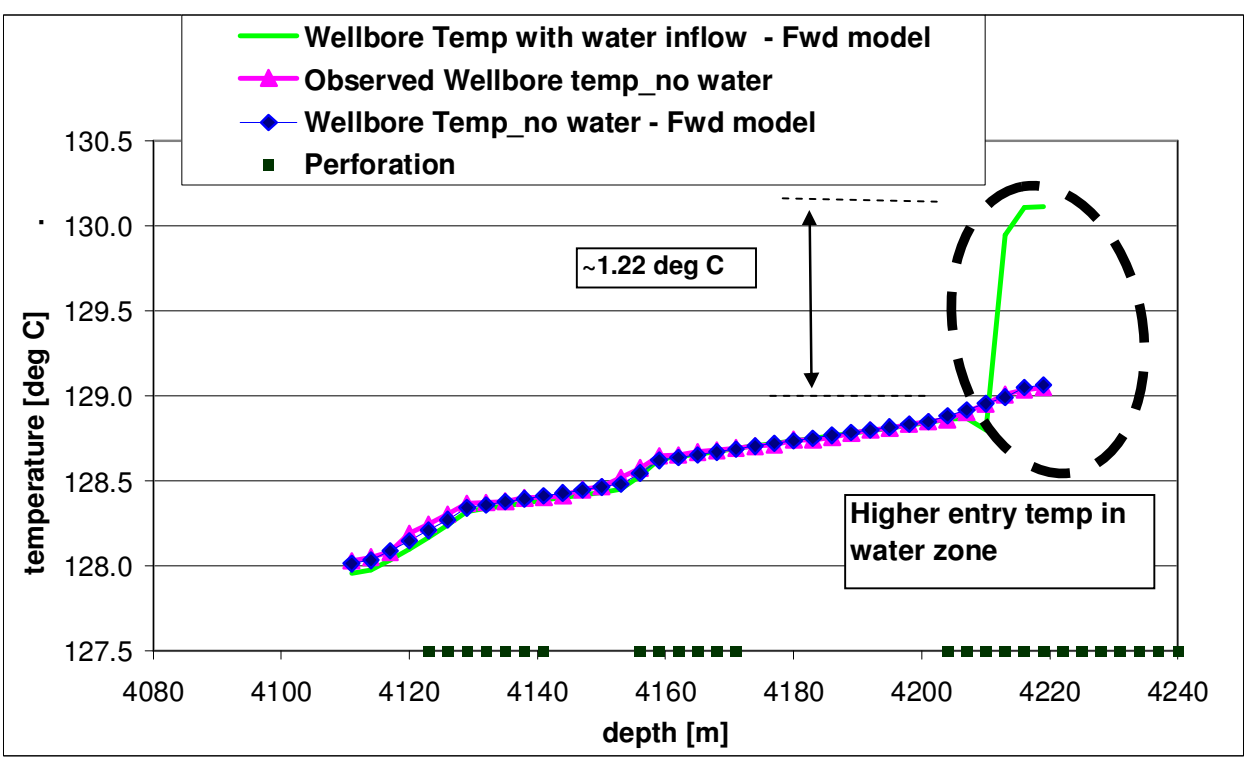

\section{b. Temperature.}

Fig. 4.2 Water entry at the bottom of the well. 


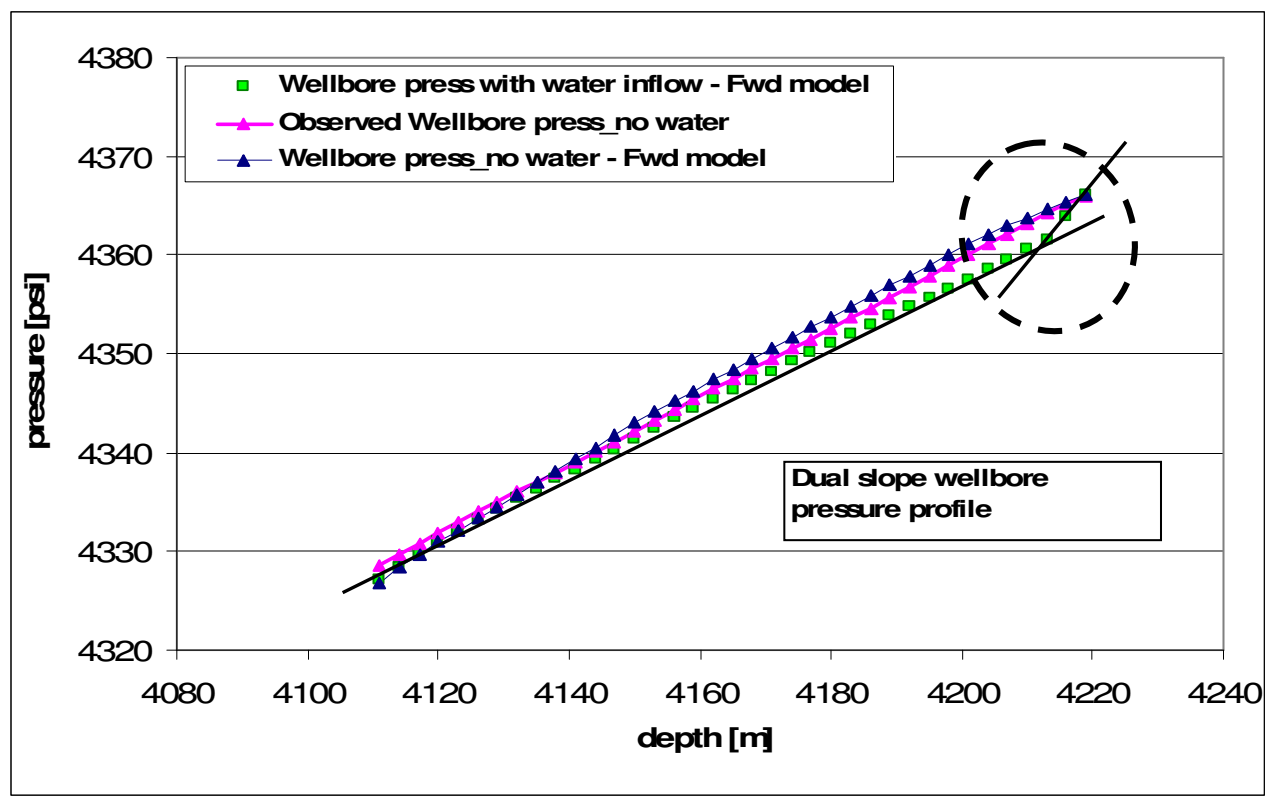

c. Pressure.

Fig. 4.2 Continued.

Comparing Figs. 4.2 and 4.3, clearly, we see the characteristic that helps on the initial estimate for the gas/water producing case. When water enters the wellbore from the bottom, we see the noticeable temperature difference between the geothermal temperature and fluid temperature at the bottom of the perforations (Fig. 4.2b), and a slope change on the pressure curve where water is produced (Fig. 4.2c). The rest of the pressure curve becomes smooth, indicating that the bottom perforation is the only zone that produces water. If water is produced at the middle perforation, (Fig. 4.3b), the temperature curve at the perforations becomes flat rather than decreasing when gas is produced due to Joule-Thomson cooling. We do not see a clear feature on the pressure curve in this case. 
When the water to gas ratio is too small, the temperature feature diminishes, and the interpretation method does not work anymore. In this study, $0.01 \mathrm{bbl} / \mathrm{Mscf}$ ratio yields reasonable results.

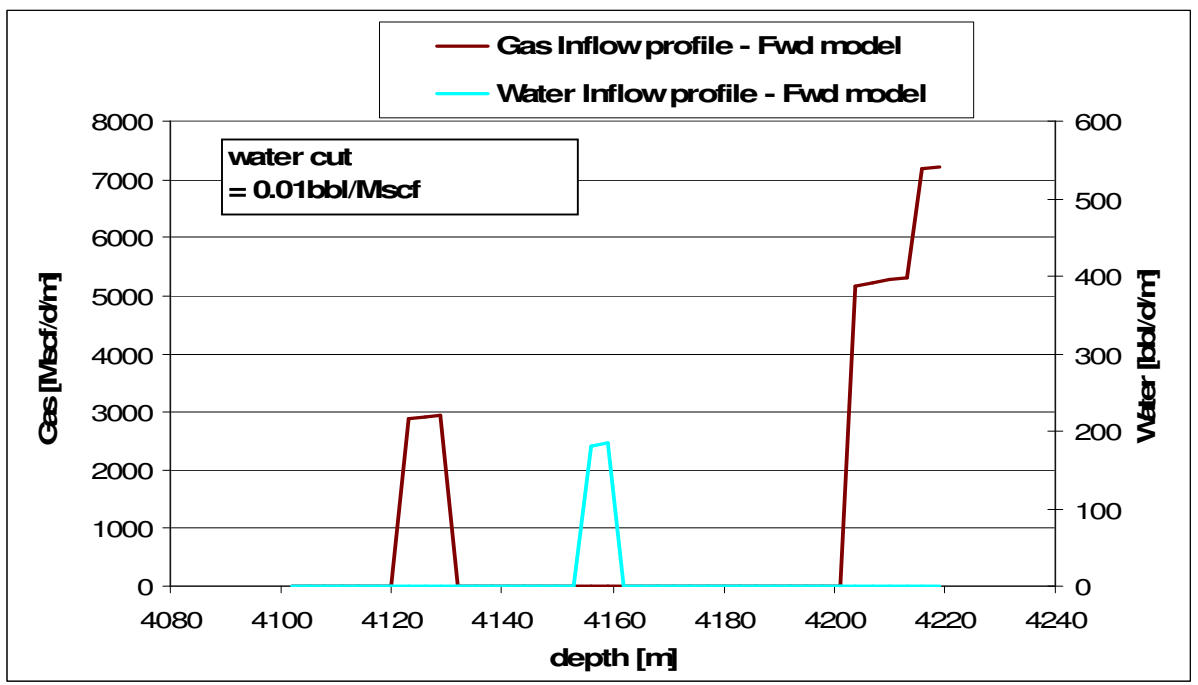

a. Inflow rate.

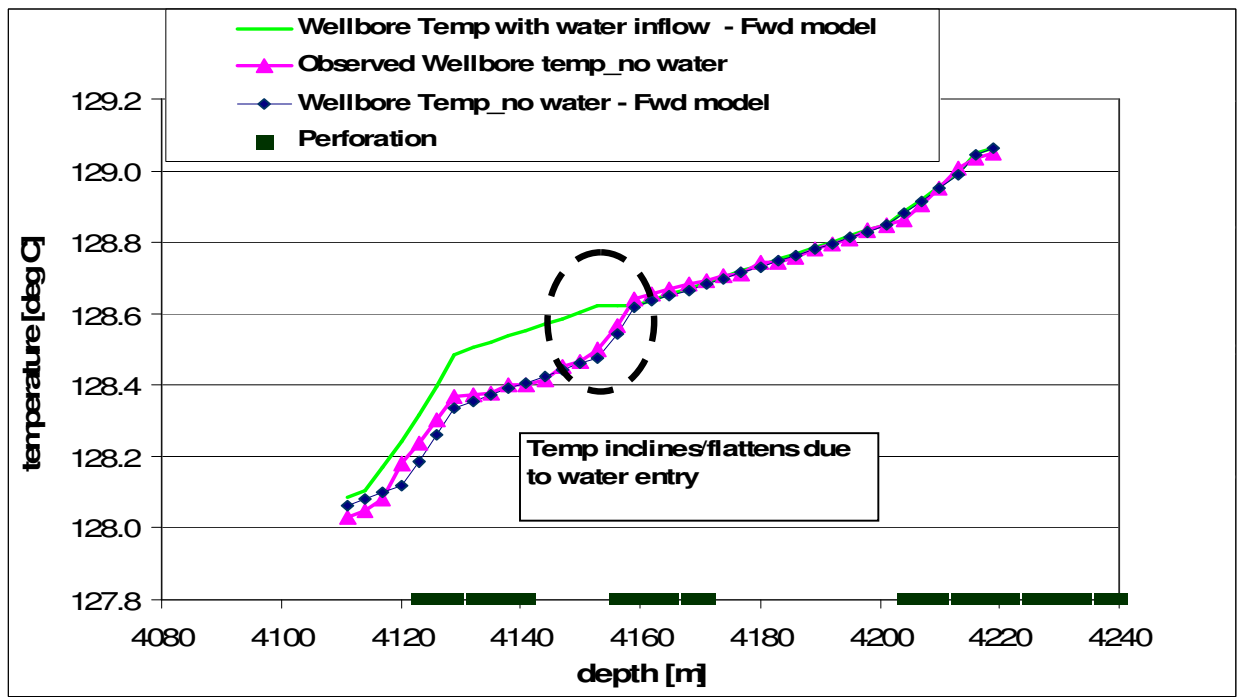

b. Temperature.

Fig. 4.3 Water entry at the middle of the well. 


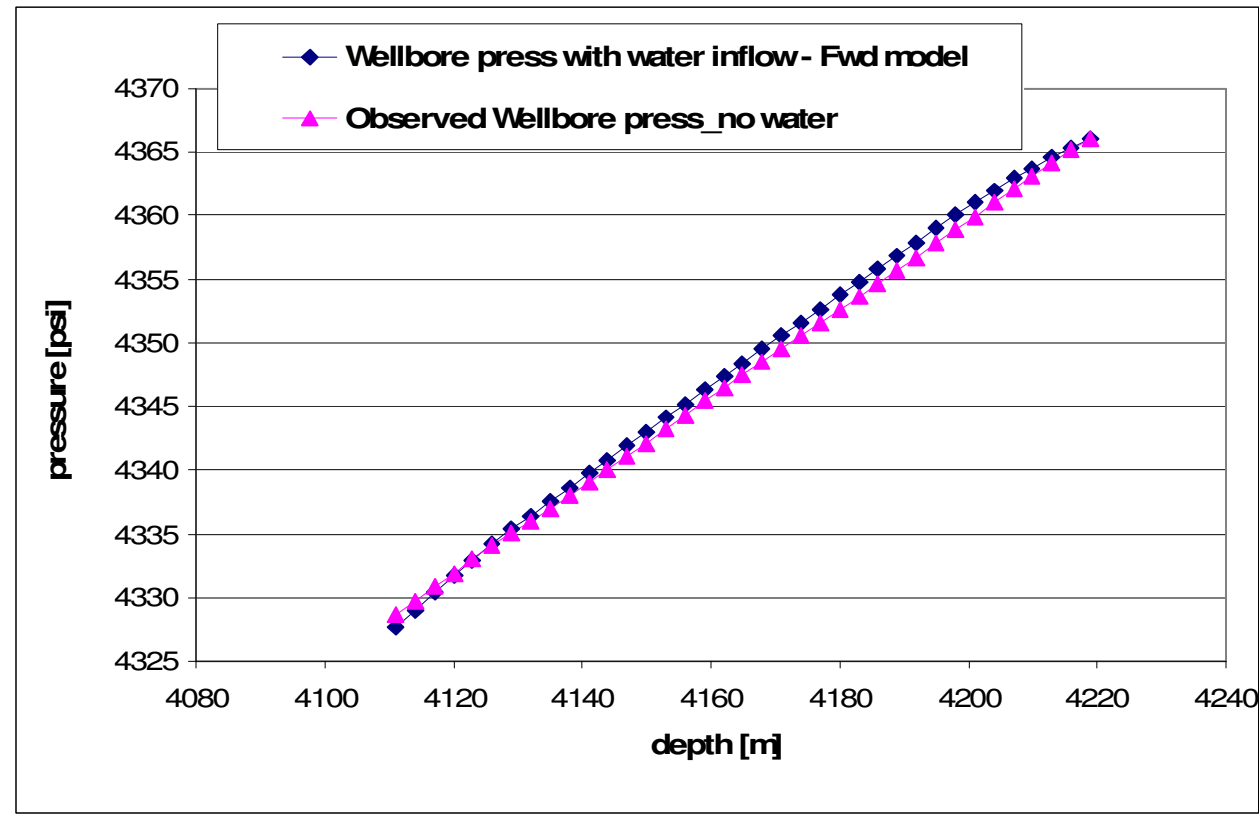

c. Pressure.

Fig. 4.3 Continued. 


\section{CHAPTER V}

\section{CONCLUSION}

We have evaluated and validated the applicability of the interpretation model for downhole flow condition to field problems. The interpretation method was applied to a gas producing well with and without water. The forward model was first used to generate temperature and pressure profiles. The comparison of the generated profile from the forward model with the ones generated from production logging confirmed that the response of temperature and pressure to the flow condition is sensitive enough and that the data can be used to estimate the flow profile. Production profile in the well was then established by analyzing temperature and pressure data in the wellbore provided from production logging, and the location of water entry was identified.

We obtained the production profile and located the productive zones along the wellbore. Sensitivity study was carried out to see the effect of the amount and location of water to the interpretation results.

The following conclusions have been made from this study:

1. For single phase gas producing well, the interpretation model can estimate the inflow distribution if the measurement of temperature and pressure along the wellbore is available.

2. When a gas well also produces water from the bottom zone, higher entry temperature of fluid than geothermal temperature suggests water coning. This 
can be confirmed by slope change on pressure profile at the bottom of completion.

3. Other than at the bottom perforation, gas inflow makes temperature decrease, and water entry slows down temperature decline at water entry locations. Pressure data has less indication of water entry if water does not enter the well from the bottom.

4. Water detection may depend on the water to gas volume ratio. For this study, when water/gas ratio is greater than $0.01 \mathrm{bbl} / \mathrm{Mscf}$, the interpretation model gives reasonable results. 


\section{REFERENCES}

Brown, G. and Field, D. 2005. Production Monitoring Through Openhole GravelPack Completions Using Permanently Installed Fiber-Optic Distributed Temperature Systems in the BP-Operated Azeri Field in Azerbaijan. Paper SPE 95419 presented at SPE ATCE, Dallas, Texas, 9 - 12 October.

Brown, G. A. 2006. Monitoring Multilayered Reservoir Pressures and Gas/Oil Ratio Changes Over Time Using Permanently Installed Distributed Temperature Measurements. Paper SPE 101886 presented at SPE ATCE, San Antonio, Texas, 24 -27 September.

Changhong, G., Rajeswaran, T. and Nakagawa, E. 2007. A Literature Review on Smart-Well Technology. Paper SPE 106011 presented at SPE Production and Operations Symposium, Oklahoma City, Oklahoma, 31 March - 3 April.

Chukwueke, V. 2004. EA Field Development: Intelligent Well Completion, Offshore Nigeria. Paper SPE 88967 presented at the 28th Annual SPE International Conference and Exhibition, Abuja, Nigeria, 2 - 4 August.

Dawkrajai, P., Lake, W. L., Yoshioka, K., Zhu D. and Hill, A. D. 2006. Detection of Water or Gas Entries in Horizontal Wells from Temperature Profiles. Paper SPE 100050 presented at SPE/DOE Symposium on Improved Oil Recovery, Tulsa, Oklahoma, 22 - 26 April.

De-Best, L. and Van-den-Berg, F. 2006. Smart Fields - Making the Most of Our 
Asset. Paper SPE 103575, presented at the SPE Russian Oil and Gas Technical Conference and Exhibition, Moscow, Russia, 3 - 6 October.

Drakeley, B. K., Johansen, E. S., Zisk, E. J. and Bostick, F. X. III. 2006. In-well Optical Sensing-State-of-the-Art Applications and Future Direction for Increasing Value in Production - Optimization Systems. Paper SPE 99696 presented at the SPE Intelligent Energy Conference and Exhibition, Amsterdam, Netherlands, 11 - 13 April.

Drakeley, B. K. and Omdal, S. 2008. Fiber Optics Sensing Systems for Subsea Application - Sensing Capabilities, Applications and the Challenges Being Faced in Order to Provide Reliable Transmission of Data for Online Reservoir Management. Paper SPE 112205 presented at the SPE Intelligent Energy Conference and Exhibition, Amsterdam, Netherlands, 25-27 February.

Frota, H. M. and Destro, W. 2006. Reliability Evolution of Permanent Download Gauges for Campos Basin Sub Sea Wells: A 10-year Case Study. Paper SPE 102700 presented at SPE ATCE, San Antonio, Texas, 24 - 27 September.

Fryer, V. and Shuzing, D. 2005. Monitoring of Real-Time Profiles Across Multizone Reservoirs During Production and Shut-in Periods Using Permanent Fiber-optic Distributed Temperature Systems. Paper SPE 92962 presented at SPE Asia Pacific Oil and Gas Conference and Exhibition, Jarkata, Indonesia, 5 - 7 April.

Glandt, C. A. 2003. Reservoir Management Employing Smart Wells: A Review. Paper SPE 81107 presented at SPE Latin American and Caribbean Petroleum Engineering Conference, Port-of-Spain, Trinidad, 27 - 30 April. 
Hill, A.D. 1990. Production Logging - Theoretical and Interpretive Elements, Monograph Series, SPE, Richardson, Texas 14: 15-18

Johnson, D., Gualtieri, D. and Kaura, J. 2006a. DTS Transient Analysis: A New Tool to Assess Well-Flow Dynamics. Paper SPE 103093 presented at SPE ATCE San Antonio, Texas, $24-27$ September.

Johnson, D., Sierra, J. and Gualtieri, D. 2006b. Successful Flow Profiling of Gas Wells Using Distributed Temperature Sensing Data. Paper SPE 103097 presented at SPE ATCE, San Antonio, Texas, 24 - 27 September.

Johnson, D. O. and Sugianto, R. 2002. Identification of Steam Break Through Intervals Using DTS Technology. Paper SPE 77460 presented at SPE ATCE, San Antonio, Texas, 29 September - 2 October.

Julian, J. Y., King, G. E., Cismoski, D. A. et al. 2007. Downhole Leak Determination Using Fiber-Optic Distributed -Temperature Surveys at Prudhoe Bay, Alaska. Paper SPE 107070, presented at the SPE ATCE, Anaheim, California, 11 - 14 November.

Kragas, T. K., Turnbull, B. F. and Francis, M. J. 2002. Permanent Fiber-Optic Monitoring at Northstar: Pressure/Temperature System and Data Overview. Paper SPE 87681 presented at SPE Western Regional/AAPG Pacific Section Joint Meeting, Anchorage, Alaska, 20 - 22 May.

Lanier, G. H., Brown, G. and Adams, L. 2003. Brunei Field Trial of a Fiber Optic Distributed Temperature Sensor (DTS) System in a 1,000m Open Hole Horizontal Oil Producer. Paper SPE 84324, presented at the SPE ATCE, Denver, Colorado, 5 8 October. 
Marquardt, D.W. 1963. An Algorithm for Least-Squares Estimation of Nonlinear Parameters. J. of the Society for Industrial and Applied Mathematics 11 (2): 431441.

Ouyang, L.-B. and Belanger, D. 2004. Flow Profiling via Distributed Temperature Sensor (DTS) System - Expectation and Reality. Paper SPE 90541 presented at SPE ATCE, Houston, Texas, 26 - 29 September.

Ouyang, L.-B., Arbabi, S. and Aziz, K. 1998. General Wellbore Flow Model for Horizontal, Vertical, and Slanted Well Completions. SPEJ 3 (2): 124-133. SPE 36608-PA.

Ouyang, L.-B. and Aziz, K. 2000. A Homogeneous Model for Gas-Liquid Flow in Horizontal Wells. J. Pet. Sci. and Eng. 27 (3): 119-128.

Pinzon, I. D., Davies, J. E., Mammadkhan, F. and Brown, G. A. 2007. Monitoring Production From Gravel-Packed Sand-Screen Completions on BP's Azeri Field Wells Using Permanently Installed Distributed Temperature Sensors. Paper SPE 110064 presented at SPE ATCE, Anaheim, California, 11 - 14 November.

Sui, W., Zhu, D., Hill, A. D. and Economides, E. 2008. Determining Multilayer Formation Properties From Transient Temperature and Pressure Measurement. Paper SPE 112670 presented at the SPE Annual Technical Conference and Exhibition, Denver, Colorado, 21-24 September.

Tolan, M., Boyle, M. and Williams, G. 2001. The Use of Fiber-Optic Distributed Temperature Sensing and Remote Hydraulically Operated Interval Control Values for the Management of Water Production in the Douglas Field. Paper SPE 71676, 
presented at SPE ATCE, New Orleans, Louisiana, 30 September - 3 October.

Van der Steen, E. 2006. An Evolution From Smart Wells to Smart Fields. Paper SPE 100710 presented at SPE Intelligent Energy Conference and Exhibition, Amsterdam, Netherlands, 11 - 13 April.

Van Gisbergen, S. J. C. H. M. and Vandeweijer, A. A. H. 1999. Reliability Analysis of Permanent Downhole Monitoring Systems. Paper OTC 10945 presented at Offshore Technology Conference, Houston, Texas, 3 - 6 May

Wang, X., Lee, J., Thigpen, B., Vachon, G., Poland, S. and Norton, D. O. 2008. Modeling Flow Profile Using Distributed Temperature Sensor (DTS) System. Paper SPE 111790 presented at the SPE Intelligent Energy Conference and Exhibition, Amsterdam, Netherlands, 25 - 27 February.

Wijaya, Z., Nath, D. K. and Andayani, Y. 2005. Fiber-Optic Used to Support Reservoir Temperature Surveillance in Duri Steam Flood. Paper SPE 93240 presented at SPE Asia Pacific Oil and Gas Conference and Exhibition, Jarkata, Indonesia, 5 - 7 April.

Yoshioka, K. 2007. Detection of Water or Gas Entry into Horizontal Wells by Using Permanent Downhole Monitoring Systems. $\mathrm{PhD}$ dissertation, Texas A\&M University, College Station, Texas.

Yoshioka, K., Zhu, D., Hill, A.D., Dawkrajai, P. and Lake, L.W. 2005. A Comprehensive Model of Temperature Behavior in a Horizontal Well. Paper SPE 95656 presented at SPE Annual Technical Conference and Exhibition, Dallas, Texas, 9-12 October. 
Yoshioka, K., Zhu, D., Hill, A. D., Dawkrajai, P. and Lake, W. L. 2006. Detection of Water or Gas Entries in Horizontal Wells From Temperature Profiles. Paper SPE 100209 presented at SPE Europe/EAGE Annual Conference and Exhibition, Vienna, Austria 12 - 15 June.

Zhu, D. and Furui, K. 2006. Optimizing Oil and Gas Production by Intelligent Technology. Paper SPE 102104 presented at the SPE Annual Technical Conference and Exhibition, San Antonio, Texas, 24 - 27 September. 


\section{NOMENCLATURE}

$\underline{\text { Symbol }}$

\begin{tabular}{|c|c|}
\hline$C_{p}$ & heat capacity \\
\hline D & weight matrix for observations \\
\hline$D$ & wellbore diameter \\
\hline d & derivative vector \\
\hline $\mathrm{E}$ & error function \\
\hline $\mathbf{e}$ & total energy flux \\
\hline$e$ & total energy \\
\hline$f_{o}$ & friction factor \\
\hline$f$ & friction factor with wall flux \\
\hline $\mathbf{g}$ & gravity acceleration vector \\
\hline$g$ & gravity acceleration \\
\hline $\mathbf{H}$ & Hessian matrix \\
\hline$H$ & enthalpy \\
\hline $\mathbf{I}$ & identity matrix \\
\hline $\mathbf{J}$ & Jacobian matrix \\
\hline$J$ & productivity index \\
\hline $\mathbf{k}$ & permeability tensor \\
\hline$K_{J T}$ & Joule-Thomson coefficient \\
\hline$k$ & permeability \\
\hline $\mathrm{m}$ & meter \\
\hline$N_{\mathrm{Re}}$ & Reynolds number \\
\hline 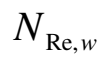 & wall Reynolds number \\
\hline
\end{tabular}

$\underline{\text { Description }}$ 


\begin{tabular}{ll}
$p$ & pressure \\
$p_{R}$ & reservoir pressure \\
$\mathbf{q}$ & conductive heat flux \\
$q$ & flow rate \\
$R$ & pipe inner diameter \\
$T$ & temperature \\
$T_{I}$ & inflow temperature \\
TVD & True vertical depth \\
$t$ & time \\
$U$ & internal energy \\
$\mathbf{u}$ & Darcy velocity vector \\
$u$ & Darcy velocity \\
$\mathbf{v}$ & velocity vector \\
$v$ & superficial velocity of water \\
$v_{s g}$ & superficial velocity of gas \\
$v_{s l}$ & superficial velocity of liquid \\
$v_{s w}$ & superficial velocity of oil \\
& sumeter vector \\
\hline &
\end{tabular}

\section{Greek}
$\alpha$
overall heat transfer coefficient
$\alpha_{I}$
combined overall heat transfer coefficient
$\beta$
coefficient of isobaric thermal expansion 


$\begin{array}{ll}\gamma & \text { pipe open ratio } \\ \varepsilon & \text { relative pipe roughness } \\ \phi & \text { porosity } \\ \lambda & \text { Marquardt parameter } \\ \theta & \text { wellbore inclination } \\ \mu & \text { viscosity } \\ \rho & \text { density } \\ \tau & \text { shear stress tensor } \\ \tau & \text { shear stress }\end{array}$

\section{Subscripts}

$\begin{array}{ll}g & \text { gas } \\ I & \text { inflow } \\ i & \text { phase index } \\ j, k & \text { position index } \\ l & \text { liquid } \\ m & \text { mixture } \\ o & \text { oil } \\ T & \text { total } \\ T P & \text { two phase } \\ w & \text { water }\end{array}$




\section{APPENDIX A}

\section{PARTIAL COMPLETION AND SLANTED SKIN FOR}

\section{SEGMENT}

This section derives the partial completion skin and slanted wellbore skin for the field case studied in the research. The well is cased and perforated in four completion zones over the reservoir layers.

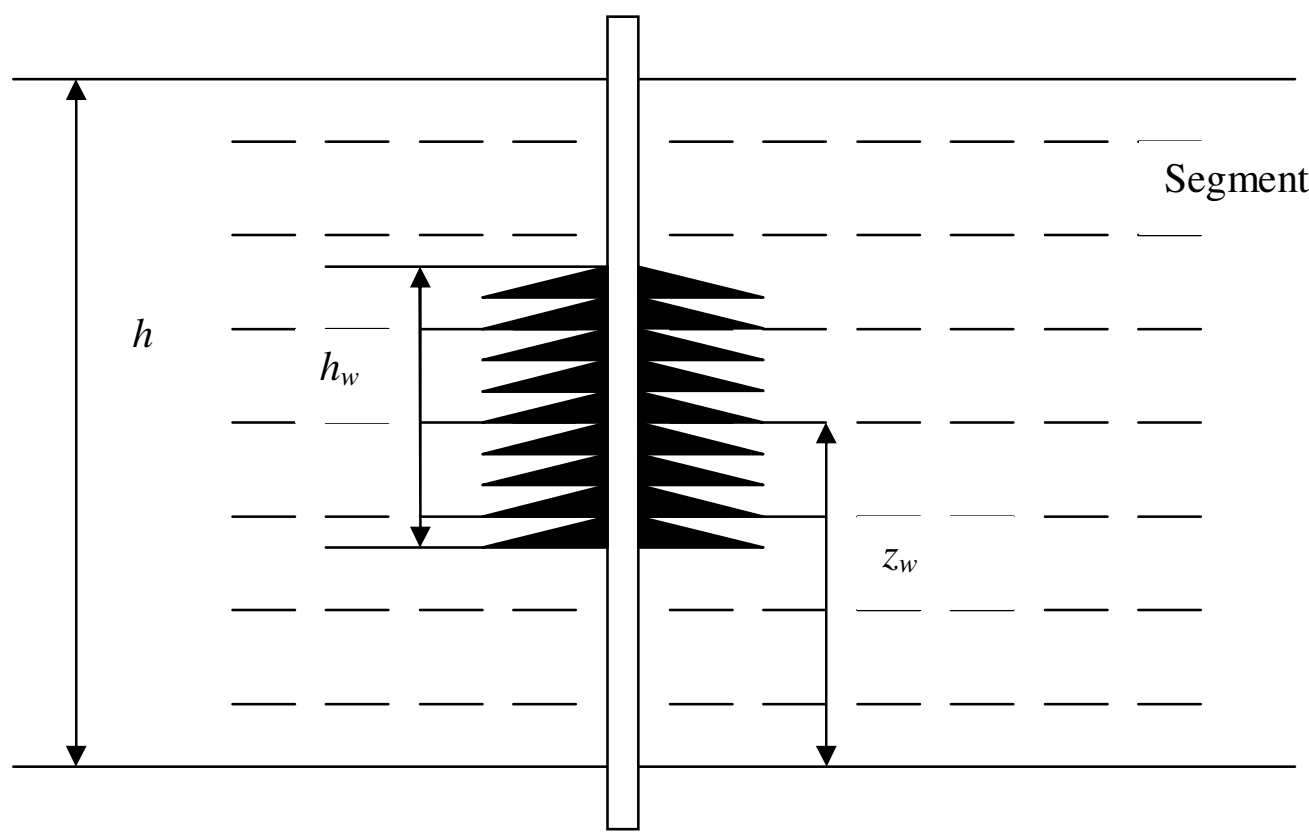

For a whole reservoir, steady state oil flow, we can calculate the production rate as:

$q=\frac{141.2 k h\left(p_{e}-p_{w f}\right)}{\mu B\left[\ln \left(r_{e} / r_{w}\right)+s_{d}+s_{p}+s_{c+\theta}+D q\right]}$ 
When we use segment method, we will get the production rate for each segment as:

$$
q_{i}=\frac{141.2 k_{i} h_{i}\left(p_{e}-p_{w f}\right)_{i}}{\mu B\left[\ln \left(r_{e} / r_{w}\right)+s_{d}+s_{p}+\left(s_{c+\theta}\right)_{i}+D q_{i}\right]}
$$

The segments which are not perforated have zero flow rates.

Make the sum of the flow rate of each segment equal to the result calculated from the equation (1), then

$$
\begin{aligned}
\sum_{i=p e r} q_{i} & =\sum_{i=p e r} \frac{141.2 k_{i} h_{i}\left(p_{e}-p_{w f}\right)_{i}}{\mu B\left[\ln \left(r_{e} / r_{w}\right)+s_{d}+s_{p}+\left(s_{c+\theta}\right)_{i}+D q_{i}\right]} \\
& =q=\frac{141.2 k h\left(p_{e}-p_{w f}\right)}{\mu B\left[\ln \left(r_{e} / r_{w}\right)+s_{d}+s_{p}+s_{c+\theta}+D q\right]}
\end{aligned}
$$

If we assume that non-Darcy flow has a minor effect on the flow rate, each segment with perforation will have the same partial completion skin factor, and the pressure drop in each segment is almost the same, then the equation (3) becomes

$$
\frac{141.2\left(p_{e}-p_{w f}\right) \sum_{i=p e r} k_{i} h_{i}}{\mu B\left[\ln \left(r_{e} / r_{w}\right)+s_{d}+s_{p}+\left(s_{c+\theta}\right)_{s e g}\right]}=\frac{141.2 k h\left(p_{e}-p_{w f}\right)}{\mu B\left[\ln \left(r_{e} / r_{w}\right)+s_{d}+s_{p}+s_{c+\theta}\right]}
$$


80

$$
\begin{aligned}
\left(s_{c+\theta}\right)_{\text {se }}= & \frac{\sum_{i=p e r} k_{i} h_{i}}{k h}\left[\ln \left(r_{e} / r_{w}\right)+s_{d}+s_{p}+s_{c+\theta}\right]-\left[\ln \left(r_{e} / r_{w}\right)+s_{d}+s_{p}\right] \\
= & \frac{\sum_{i=p e r} k_{i} h_{i}}{k h}\left[\ln \left(r_{e} / r_{w}\right)+s_{d}+s_{p}\right]+\frac{\sum_{i=p e r} k_{i} h_{i}}{k h} s_{c+\theta}-\left[\ln \left(r_{e} / r_{w}\right)+s_{d}+s_{p}\right] \\
= & \frac{\sum_{i=p e r} k_{i} h_{i}}{k h} s_{c+\theta}+\frac{\sum_{i=p e r} k_{i} h_{i}}{k h}\left[\ln \left(r_{e} / r_{w}\right)+s_{d}+s_{p}\right]-\left[\ln \left(r_{e} / r_{w}\right)+s_{d}+s_{p}\right] \\
= & \frac{\sum_{i=p e r} k_{i} h_{i}}{k h} s_{c+\theta}+\left(\frac{\sum_{i=\text { per }} k_{i} h_{i}}{k h}-1\right)\left[\ln \left(r_{e} / r_{w}\right)+s_{d}+s_{p}\right] \\
& \sum_{i=p e r} k_{i} h_{i} \\
k h & k_{i} h_{i} \\
k h & \frac{i=n o-\text { perforation }}{k h}\left[\ln \left(r_{e} / r_{w}\right)+s_{d}+s_{p}\right]
\end{aligned}
$$

For $s_{d}+s_{p}=0$,

We have

$$
\begin{aligned}
\left(s_{c+\theta}\right)_{\text {se }}= & \frac{\sum_{i=p e r} k_{i} h_{i}}{k h}\left[\ln \left(r_{e} / r_{w}\right)+s_{d}+s_{p}+s_{c+\theta}\right]-\left[\ln \left(r_{e} / r_{w}\right)+s_{d}+s_{p}\right] \\
= & \frac{\sum_{i=p e r} k_{i} h_{i}}{k h} S_{c+\theta}-\frac{\sum_{i=n o-\text { perforation }} k_{i} h_{i}}{k h}\left[\ln \left(r_{e} / r_{w}\right)\right]
\end{aligned}
$$




\section{VITA}

Ochi Ikoku Achinivu received his Bachelor of Engineering degree in Petroleum Engineering from the University of Port-Harcourt in February 1998. In August 2006, he entered Texas A\&M University for his M.S. degree in petroleum engineering and graduated in December 2008.

Mr. Achinivu may be reached at 2 Chevron Drive, Lekki Lagos, Nigeria. His email is oiac@chevron.com. 